Historical perspective

\title{
Recent progress and perspectives of gas sensors based on vertically oriented $\mathrm{ZnO}$ nanomaterials
}

\author{
Rafiq Ahmad ${ }^{\mathrm{a}, *, 1}$, Sanjit Manohar Majhi ${ }^{\mathrm{a}, 1}$, Xixiang Zhang ${ }^{\mathrm{b}}$, Timothy M. Swager ${ }^{\mathrm{c}}$, Khaled N. Salama ${ }^{\mathrm{a}, *}$

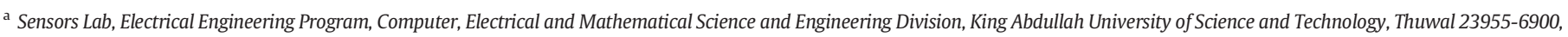 \\ Saudi Arabia \\ ${ }^{\mathrm{b}}$ Physical Sciences and Engineering Division, King Abdullah University of Science and Technology, Thuwal 23955-6900, Saudi Arabia \\ c Department of Chemistry and Institute for Soldier Nanotechnologies, Massachusetts Institute of Technology, Cambridge, MA, USA
}

\section{A R T I C L E I N F O}

\section{Article history:}

3 May 2019

Available online 22 May 2019

\section{Keywords:}

$\mathrm{ZnO}$

Nanomaterial

Vertically oriented

Nanorods, nanowires, gas sensor

\begin{abstract}
A B S T R A C T
Vertically oriented zinc oxide ( $\mathrm{ZnO}$ ) nanomaterials, such as nanorods (NRs), nanowires (NWs), nanotubes (NTs), nanoneedles (NNs), and nanosheets (NSs), are highly ordered architectures that provide remarkable properties for sensors. Furthermore, these nanostructures have fascinating features, including high surface-area-to-volume ratios, high charge carrier concentrations, and many surface-active sites. These features make vertically oriented $\mathrm{ZnO}$ nanomaterials exciting candidates for gas sensor fabrication. The development of efficient methods for the production of vertically oriented nanomaterial electrode surfaces has resulted in improved stability, high reproducibility, and gas sensing performance. Moving beyond conventional fabrication processes that include binders and nanomaterial deposition steps has been crucial, as the materials from these processes suffer from poor stability, low reproducibility, and marginal sensing performance. In this feature article, we comprehensively describe vertically oriented $\mathrm{ZnO}$ nanomaterials for gas sensing applications. The uses of such nanomaterials for gas sensor fabrication are discussed in the context of ease of growth, stability on an electrode surface, growth reproducibility, and enhancements in device efficiency as a result of their unique and advantageous features. In addition, we summarize applications of gas sensors for a variety of toxic and volatile organic compound (VOC) gases, and we discuss future directions of the vertically oriented $\mathrm{ZnO}$ nanomaterials.
\end{abstract}

(c) 2019 Elsevier B.V. All rights reserved.

\section{Contents}

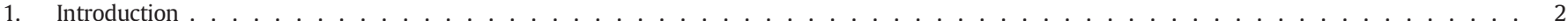

2. Gas sensing properties of $\mathrm{ZnO}$ nanomaterials $\ldots \ldots \ldots \ldots \ldots$

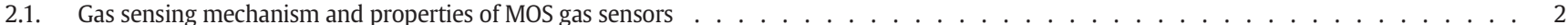

2.1.1. Basic principle of MOS gas sensors. . . . . . . . . . . . . . . . . . . . . . . . . . . . . . . . . .

2.1.2. Mechanism for enhancement of gas sensing properties . . . . . . . . . . . . . . . . . . . . . . . 3

3. Detection of different toxic, VOC, and combustible gases . . . . . . . . . . . . . . . . . . . . . . . . . . . . . . . . . .

4. Synthesis of vertically oriented $\mathrm{ZnO}$ nanostructures . . . . . . . . . . . . . . . . . . . . . . . . . . . . . 8

5. Gas sensing applications of vertically oriented $\mathrm{ZnO}$ nanomaterials . . . . . . . . . . . . . . . . . . . . . . . . . .

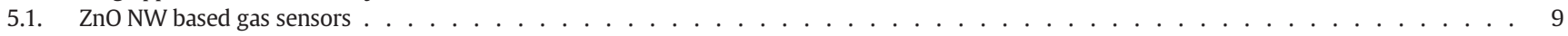

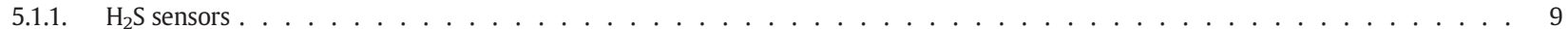

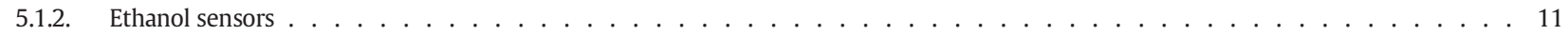

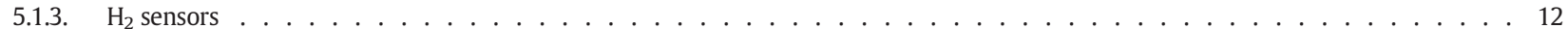

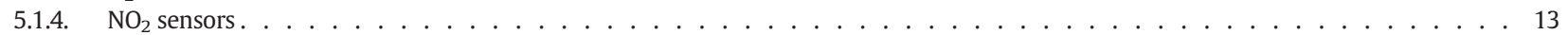

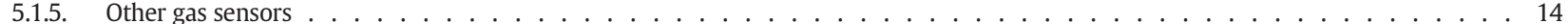

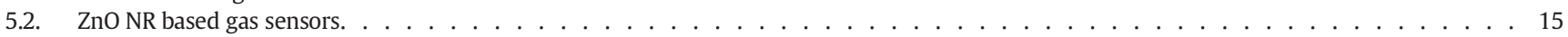

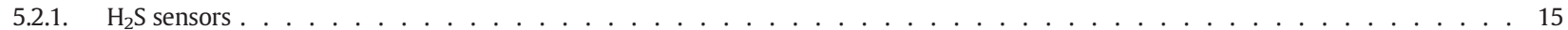

5.2.2. Ethanol sensors . . . . . . . . . . . . . . . . . . . . . . . . . . . . . . . . . . . . . . . . . . . . . . . . . 17

\footnotetext{
* Corresponding authors.

E-mail addresses: rafiq.ahmad@kaust.edu.sa (R. Ahmad), sanjit.majhi@kaust.edu.sa (S.M. Majhi), xixiang.zhang@kaust.edu.sa (X. Zhang), tswager@mit.edu (T.M. Swager), khaled.salama@kaust.edu.sa (K.N. Salama).
}

${ }^{1}$ These authors contributed equally. 


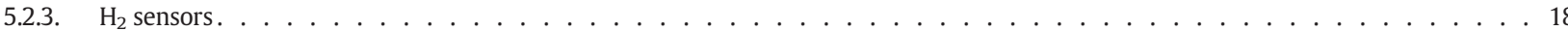

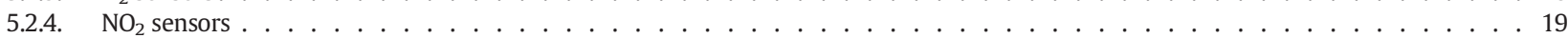

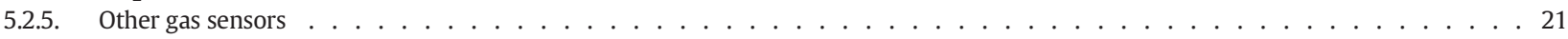

5.2.6. Other vertically oriented $\mathrm{ZnO}$ nanomaterial based gas sensors $\ldots \ldots \ldots \ldots$

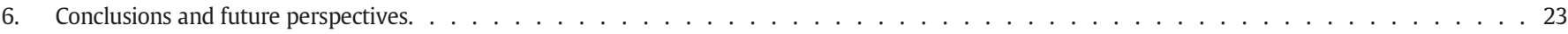

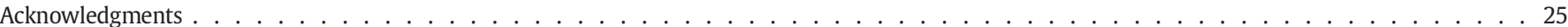

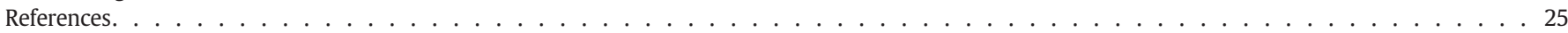

\section{Introduction}

Rapid advancements in nano-science and technology have paved the way to develop novel nanostructured materials for many potential device applications [1-4]. The properties of nanostructured materials are unique because they generally diverge from those of bulk materials when critical dimensions are on the nanometer $(\mathrm{nm})$ scale $(1-100 \mathrm{~nm})$ [5]. To utilize these nanomaterials, attention has been paid to tailoring their properties and constructing novel multifunctional nanostructures. Among different potential nanomaterial applications, their utility in gas sensors has been particularly attractive to meet ongoing needs for improved performance [5-9].

For decades, metal oxide semiconductors (MOSs) have dominated commercial gas sensing. MOS nanomaterials exhibit many attractive features, such as high chemical and thermal stability, high surface area, tunable electronic states, quantum confinement, high electron mobility, and excellent catalytic properties [5,6]. Various types of MOS nanomaterials have been explored for gas sensing applications. Examples include nanostructured variants of tin oxide $\left(\mathrm{SnO}_{2}\right)$, indium oxide $\left(\mathrm{In}_{2} \mathrm{O}_{3}\right)$, zinc oxide $(\mathrm{ZnO})$, tungsten trioxide $\left(\mathrm{WO}_{3}\right)$, cuprous oxide $\left(\mathrm{Cu}_{2} \mathrm{O}\right)$, cobalt oxide $\left(\mathrm{Co}_{3} \mathrm{O}_{4}\right)$, nickel oxide $(\mathrm{NiO})$, and titanium oxide $\left(\mathrm{TiO}_{2}\right)$ [10-17]. Among these, $\mathrm{ZnO}$ stands out as a promising and widely investigated nanomaterial for sensing applications: $\mathrm{ZnO}$ nanomaterials possess high thermal and chemical stability, high mobility of conduction electrons, and diverse sensing properties that can include the detection of biomolecules, chemicals, and gases [18]. Importantly, this development has been assisted by the fact that nanostructures and morphologies of $\mathrm{ZnO}$ can be prepared on a large scale using simple wet chemical routes at relatively low temperatures compared to typical metal oxide syntheses [19-21].

The sensing performance of gas sensors depends on the nanomaterial morphology, surface-to-volume ratios, crystallinity, electronic properties, and the deposition method used in device fabrication [22-25]. Two steps (i.e. synthesis of the desired nanomaterials and assembly of the nanomaterials on the electrode surface) are needed for sensor device fabrication. Most sensors utilize pre-synthesized nanomaterials during the fabrication process, wherein nanomaterials are mixed with the binders or solvents to prepare pastes/slurries. These pastes/slurries are then deposited on the electrode surface by drop casting, spin coating, or screen-printing [10-18,25]. A downside of this approach is that it can result in an inhomogeneous or dense film, poor stability, and limited electrical contact on the electrode. Moreover, binders can block the catalytically active sites, which reduced the sensing performance and leads to poor reproducibility and stability [26]. Therefore, direct integration of nanomaterials on electrode surfaces is beneficial as it promotes high stability, adhesion, and improved electrical contact between the sensing materials and sensor electrode chips [27].

In this feature article, we detail recent progress in vertically oriented $\mathrm{ZnO}$ nanomaterial based gas sensors. We discuss direct integration on the electrode surfaces of such nanomaterials, including nanorods (NRs), nanowires (NWs), nanotubes (NTs), nanoneedles (NNs), and nanosheets (NSs), and then we summarize and compare their sensing performance. Finally, we discuss the advantages, challenges, and future directions for the development of high-performance gas sensors using functionalized vertically oriented $\mathrm{ZnO}$ nanomaterials.

\section{Gas sensing properties of $\mathrm{ZnO}$ nanomaterials}

\subsection{Gas sensing mechanism and properties of MOS gas sensors}

\subsubsection{Basic principle of MOS gas sensors}

The fundamental and typical gas sensing mechanism of conductometric MOS gas sensors is based on the change of resistance induced due to the chemical interactions between the adsorbed oxygen ions and exposed target gas molecules on the surface of MOS gas sensors $[28,29]$. However, the gas sensing mechanism also changes depending upon the types of MOSs (n-type MOSs and p-type MOSs) and gaseous analytes. For example, in the case of an n-type MOS gas sensor with electrons $(\mathrm{e}-$ ) as majority carriers, the resistance decreases for reducing gases (donor) and increases for oxidizing gases (acceptor). Similarly, for a p-type MOS gas sensor with holes as majority charge carriers, the gas sensing mechanism is opposite to it. In general, from the air atmosphere, oxygen molecules $\left(\mathrm{O}_{2}\right)$ with high electronegativity and lone pairs of electrons are chemisorbed onto the surface of an n-type MOS film [29]. Since $\mathrm{O}_{2}$ molecules are oxidizing gases and act as acceptors of electrons, they are ionized into different oxygen species $\left(\mathrm{O}_{2}^{-}, 2 \mathrm{O}^{-}\right.$, $\mathrm{O}^{2-}$ ) by trapping electrons from the conduction band of the n-type MOS. It should be noted that the formation of different types of chemisorbed oxygen ionic species such as $\mathrm{O}_{2}^{-}, \mathrm{O}^{-}$, and $\mathrm{O}^{2-}$ are strongly dependent upon the operation temperature of the gas sensor [30]. An electron depletion layer or charge space region emerges on the surface of the n-type MOS, and a potential barrier is created due to the decrease in electron density (Fig. 1a) [23]. Therefore, the electron conduction of the MOS decreases, thus resulting in an increase in resistance. This is also called the baseline resistance in air. The depth of the depletion layer from the surface of an MOS sensor is defined as the Debye length $\left(\mathrm{L}_{\mathrm{D}}\right)$ and usually measures a few nanometers (nm) [31].

The calculation of the Debye length of an MOS gas sensor is expressed as follows [32]:

$L_{D}=\left(\frac{\varepsilon K T}{q^{2} \eta_{d}}\right)^{1 / 2}$

where $\varepsilon, \mathrm{k}, \mathrm{T}, \mathrm{q}$, and $\eta_{\mathrm{c}}$ are the static dielectric constant, Boltzmann's constant, absolute temperature, electrical charge of the carrier, and carrier concentration, respectively. In contrast, the width of depletion or accumulation layer is calculated as follows [32]:

$\mathrm{x}=2 L_{D}\left(\frac{q V s}{k T}\right)^{1 / 2}$

where Vs is the potential barrier height [32]. When reducing gases ( $\mathrm{CO}$, $\mathrm{H}_{2}, \mathrm{NH}_{3}, \mathrm{H}_{2} \mathrm{~S}, \mathrm{C}_{2} \mathrm{H}_{5} \mathrm{OH}$, etc.) are exposed to the MOS gas sensor, the gas molecules are adsorbed on the MOS surface and then react with chemisorbed oxygen ions, thereby releasing electrons back into the electron depletion layer (the schematic diagram in Fig. 1 shows the gas sensing mechanism for an n-type MOS with reducing gas). This results in a decrease in the electron depletion layer's thickness and 

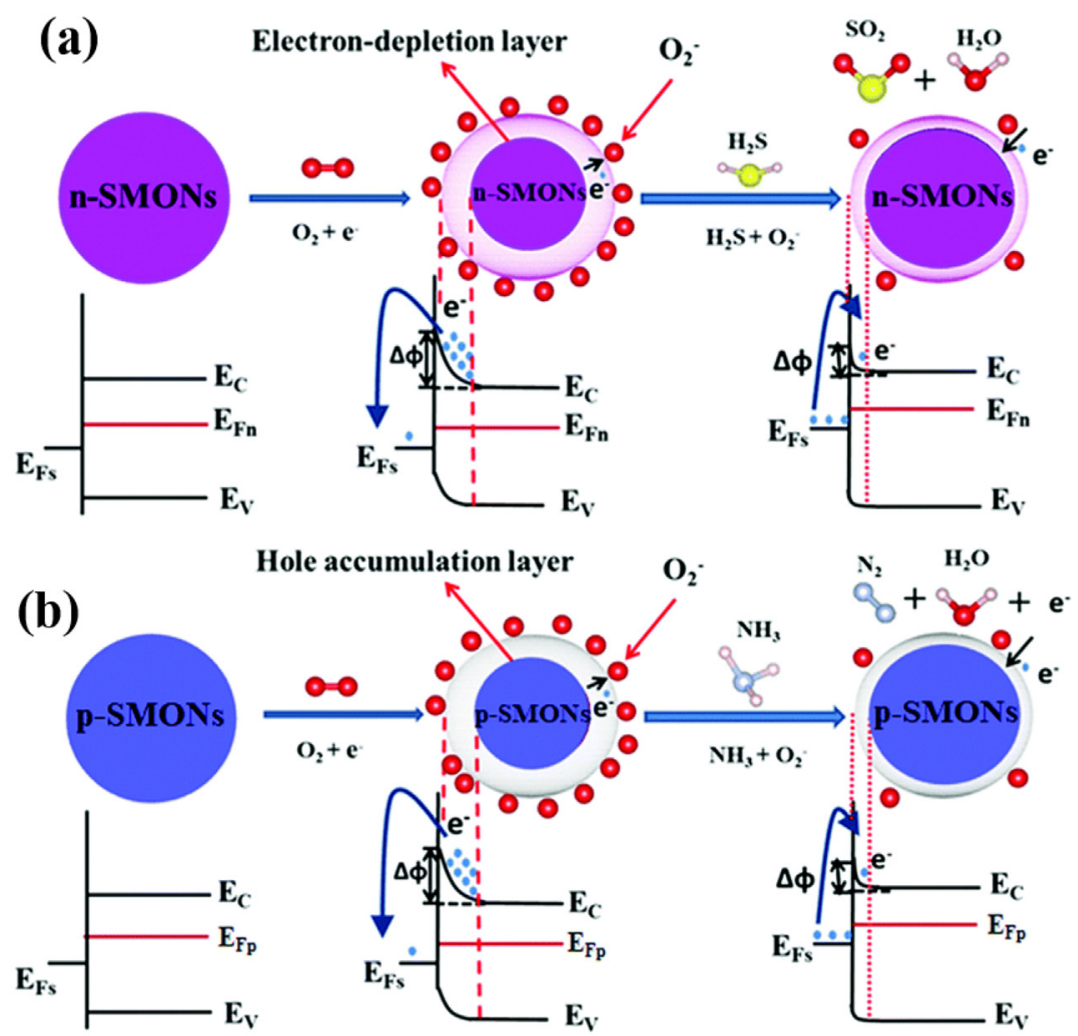

$\mathbf{E}_{\mathbf{C}}:$ bottom of conduction band; $\mathbf{E}_{\mathrm{V}}$ : top of valence band; $\mathbf{E}_{\mathrm{Fn}}$ : bulk Fermi level; $\mathbf{E}_{\mathrm{Fs}}$ : surface Fermi level; $\Delta \varphi$ : potential barrier;

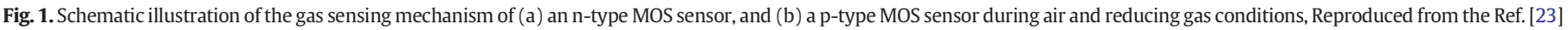
with permission, Copyright 2019, Royal Society of Chemistry.

potential barrier (as shown in Fig. 1a), which eventually decreases the resistance of the MOS gas sensor. In contrast, with oxidizing gases $\left(\mathrm{NO}_{2}, \mathrm{NO}, \mathrm{O}_{3}\right.$, etc.), the results are inversed: namely, the electron depletion layer and potential barrier grow, which increases the resistance of the MOS gas sensor. However, the p-type MOS behaves completely contrarily to the n-type MOS (Fig. 1b). Since our review is focused on n-type $\mathrm{ZnO}$ based nanostructures, the discussion is limited to n-type MOSs only. The MOS nanomaterials used as gas sensing materials are generally crystalline or polycrystalline in nature, which are interconnected with different grains having grain boundaries. According to Yamazoe et al. [33], the gas sensing behavior of a sensor is governed by three key functions: the receptor function, transducer function, and utility factor. The receptor function includes the ability of metal oxide sensing materials to recognize the oxygen molecules and target analytes in the surrounding atmosphere, and the interaction between them. However, this function will be greatly changed if the metal oxide is modified with other impurities or new constituents. On the other hand, the transducer function entails the transformation of the surface interaction phenomenon (charge carrier mobility and change of resistance) into an electrical signal (i.e., sensor response). The depletion layer formed due to the chemisorbed oxygen ion species results in a double Schottky barrier between adjacent grains (as shown in Fig. 2), which hinders the carrier mobility inside the grain. However, the potential barrier is modulated in the presence of target gases, resulting in a decrease in resistance due to the electrons' mobility from one grain to another grain. Finally the last function, utility factor, concerns the effect of response behavior in a porous sensing body during the diffusion and chemical reaction of target gas molecules inside the pores. Thus, the receptor function deals with intraparticle issues, the transducer function with interparticle issues, and the utility factor with gas accessibility issues [34]. The sensing properties of MOS gas sensors depend upon various factors, such as structural features, dopants, modification of MOS with foreign materials, noble metals, morphology, working temperature, etc., which will be further detailed later. Furthermore, the gas sensing performance of these sensors can be evaluated using a few important parameters, such as response or sensitivity $(\mathrm{S})$, selectivity, response/recovery time, operation temperature, stability, etc. [24]. Accordingly, for an n-type MOS gas sensor, the response values are expressed as $R_{a} / R_{g},\left(R_{a}-R_{g}\right) / R_{g}$, and $\left(R_{a}-R_{g} /\right.$ $R_{g}$ ) $\times 100 \%$ (where $R_{a}$ and $R_{g}$ are the resistance of sensors in air and the target gas, respectively). However, for the oxidizing gases, $R_{a}$ and $R_{g}$ need to be reversed. The time needed to reach $90 \%$ of the resistance change during exposure to the target gas is defined as the response time $\left(T_{\text {resp }}\right)$, and the time needed to recover $90 \%$ of the resistance after extraction of the target gas is defined as recovery time $\left(\mathrm{T}_{\text {recv }}\right)[23]$.

\subsubsection{Mechanism for enhancement of gas sensing properties}

Recently, a great variety of novel synthetic processes have been employed to produce interesting MOS based nanostructures for gas sensing applications. Considerable attention has been paid to improving their sensing properties, such as sensitivity, selectivity, reproducibility, reduced working temperature, etc. To this end, various strategies have been undertaken and investigated. The sensing performance of MOS based gas sensors is affected by various parameters, such as morphology, grain size, porosity, decoration of noble metals, construction of $\mathrm{p}-\mathrm{n}$ junctions, working temperature, etc. This section discusses the effect of the above factors on the sensing properties and their mechanisms. 


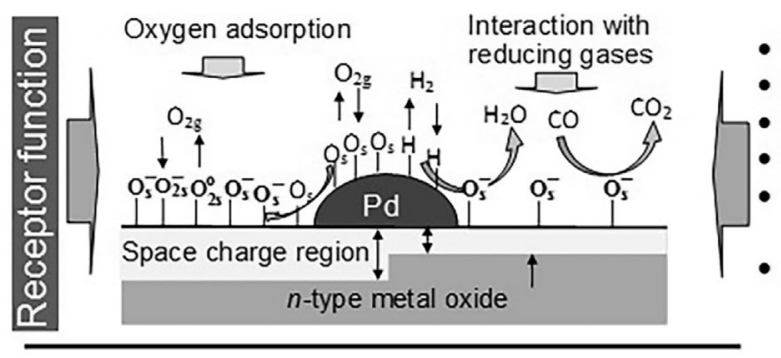

- Redox property

- Stoichiometry

- Surface additives

- Crystallite's faceting

- Adsorption/desorption parameters

- Dopants
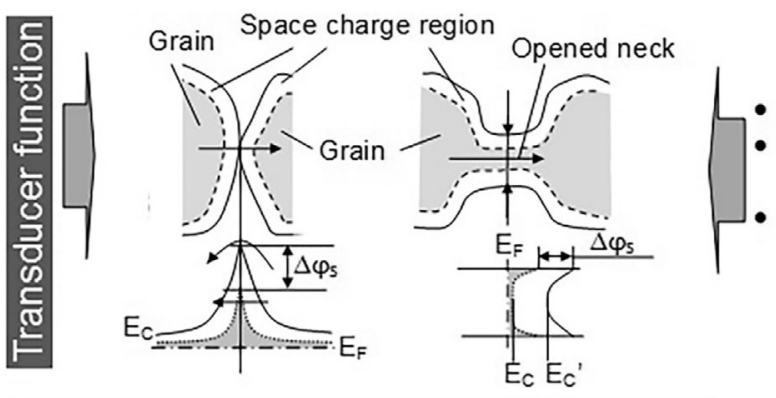

Grain size

- Carrier mobility and concentration - Crystallite network

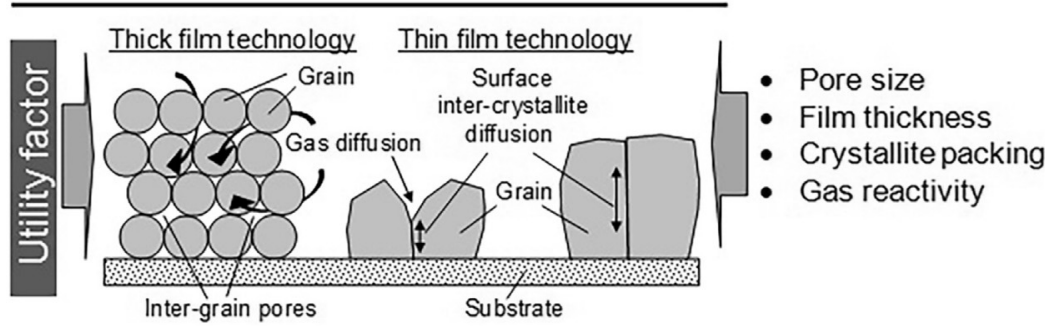

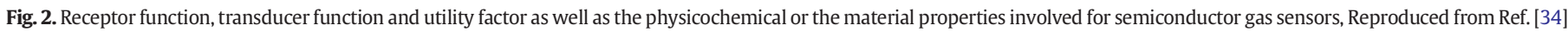
with permission, Copy right 2017, Elsevier.

2.1.2.1. Effect of noble metal modification. In gas sensing applications, noble metal catalysts such as Au, Pt, Ag, and Pd have been widely studied for the decoration onto MOS gas sensor surfaces to enhance their sensing properties, such as sensitivity, selectivity, response/recovery, and reduced working temperature. Two sensitization effects, called electronic sensitization and chemical sensitization, are mainly responsible for the enhanced sensing behavior of gas sensors [32]. The chemical sensitization effect is also known as the spillover effect in many of the sensors. In this effect, metal nanoparticles, which are excellent catalysts, can dissociate molecular oxygen into oxygen species by quickly adsorbing on MOS surfaces and then spilling over on them. As a result, more oxygen ionic species are adsorbed on the sensor surface. Furthermore, the target gas molecules can be directly adsorbed onto the active sites of these noble metal catalysts and then migrate onto the MOS surface to react with already existing chemisorbed oxygen ions. Thus, this effect eventually leads to a faster adsorption of oxygen and target gas molecules, thereby increasing the sensing performance. Fig. 3a shows the chemical sensitization process of an n-type MOS. Occurring simultaneously with the chemical sensitization effect, the electronic sensitization effect also greatly enhances the sensing performance. In this effect, when a noble metal catalyst has electronic contact with an MOS sensor, the charge transfer occurs from the MOS sensor to the noble metal catalyst due to the difference in their work functions. As a result, the electrons accumulate in the noble metal catalyst, resulting in a charge depletion layer on the MOS sensor surface. This process eventually yields a "Schottky potential barrier," which is characterized by a band bending in the MOS sensor. This whole process increases the baseline resistance of the gas sensor. After the target gas reacts with adsorbed oxygen ions on the sensor surface, the released electrons lead to the decrease in sensor resistance and hence the potential barrier height. The height and depth of the potential barrier at the surface depend on the charge carrier concentration, which in turn directly depends on the amount and type of adsorbed oxygen ions [35]. Fig. 3b shows the mechanism of the electronic sensitization effect along with the band bending and charge transfer process [36]. Fig. $3 c$ and $d$ show the baseline resistance changes that occur before and after noble metal loading [37].

2.1.2.2. Effect of $P-N$ heterojunction. Researchers around the world have tried many approaches to enhance gas sensors' performance, because single-component MOS gas sensors are not able to satisfy all practical demands. One of these approaches is to design heterojunction nanostructures by combining n-type MOSs with p-type MOSs or vice versa to form a p-n junction heterostructure. The enhanced sensing properties of $\mathrm{p}-\mathrm{n}$ junction heterostructures are generally attributed to the synergistic effect of the heterointerface between p- and n-type MOSs. In a typical p-n junction nanostructure, the electrons from the conduction band of n-type MOSs will be transferred to the lower energy valence band of p-type MOSs at their interface to equalize the Fermi level energy. This process results in a "band bending" at the heterointerface of p- and n-type MOSs, which further extends the width of the electron depletion layer [23], as shown in Fig. 4a. This process increases the baseline resistance in air $\left(R_{a}\right)$ of the sensor, making it more sensitive for gas sensing reactions, which results in high sensing performance. In addition, the selectivity of the gas sensor can also be controlled when one of the components shows high catalytic activity toward a specific target gas. For instance, the decoration of n-type $\mathrm{MoS}_{2}$ nanoparticles on p-type $\mathrm{CuO}$ nanorods to design $\mathrm{CuO}-\mathrm{MOS}_{2} \mathrm{p}-\mathrm{n}$ heterojunction nanostructures significantly enhances the selectivity to $\mathrm{H}_{2} \mathrm{~S}$ (Fig. 4b) [38]. This can be attributed to the transformation of a resistive $\mathrm{CuO}-\mathrm{MoS}_{2} \mathrm{p}-\mathrm{n}$ junction into a highly conducting $\mathrm{CuS}-\mathrm{MoS}_{2}$ metal p-n junction nanostructure upon exposure to $\mathrm{H}_{2} \mathrm{~S}$, as well as the combination of the synergistic effect of a binary nanostructure and the modulation of the charge transfer at the heterointerface (Fig. 4c). 

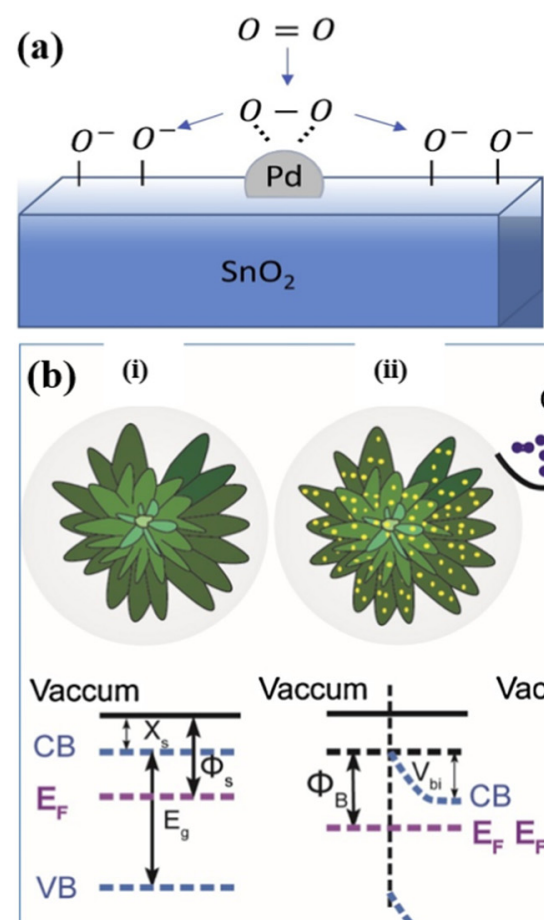

(ii)

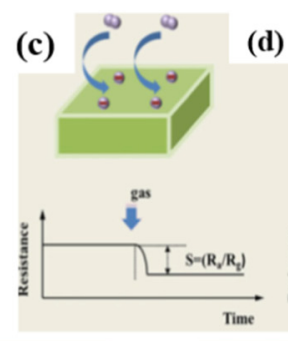

(iii (d)

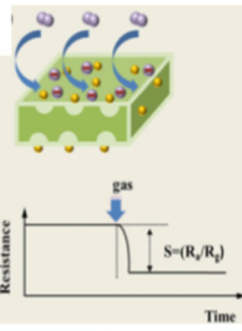

(iv)
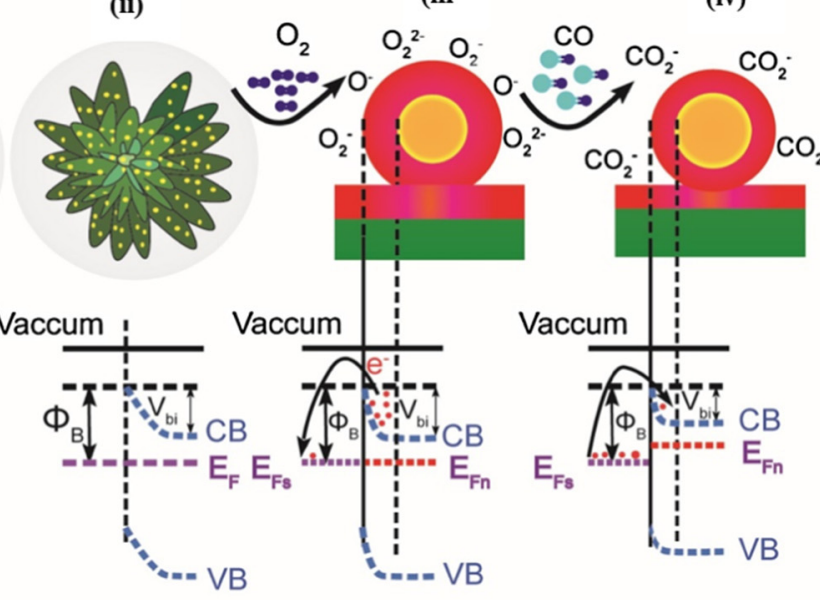

$\mathrm{ZnO}=\mathrm{Air} \quad \mathrm{Au} \square$ Depletion area $\bullet \mathrm{O}_{2} \leftrightarrow \mathrm{CO}$

CB: Conduct band; VB: Valance band; $E_{F}$ : Fermi level; $E_{F n}$ : bulk Fermi level; $E_{F s}$ : surface Fermi level; $X_{s}$ : electron affinity; $\Phi_{B}$ : the energy to across the barrier; $V_{b i}$ : internal field; $\Phi_{s}$ : work function.

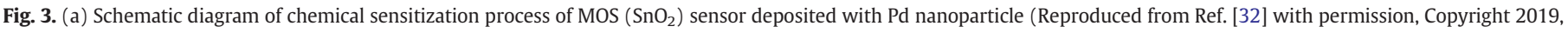

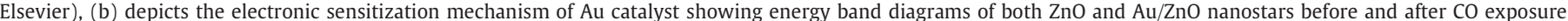

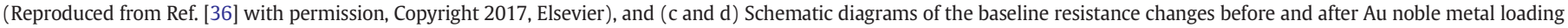
on $\mathrm{WO}_{3} \cdot \mathrm{H}_{2} \mathrm{O}$ sensor. Reprinted with permission from Ref. [37], Copyright 2017, Elsevier.

\subsubsection{Effect of microstructure and surface morphology}

2.1.2.3.1. Effect of grain size, porosity, crystallinity, and size of gas molecules. It is known that MOS based sensing materials are composed of aggregate particles with many grains that are interconnected with their neighbors by grain boundaries. The sizes of these grains play an important role in changing the sensitivity of MOS gas sensors. This is because on the surface of grains, adsorbed oxygen molecules in the form of oxygen ionic species extract electrons from the conduction band and trap them near surface, which induces band bending and a charge depletion layer [39]. Xu et al. proposed a relation between the particle size (D) and the width of the depletion layer $\left(\mathrm{L}_{\mathrm{d}}\right)$ through a semiquantitative model (Fig. 5) [40]. According to this model, if $D>>2 \mathrm{~L}_{\mathrm{d}}$, the electronic conductivity of sensing nanomaterials is determined by Schottky barrier heights at grain boundaries, which are independent of the individual grain size. Hence, with decreasing grain size, the surface area increases, leading to high sensitivity. If $\mathrm{D} \geq 2 \mathrm{~L}_{\mathrm{d}}$, the depletion layers around the grains create narrow conduction channels. In this case, the conductivity depends on the barriers at the grain boundary and the cross-sectional area of the channels. When $\mathrm{D}<2 \mathrm{~L}_{\mathrm{d}}$, the depletion layer is larger than the grain, and therefore inter-grain barriers for charge transport are insignificant. As a consequence, the gas sensitivity increases for materials with small particle sizes. The gas sensing reactions also occur due to the typical gas-solid interaction. Hence, the sensing properties of a gas sensor are dependent on the pore size and porosity of sensing materials [40]. In addition, this porosity affects the surface area and diffusion rate of gases, which eventually alter the sensing response because porous bodies facilitate gas diffusion inside the sensing films and obtain higher sensing properties. There are different kinds of porous materials: microporous ( $<2 \mathrm{~nm})$, macroporous
( $50 \mathrm{~nm}$ ), and mesoporous ( 2 to $50 \mathrm{~nm}$ ). In gas sensing, large pores are beneficial for diffusion of gas molecules but induce low surface area, while smaller pore size provides higher surface area but limits the target gas diffusion and mass transport within the sensing layer. Hence, mesoporous materials with appropriate pore sizes and surface area are ideal candidates for gas sensing applications. According to Sakai et al., the gas diffusion dynamics in the response of gas sensors is defined by the following equation [41]:

$D k=\frac{4 r}{3}\left[\frac{2 R T}{\pi M}\right]^{1 / 2}$

In addition, the crystallinity of sensing materials also affects gas sensing properties. For example, Xu et al. proposed a relationship between crystallinity (polycrystalline and single crystalline) and porosity, and the gas sensing performance of $\mathrm{In}_{2} \mathrm{O}_{3}$ nanostructures [42]. In their study, the $\mathrm{In}_{2} \mathrm{O}_{3}$ nanostructures with a single-crystalline structure and larger pore size showed enhanced sensing performance (Fig. 6b). Such single-crystalline nanostructures are beneficial for charge carrier transportation through the semiconductor matrix during the gas sensing process. Furthermore, larger pores provide more active sites for adsorption of oxygen molecules and target gas, enhancing the gas sensing performance [43]. On the other hand, $\mathrm{In}_{2} \mathrm{O}_{3}$ nanostructures with small pores (Fig. 6a) possess many potential barriers between the adjacent particles and grain boundaries due to the formation of depletion layers; this hinders the mobility of electrons, resulting in a decrease in the sensor performance. In contrast, a single-crystalline $\mathrm{In}_{2} \mathrm{O}_{3}$ nanostructure with the absence of grain boundary can decrease the potential barrier in the sensing film (Fig. 6b) and enhance conductivity. 
In addition to pore size and crystallinity of materials, the molecular size of gas analytes is important for the adsorption of gas molecules and gas sensing reactions, especially for selectivity. The gas sensing properties can be regulated depending on the pore size of sensing materials and the molecular size of target gases. For example, Tian et al. [44] established the relationship between the pore size of metal organic frameworks (MOFs), a molecular sieving material coated with $\mathrm{ZnO}$ nanorods, and the molecular kinetic diameter of different test gases, as shown in Fig. 7. They prepared MOFs such as ZIF-8 with a nominal pore diameter of $3.4 \AA$. In Fig. 7c, it can be seen that the molecular size of formaldehyde is smaller than the rest of the VOCs, which allows the passing of the ZIF-8 to be detected. Therefore, the selectivity to formaldehyde is higher than that to other gases (Fig. 7d). It can hence be concluded that the selectivity of a gas sensor can be tuned by regulating the pore size of the sensing body, which depends on the kinetic molecular diameter of the gas molecules.

2.1.2.4. Effect of different morphologies. Morphology controlled synthesis of nanostructures into various shapes and sizes is one of many approaches to enhance the sensing performance of gas sensors. Hence, preparing MOS nanostructures with precisely controlled morphologies is important. In view of this, significant research progress has been made in producing different morphologies of nanostructures for the development of high-performance gas sensors. Here, we explain the typical gas sensing mechanisms of MOS nanostructures with different sizes and morphologies, such as nanoparticles, nanorods, and nanowires, to further review materials related to these structures. Shankar et al. [45] proposed the gas sensing mechanism of $\mathrm{ZnO}$ nanostructures with two different morphologies, namely nanoparticles and nanowires, toward ethanol, as shown in Fig. 8. Fig. 8a shows that the $\mathrm{ZnO}$ nanoparticles contain numerous potential barriers in grain boundaries due to the formation of the space charge region at their intergranular contacts. As a result, the percolation path is broadened, which hinders the transport of charge carriers, increasing the potential barrier height (Fig. 8a) and the resistance of the sensor during the gas sensing reaction. On the other hand, in the case of $\mathrm{ZnO}$ nanowire structures, the intergranular contact resistance is reduced due to the unidirectional percolation path (UPP), which decreases the potential barrier height and thus the sensor resistance [32]. Rai et al. [46] investigated the effects of different morphologies of $\mathrm{ZnO}$, such as nanoparticles and nanorods, on sensing properties, and they compared their sensing mechanism with regard to morphology and interelectrode gaps. The authors proposed that the number of grains present between interelectrode gaps affects the sensing performance (response) (Fig. 8). Since grain boundaries are regarded as highly resistive barriers, the overall resistance of $\mathrm{ZnO}$ nanoparticles increases during $\mathrm{NO}_{2}$ sensing. The response to $\mathrm{NO}_{2}$ is measured by $R_{g} / R_{a}$; the higher the $R_{a}$ value, the lower the response to $\mathrm{NO}_{2}$ will be. Furthermore, Tamaki et al. proposed a relationship between number of grains and resistance, in which the sensor resistance is directly related to the number of grains between two electrodes, as follows [47-49]:

$\left.\mathrm{R}_{\mathrm{a}}=2 R_{a}(\mathrm{i})+(\mathrm{N}-1) R_{a}(\mathrm{gb})=(2 R a(\mathrm{i}))-R_{a}(\mathrm{gb})\right)+R_{a}(\mathrm{gb}) N$

where $R_{a}(i)$ and $R_{a}(g b)$ are the resistance at the interface and at the grain boundary in the air, respectively, and $\mathrm{N}$ is the number of grains present in the electrode gap.

2.1.2.4.1. Effect of crystal planes. It is known that that in MOS gas sensors, the sensing reactions result from the adsorption and desorption of oxygen molecules and from the target gas occurring on the sensor's surfaces. Hence, the gas sensing characteristics of an MOS gas sensor are strongly dependent on the nature of its crystal facets exposed to the gas molecules [50]. Different crystallographic facets have different atomic terminated features, which show different gas sensing properties [51]. In this regard, during the synthesis of nanostructures, the growth condition is a crucial factor in controlling morphologies and exposing facets. The effect of crystal planes on the gas sensing properties of MOS gas sensors have been reported by various authors. $\mathrm{ZnO}$, a promising n-type MOS, has been studied in many fields, including the field of gas sensors. The most stable crystal structure of $\mathrm{ZnO}$ in ambient conditions is wurtzite with a hexagonal structure, which is tetrahedrally coordinated with zinc and oxygen atoms stacked alternatively along the caxis [52]. ZnO has two different crystal surfaces: polar (Zn terminated (0001) plane and 0 terminated (000-1) plane) and nonpolar (mix terminated (100). Of the two, the polar crystal facets (0001) have high surface energy and a high crystal growth rate shows different properties than polar facets. Many studies have investigated $\mathrm{ZnO}$ as a gas sensor with high-energy crystal facets exposed. For example, Han et al. [53] examined three types of $\mathrm{ZnO}$ nanostructures, flakes, columns, and pyramids, by hydrothermal routes. The dominant surfaces of ZnO flakes, columns, and pyramids are (0001), $\{100\}$, and $\{101\}$ facets, respectively (as shown in Fig. 9a-i). The ethanol gas sensing properties of these gas sensors reveal that the responses $\left(R_{a} / R_{g}\right)$ of $Z n O$ flakes, columns, and pyramids are in the order of $75.7,31.5$, and 9.3 , respectively, at $350{ }^{\circ} \mathrm{C}$ (Fig. 9j). In addition, many other reports on the effect of crystal facets have been published and are helpful to understand their influence in gas sensing performance [54-57]. The surface atomic structures of wurtzite ZnO with different crystal facets, shown in Fig. 9h-k, play a crucial role in gas sensing and adsorption of oxygen species. Due to the unsaturated oxygen coordination of the Zn terminated (0001) plane, it shows a strong chemisorption process. In contrast, in the case of $\mathrm{O}$ terminated (000) and $\{101\}$ planes, the absorption of oxygen is weak because the terminated $\mathrm{O}^{2-}$ ions are less prone to further absorbing any oxygen species. Hence, it can be concluded that the gas sensing activity of the $\mathrm{ZnO}$ crystal facets is in the order of $(0001)>\{10-10\}>\{10-11\}$ and (000-1), respectively [53].

2.1.2.5. Effect of working temperature. It is known that the gas sensing reaction occurs at the gas-solid interface, which affects the receptor function of sensors. The operating temperature strongly influences the receptor function and thus determines the sensing performance. It should be noted that the formation of different types of chemisorbed oxygen ionic species, such as $\mathrm{O}_{2}^{-}, \mathrm{O}^{-}$, and $\mathrm{O}^{2-}$, are strongly dependent upon the operation temperature of a gas sensor, as shown in the following equations $[35,40,45,52,58]$ :

$$
\begin{aligned}
& \mathrm{O}_{2 \text { (gas) }} \rightarrow \mathrm{O}_{2} \text { (ads) } \\
& \mathrm{O}_{2 \text { (ads) }}+\mathrm{e}-{ }_{\text {(surface) }} \leftrightarrow \mathrm{O}_{2^{-}}{ }_{\text {(ads) }}\left(<100{ }^{\circ} \mathrm{C}\right) \\
& \left.\mathrm{O}_{2 \text { (ads) }}+2 \mathrm{e}-\text { (surface }\right) \leftrightarrow 2 \mathrm{O}^{-}{ }_{\text {(ads) }}\left(100-300{ }^{\circ} \mathrm{C}\right) \\
& \mathrm{O}^{-}{ }_{(\text {ads })}+\mathrm{e}-{ }_{\text {(surface })} \leftrightarrow \mathrm{O}^{2-}{ }_{(\text {ads })}\left(300{ }^{\circ} \mathrm{C}\right)
\end{aligned}
$$

Usually, MOS based gas sensors are heated at elevated temperatures (between $100{ }^{\circ} \mathrm{C}$ to $400^{\circ} \mathrm{C}$ ) to observe the gas sensing performance. As shown in Fig. 10a, the appearance of a volcano shaped (rise-maximumdecline) tendency is due to the temperature-dependent reaction between the chemisorbed oxygen and target gas. A sensitivity below the optimum working temperature value can be expected, because the target gases do not have enough thermal energy to react with the adsorbed oxygen species [59]. The response slowly increases with a rise in temperature up to the optimum temperature, which can be expected to the fact that the thermal energy obtained is high enough to overcome the activation energy barrier to the sensing reaction. However, when the operating temperature is further increased, the response of the sensor gradually decreases, which may be due to the difficult adsorption of both oxygen and target gas molecules on the sensor surface at high temperatures. Hence, in general, an optimum operating temperature is considered to obtain a high response. The relative humidity $(\mathrm{RH})$ has a greater influence on the semiconducting gas sensor. In high humidity conditions, the water molecules disturb the gas sensing performance. For example, recently, Zhang et al. [60] investigated a spinel type 

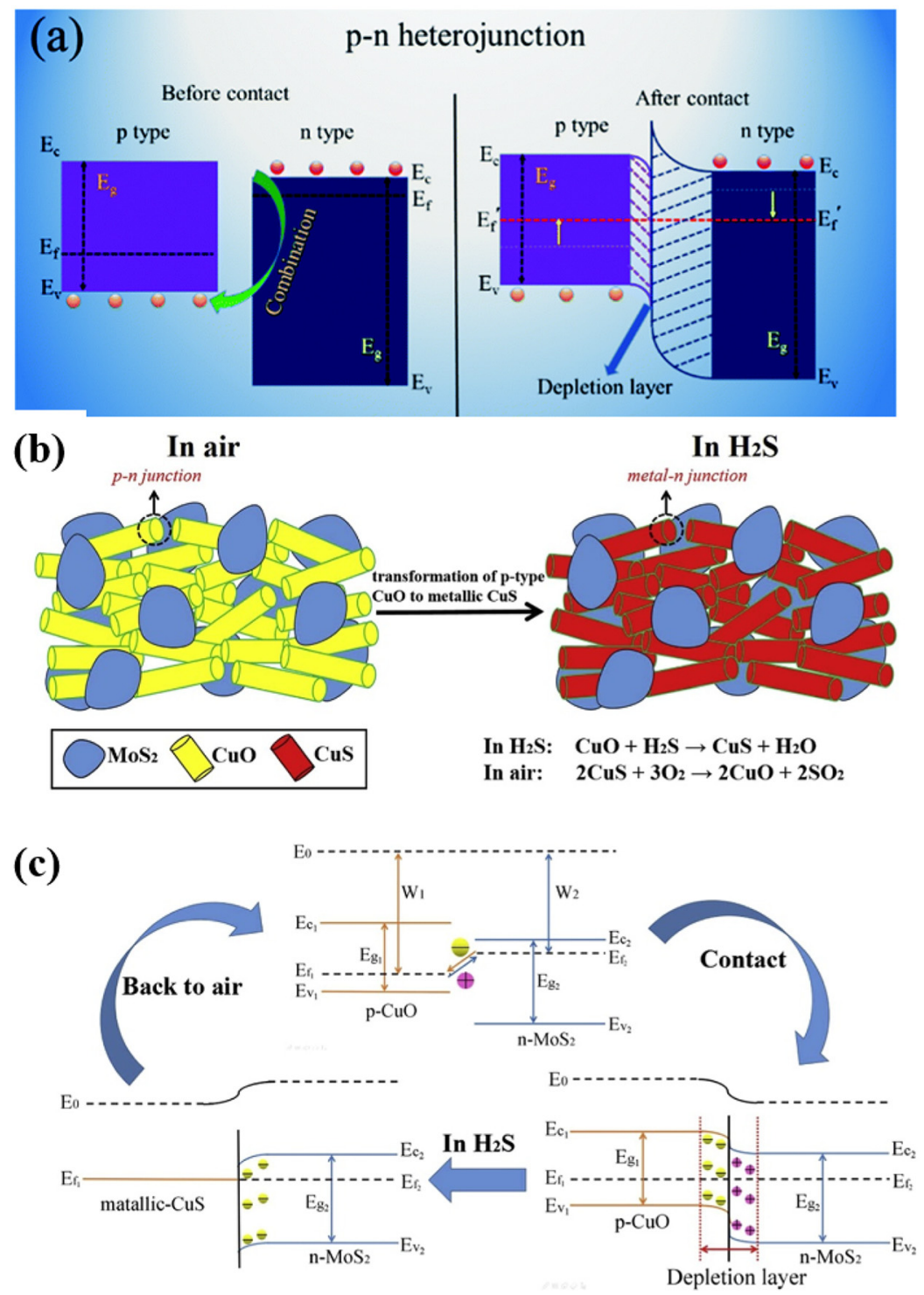

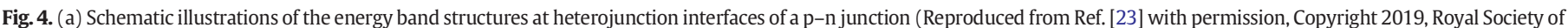

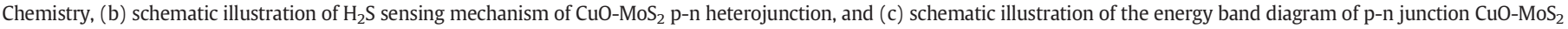
sensor (b-c, Reproduced from Ref. [38] with permission, Copyright 2019, Elsevier).

oxide $\left(\mathrm{NiFe}_{2} \mathrm{O}_{4}\right)$ for acetone gas sensors. They tested the response of the prepared $\mathrm{NiFe}_{2} \mathrm{O}_{4}$ sensor to $100 \mathrm{ppm}$ acetone in different $\mathrm{RH}$ conditions (25 to $98 \%$ ) at an operating temperature of $250{ }^{\circ} \mathrm{C}$. Their results showed that the response as well as the baseline resistances almost linearly decreased with the increasing $\mathrm{RH}$, which can be explained by the fact that water molecules slowly occupied the reaction zone of the sensing material surface (Fig. 10b-c). On the other hand, when the operating temperature was reduced to room temperature (RT), the adsorbed oxygen ions on the surface of the MOS sensor were mainly $\mathrm{O}_{2}^{-}$ions. At RT operation, the $\mathrm{RH}$ effect also had a strong influence on the sensor performance $[61,62]$. In wet atmosphere, $\mathrm{H}_{2} \mathrm{O}$ molecules compete for the surface reaction sites with oxygen molecules and in turn limit oxygen adsorption. The number of oxygen species decreases as the RH level increases, causing a decline of the baseline resistance in ambient atmosphere with a lower sensor response [62].

\section{Detection of different toxic, VOC, and combustible gases}

The rapid industrialization and increase in the number of automobiles have led to severe pollution in indoor and outdoor environments due to the release of toxic and hazardous gases, and volatile organic compounds (VOCs). VOCs are organic chemicals with high vapor pressure and a low boiling point, which makes them volatile in nature [63]. Common pollutants of VOCs include acetone, ethanol, benzene, formaldehyde, methanol, benzene, xylene, toluene, and n-butanol, among others. Common examples of toxic gases are $\mathrm{CO}, \mathrm{H}_{2} \mathrm{~S}, \mathrm{NH}_{3}, \mathrm{NO}_{2}, \mathrm{SO}_{2}$, trimethylamine, etc. In addition, hydrogen $\left(\mathrm{H}_{2}\right)$ gas is regarded as an explosive gas when it is mixed with air. These gases are dangerous to the environment, health, and safety. Therefore, the development of high-performance gas sensors is important for the early detection of these lifethreatening gases. Due to the adverse effects of these gases on human health and society, several environmental safety and health agencies have set guidelines regarding the exposure limit for human beings, such as the Occupied and Safety Health Association (OSHA), the National Institute of Occupational Safety and Health (NIOSH), and the American Conference of Governmental Industrial Hygienists (ACGIH). Table 1 lists a few VOC, toxic, and combustible gases with their properties, exposure limits, and harmful effects [64-84]. 


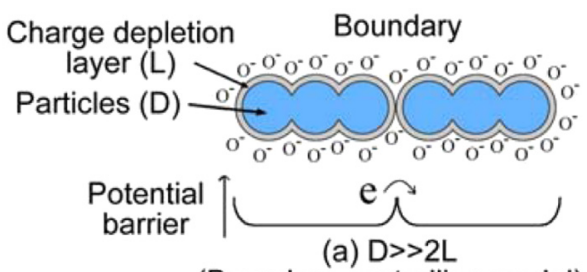

(Boundary-controlling model)

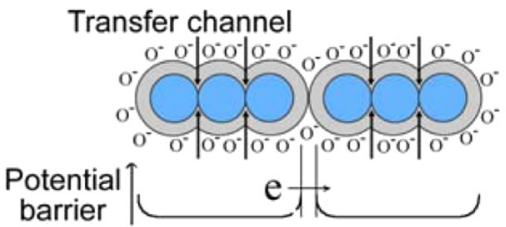

(b) $D \geqslant 2 L$

(Neck-controlling model)

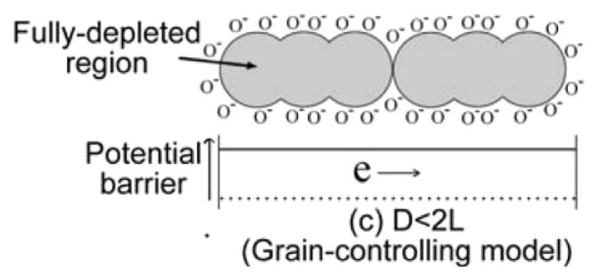

Fig. 5. Schematic illustration of the model depicting the relationship between particle diameter and charge depletion layer on the gas sensitivity (Reproduced from Ref. [40] with permission, Copyright 2012, MDPI AG, Basel, Switzerland).

\section{Synthesis of vertically oriented $\mathrm{ZnO}$ nanostructures}

Different morphologies of nanomaterials possess different advantageous attributes in terms of surface-active sites, surface area, and electronic properties, which facilitate gas diffusion, absorption, and sensing reactions [85]. Vertically oriented nanostructures in particular are currently garnering attention for the fabrication of different sensing devices [86-94]. The utilization of vertically and directly grown nanostructures on the supporting electrode/substrate avoids the use of conductive binders (used to fix nanomaterials on the electrode surface) and higher annealing temperatures. Furthermore, these nanostructures offer an excellent surface area for biomolecule immobilizations (i.e. enzymes) and surface modification with metal/ metal oxides [95]. Considering the excellent properties of vertically oriented nanomaterials, $\mathrm{ZnO}$ has attracted increased interest due to its easy and tunable growth capabilities. One of the most favorable aspects of vertically oriented $\mathrm{ZnO}$ nanostructures is the high reproducibility of the desired nanostructure's morphology, which leads to reproducible sending device fabrication [95].

The most common methods for growing vertically oriented $\mathrm{ZnO}$ nanostructures are the thermal evaporation, hydrothermal, electrochemical, and electrodeposition methods [96-100]. These are all time dependent, which is beneficial for growing similar nanomaterials in different experiments. In comparison with the high temperature based thermal evaporation method, the hydrothermal method provides better control over $\mathrm{ZnO}$ nanostructure morphology because it utilizes a seeded surface and low growth temperature. Umar et al. [101] and Djurišić et al. [102] recently summarized the growth methods of vertically oriented $\mathrm{ZnO}$ nanostructures. In the present review article, we evaluate vertically

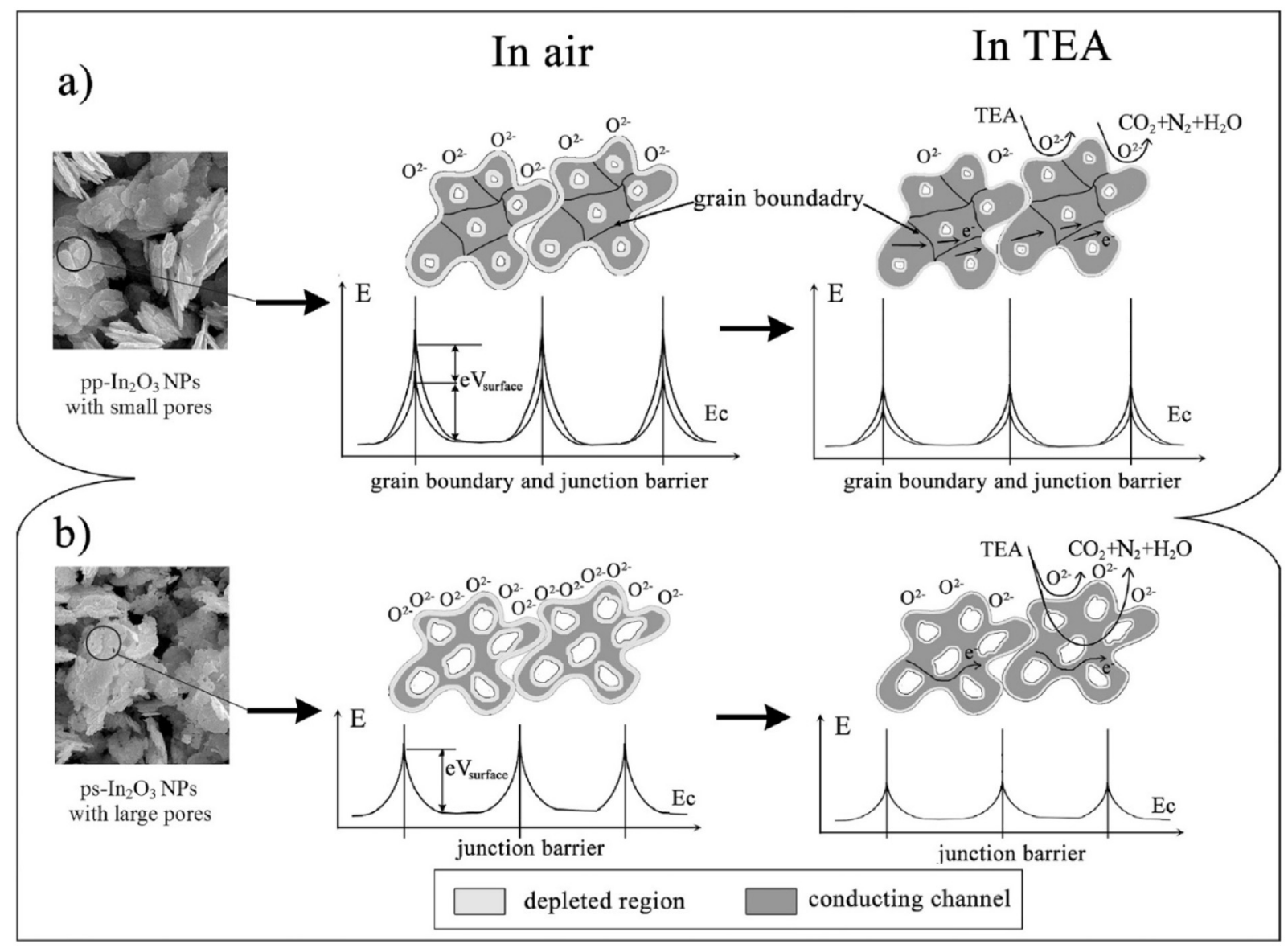

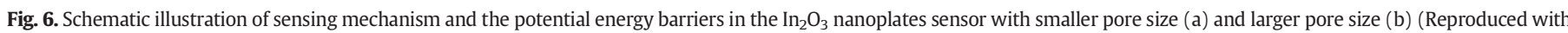
permission from the Ref [42], Copyright 2019, Elsevier. 


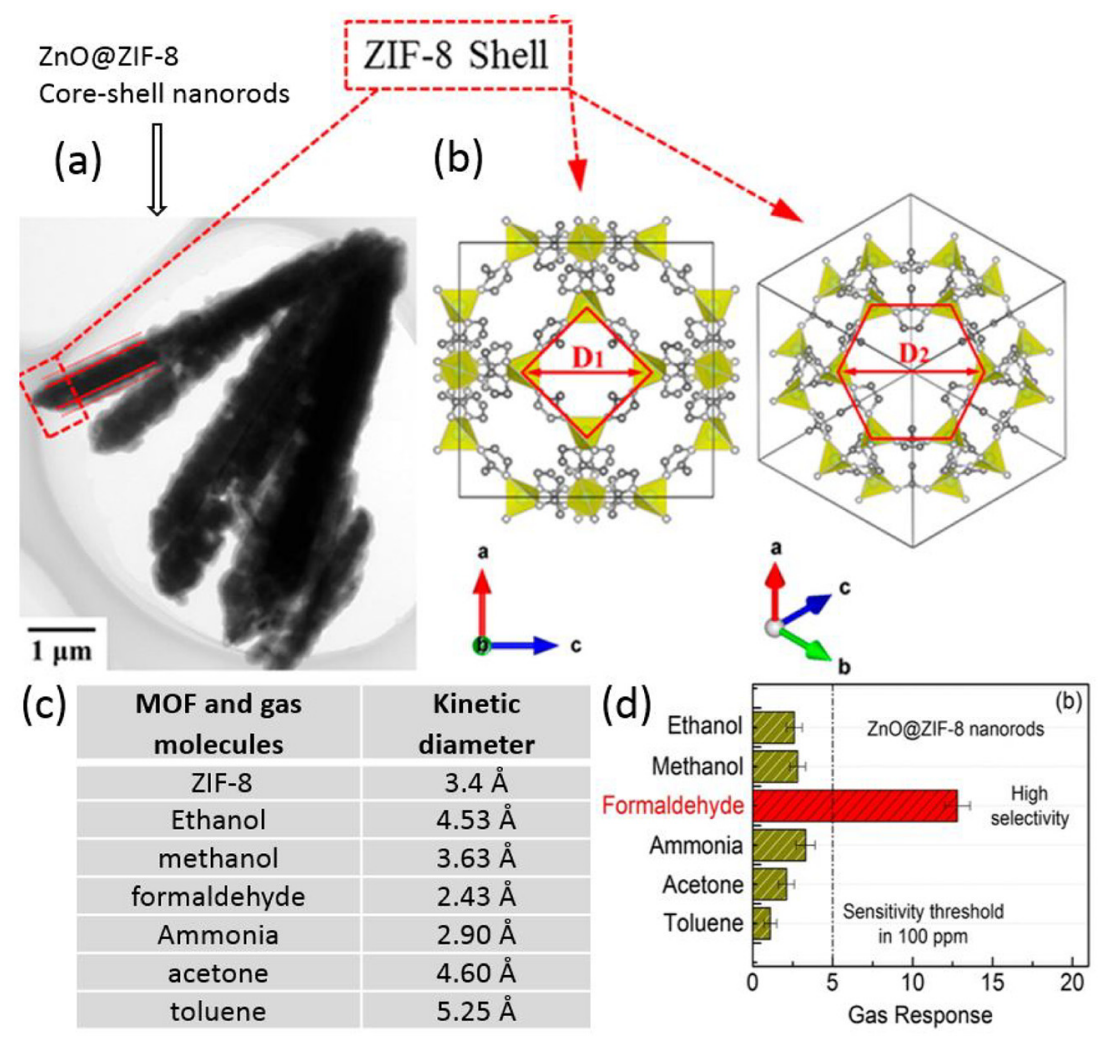

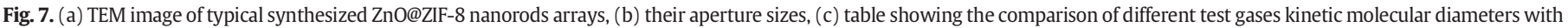

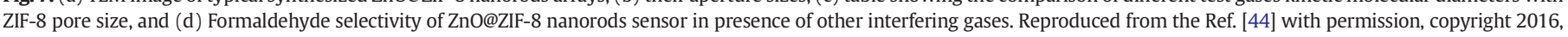
American Chemical Society.

oriented ZnO nanostructures with different morphologies, such as NWs, NRs, NTs, NNs, and NSs (Scheme 1), in gas sensing applications.

\section{Gas sensing applications of vertically oriented $\mathrm{ZnO}$ nanomaterials}

\subsection{ZnO NW based gas sensors}

NWs offer the advantage of a high surface area and other exciting properties [22]. In ZnO NW based gas sensors, gases can diffuse rapidly and effectively through the porous network, allowing a large surface area to participate in the gas sensing reactions [103]. Methods such as direct growth of vertical, horizontal, and bridging NWs have been explored for the production of NW functional gas sensing electrodes [103-105]. Among these methods, vertically oriented NWs are most often used for gas sensing applications as a result of the ease of their formation. Vertically oriented NWs can yield highly stable pathways for rapid electron transport, which enhances sensitivity to achieve ultralow detection limits [103]. As a result of the outstanding properties of vertically oriented $\mathrm{ZnO}$ NWs, several studies have explored their responses to reducing and oxidizing gases. Table 2 details the comparative sensing performance of vertically oriented $\mathrm{ZnO} \mathrm{NW}$ based gas sensors for toxic and VOC gases, including hydrogen sulfide $\left(\mathrm{H}_{2} \mathrm{~S}\right)$, ethanol, hydrogen $\left(\mathrm{H}_{2}\right)$, nitrogen dioxide $\left(\mathrm{NO}_{2}\right), \mathrm{CO}$, ammonia $\left(\mathrm{NH}_{3}\right)$, and acetone. Specific highlights of these results are discussed in the following subsections.

\subsection{1. $\mathrm{H}_{2} \mathrm{~S}$ sensors}

Reliable detection of ppb-ppm levels of hazardous $\mathrm{H}_{2} \mathrm{~S}$ is required for practical applications of this class of gas sensor. Chen et al. reported ultra-sensitive ppb levels of $\mathrm{H}_{2} \mathrm{~S}$ detection with a vertically oriented $\mathrm{ZnO} \mathrm{NW}$ based gas sensor, and they studied its nano size effect on gas sensing properties [106]. The dendritic (tree-branched) $\mathrm{ZnO} 20 \mathrm{~nm}$ diameter NWs responded to $5 \mathrm{ppb} \mathrm{H}_{2} \mathrm{~S}$, representing a performance enhancement compared to the 50-70 nm diameter ZnO NW based device. The nano size effect also appeared to provide for high selectivity, and $500 \mathrm{ppb} \mathrm{H}_{2} \mathrm{~S}$ was detected with high sensitivity compared to other interfering gases. Approaches for further enhancing the sensing performance of only vertically oriented $\mathrm{ZnO} \mathrm{NW}$ based gas sensing devices include the surface functionalization of $\mathrm{ZnO} \mathrm{NWs}$ with noble metal catalysts, doping, and surface coating with metal oxides. A gas sensor with sluggish or incomplete recovery has limited use in practical applications. Hence, the design of high-performance $\mathrm{H}_{2} \mathrm{~S}$ sensors with high sensitivity and selectivity and simultaneously good reversibility remains a challenge. Woo et al. reported that molybdenum (Mo) doped vertically oriented $\mathrm{ZnO} \mathrm{NW}$ networks are highly sensitive and selective with reversible $\mathrm{H}_{2} \mathrm{~S}$ gas sensors [107]. They found the diameters of the pure $\mathrm{ZnO} \mathrm{NWs}$ to be in the range of $50-80 \mathrm{~nm}$, whereas the length was in the order of a few micrometers (Fig. 11b). The ZnO NWs were doped with Mo using $\mathrm{MoS}_{2}$ coating by a successive ion layer adsorption and reaction (SILAR) method, followed by heat treatment at $600{ }^{\circ} \mathrm{C}$ (as shown in Fig. 11a-b). The experimental evidence showed that the $\mathrm{Mo}^{6+}$ was doped to the lattice of ZnO. Furthermore, Woo et al. investigated the effect of Mo doping on the sensing properties and found that the designed Mo doped ZnO NW sensor showed a high selectivity to $\mathrm{H}_{2} \mathrm{~S}$ and high response, with a 14.11 -fold change in resistance at 5 ppm at an operating temperature of $300^{\circ} \mathrm{C}$ and a lower cross-response to other interfering gases (Fig. 11d-e). The pure $\mathrm{ZnO}$ NW sensor showed long recovery ( $10 \mathrm{~min}$ of purging $\mathrm{H}_{2} \mathrm{~S}$ ) for $5 \mathrm{ppm}$ of $\mathrm{H}_{2} \mathrm{~S}$ at $300^{\circ} \mathrm{C}$. In contrast, the Mo doped $\mathrm{ZnO} N W$ sensor exhibited complete recovery in $\mathrm{H}_{2} \mathrm{~S}$ free ambient atmosphere, which is likely due to the stability of the Mo based NW surface. The high selectivity of the Mo doped ZnO NW sensor to $\mathrm{H}_{2} \mathrm{~S}$ was attributed to the strong chemical affinity of $\mathrm{MoO}_{3}$ to $\mathrm{H}_{2} \mathrm{~S}$ and the regenerable adsorption/desorption of the $\mathrm{MoO}_{3}$ surface [107].

The above discussion showed that in spite of using the doping method and reducing the diameter of pure $\mathrm{ZnO} N W$ s to nanoscale, the temperature still remains high for the gas response to $\mathrm{H}_{2} \mathrm{~S}$. Recently, 


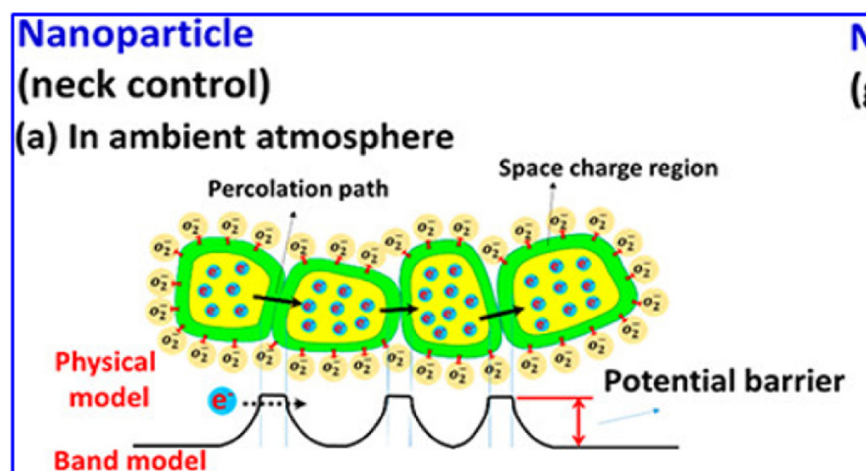

(b) In ethanol atmosphere
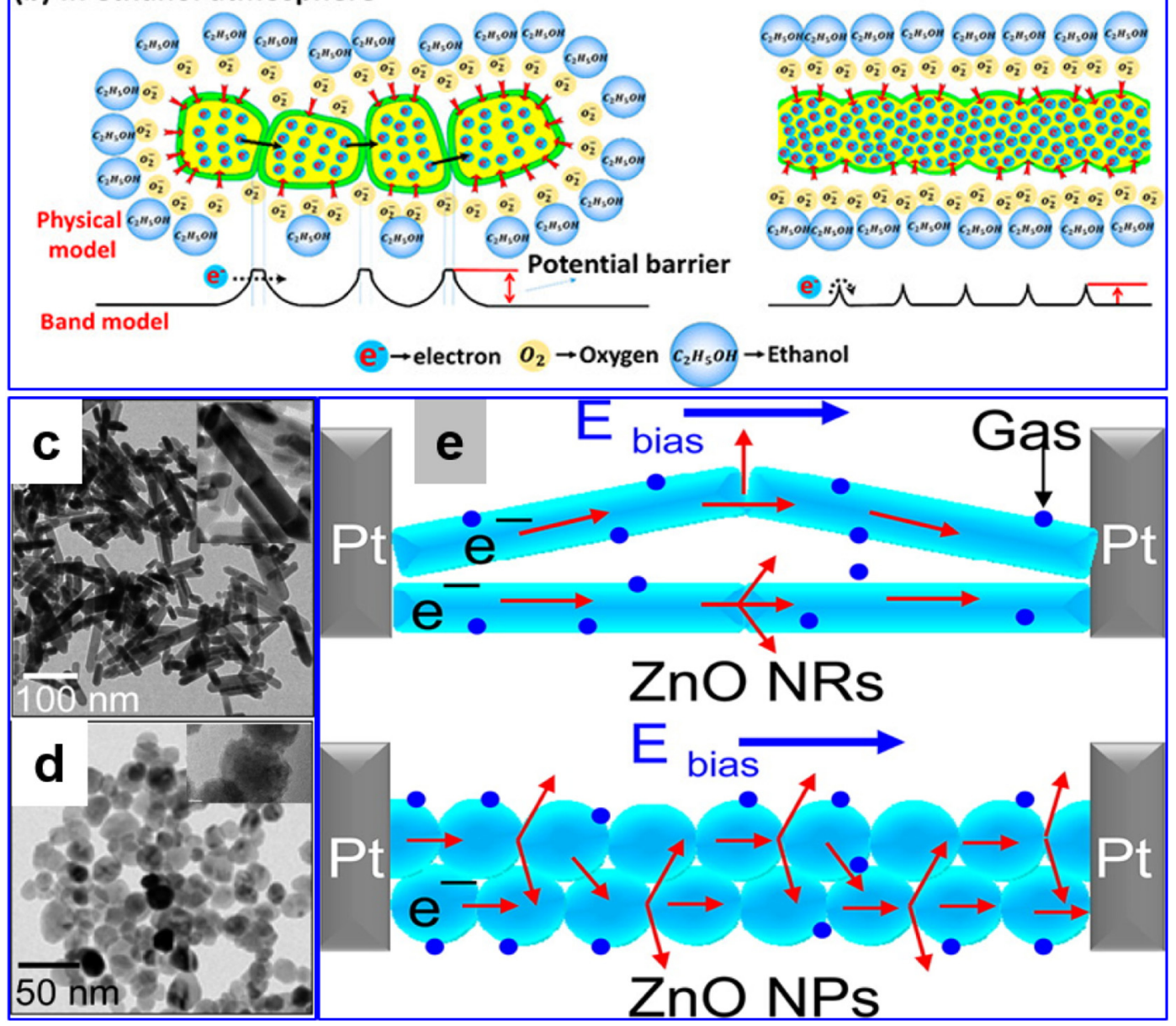

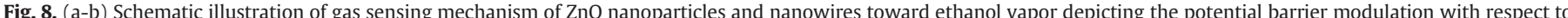

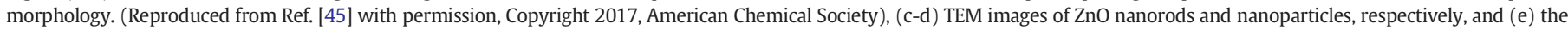

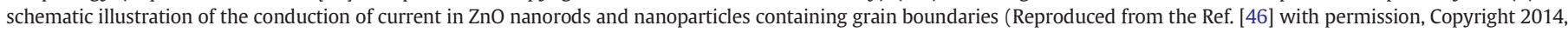
American Chemical Society).

the construction of $p-n$ heterojunctions has emerged as an efficient approach to enhance the sensing properties of pure ZnO NW gas sensors in terms of operating temperature and selectivity. Ashwini et al. [108] demonstrated the preparation of an inorganic-organic combination to develop a p-n junction as a gas sensor. Initially, the ZnO NWs were grown on a biaxially oriented polyethylene terphathalet (BOPET) flexible substrate using a facile hydrothermal process with $\mathrm{ZnO}$ nanoparticles as seeds. The p-type Co Phthalocyanine was coated with different thicknesses (5-25 nm) on the ZnO NWs using a conventional thermal evaporation technique. Choosing BOPET as the substrate is advantageous due to its flexibility, cost effectiveness, and lightweight properties. Moreover, the polar ester groups in the PET chains facilitate the strong adhesion with the $\mathrm{ZnO}$ surface's polar facets due to dipolar

\section{Nanowire \\ (grain boundary control)}

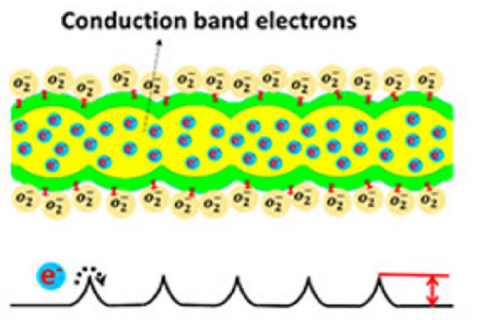

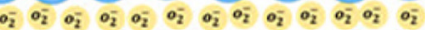
8\%

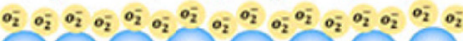

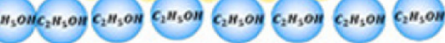



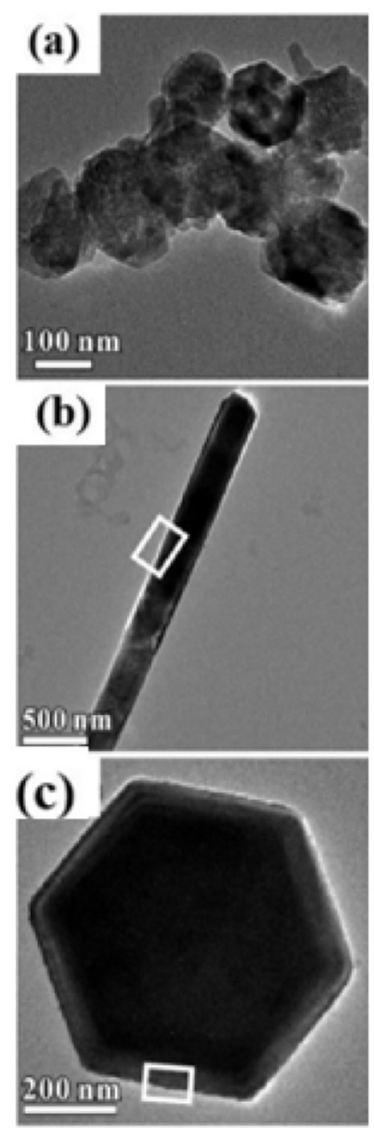
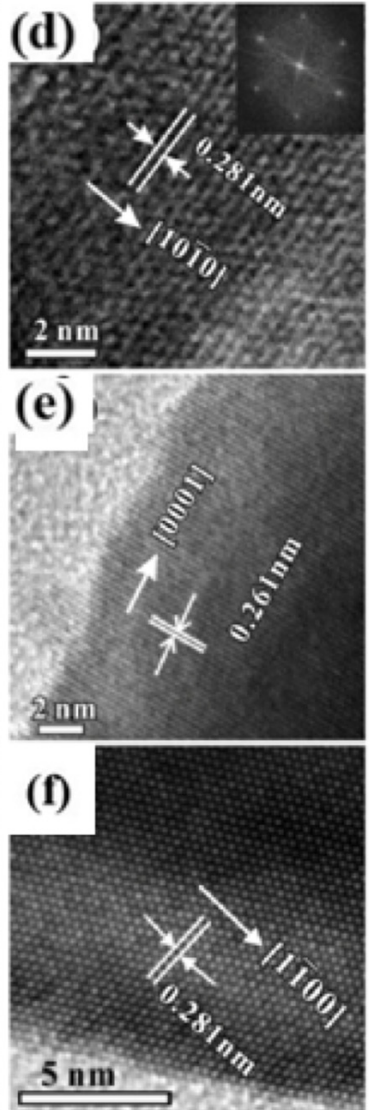
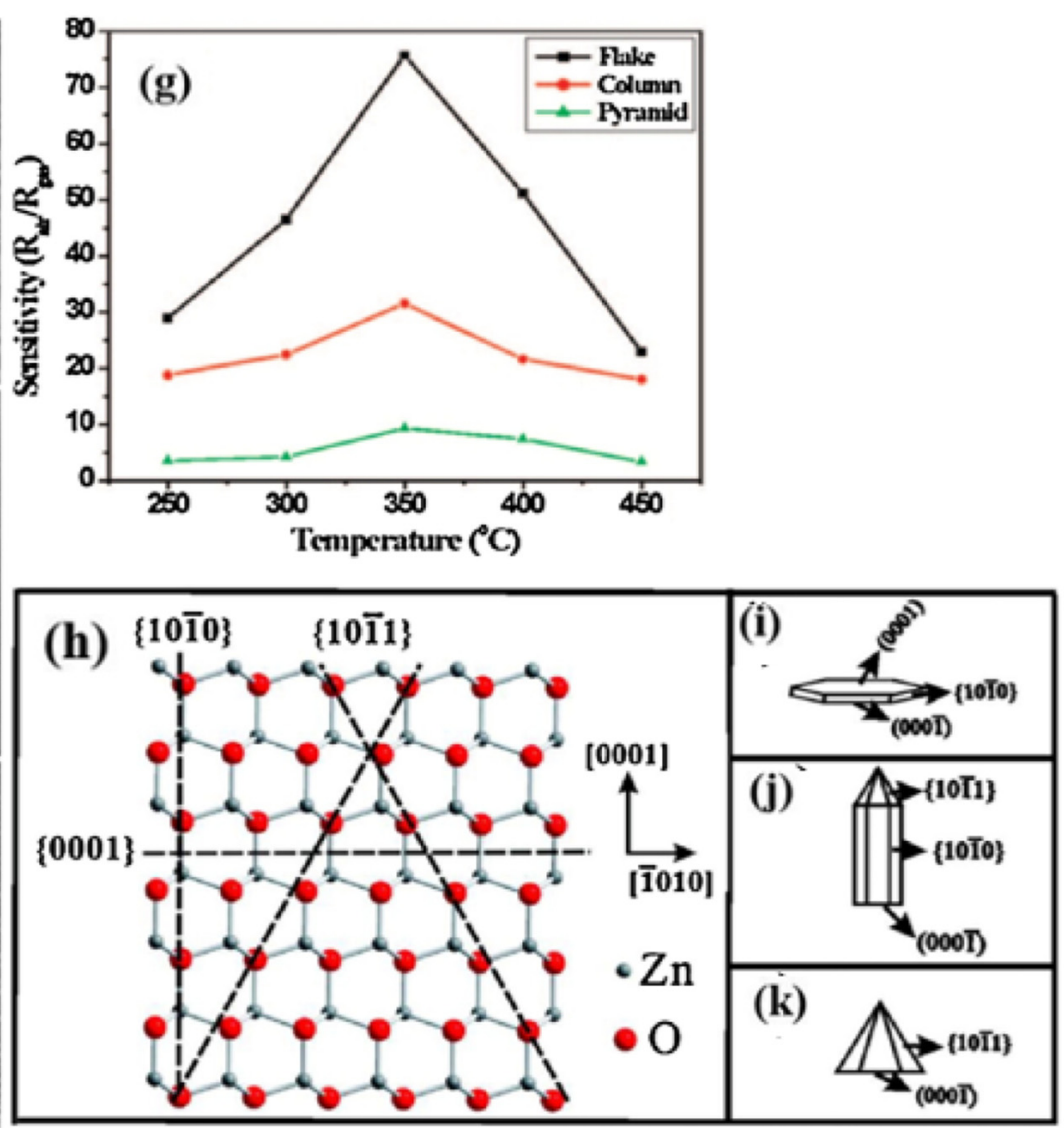

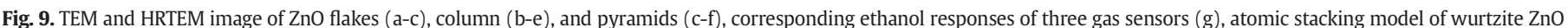

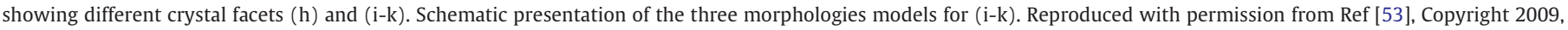
American Chemical Society.

oxygen species), which increased the depletion layer width and blocked the hole conduction channels. It can be concluded that the $\mathrm{ZnO}-\mathrm{CoPc} \mathrm{p}-$ $\mathrm{n}$ heterojunction sensor is a promising candidate for $\mathrm{H}_{2} \mathrm{~S}$ gas sensing applications due to its RT sensitivity, fast response/recovery, and high stability.

Ramgir et al. further enhanced the response and selectivity to $\mathrm{H}_{2} \mathrm{~S}$ at RT by employing Au nanoparticle functionalization on vertically oriented ZnO NWs [109]. The vertically oriented ZnO NWs were grown on a $\mathrm{Si}(100) / \mathrm{SiO}_{2}(100 \mathrm{~nm})$ substrate using a facile hydrothermal method followed by optimized Au deposition ( $0-5.7 \%$ ) by RF sputtering. The ZnO NWs had a diameter in the range of $50-250 \mathrm{~nm}$, while their length varied from 1 to $2 \mu \mathrm{m}$. The surface morphology of the synthesized ZnO NWs contained a quasi-hexagonal end with a polar plane [0001] oriented along the c-axis. The modification of Au nanoparticles on the ZnO NWs did not change any surface morphology. However, the modification of $\mathrm{ZnO} \mathrm{NWs}$ with 1.2 atom\% Au provided a 16-fold increase in the gas sensor response to $5 \mathrm{ppm} \mathrm{H}_{2} \mathrm{~S}$ as compared to pure $\mathrm{ZnO}$ NWs. In a metal-semiconductor (n-type) junction based sensor, a Schottky junction barrier is formed when the work function $(\Phi)$ of the metal $(\mathrm{M})$ is larger than the electron affinity $(\chi)$ of the semiconductor. The barrier (B) height thus formed is given as:

$\Phi_{\mathrm{B}}=\Phi_{\mathrm{M}}-\chi$

The work function of Au metal is $5.1 \mathrm{eV}$ and the electron affinity of $\mathrm{ZnO}$ is $\sim 2.08 \mathrm{eV}$; hence, the Schottky junction barrier will result at the $\mathrm{Au}-\mathrm{ZnO}$ interface. A plausible reason for the enhanced sensor response of Au-ZnO NW gas sensors is the dual role of Au: first, in the formation of nano-Schottky type barrier junction barriers at the ZnO-Au interface, and second, in the catalytic dissociation of molecular oxygen by $\mathrm{Au}$ nanoparticles, which increases the resistance and thus the response. The increased response kinetics are facilitated by the reaction of $\mathrm{H}_{2} \mathrm{~S}$ with a large number of oxygen species $\left(\mathrm{O}_{2}^{-}\right.$at $\left.\mathrm{RT}\right)$ provided by the catalytic dissociation of Au metal, and the large number of active sites due to the high surface-to-volume ratio of ZnO NWs. In conclusion, noble metal functionalization on $\mathrm{ZnO} \mathrm{NW}$ based sensors is believed to be an effective approach for highly sensitive and selective $\mathrm{H}_{2} \mathrm{~S}$ gas sensing.

\subsubsection{Ethanol sensors}

Noble metal loading on $\mathrm{ZnO}$ NWs has proven effective to enhance ethanol gas sensing properties [110,111]. For example, high-sensitivity Pd-ZnO NW based devices were effective for detecting 500 ppm ethanol at $230^{\circ} \mathrm{C}$ [111]. Shi et al. proposed a novel ZnO NW joint (NWs clumped together at the top) structure with high sensitivity and fast response/recovery values of 19 to $28 \mathrm{~s}$ at $275^{\circ} \mathrm{C}$ for ethanol gas sensing [112]. The enhanced ethanol sensing performance is the result of oxygen afforded by the high surface area and large length-to-diameter ratio of ZnO NWs, and the modulation of electronic barriers at the multi-junction joints in ZnO NWs.

$\mathrm{Na}$ et al. designed a p-n heterojunction nanostructure of $\mathrm{Co}_{3} \mathrm{O}_{4}$ deposited on $\mathrm{ZnO}$ NWs for selective detection of ethanol and $\mathrm{NO}_{2}$ [113]. They grew $\mathrm{ZnO}$ NWs on $\mathrm{Al}_{2} \mathrm{O}_{3}$ substrates using a vapor-liquid-solid (VLS) method, and then deposited lenticular nano scale p-type $\mathrm{Co}_{3} \mathrm{O}_{4}$ islands using the thermal evaporation technique. Initially, at an operating temperature of $200{ }^{\circ} \mathrm{C}$, the response of the $\mathrm{Co}_{3} \mathrm{O}_{4}$ - $\mathrm{ZnO} \mathrm{NW}$ based sensor was slightly improved as compared to bare $\mathrm{ZnO}$ NWs. However, when the operating temperature was increased to $400{ }^{\circ} \mathrm{C}$, the $\mathrm{Co}_{3} \mathrm{O}_{4}$ $\mathrm{ZnO} \mathrm{NW}$ based sensor showed high selectivity to $100 \mathrm{ppm}$ ethanol, with a response of 22 and minimal cross sensitivity. Both ZnO NW and $\mathrm{Co}_{3} \mathrm{O}_{4}-\mathrm{ZnO} \mathrm{NW}$ sensors showed the n-type gas sensing properties. 
This indicates that the electrical conduction in the $\mathrm{CO}_{3} \mathrm{O}_{4}$ - $\mathrm{ZnO} \mathrm{NW}$ sensor is dominated by the n-type ZnO NW configuration. However, compared to the $\mathrm{H}_{2} \mathrm{~S}$ discussed in the previous section, which is detectable even at RT by vertically oriented $\mathrm{ZnO} \mathrm{NW}$ based sensors, the highest response to ethanol by the current $\mathrm{CO}_{3} \mathrm{O}_{4}$ - $\mathrm{ZnO} \mathrm{NW}$ sensor at a high temperature $\left(400{ }^{\circ} \mathrm{C}\right)$ needs further explanation. The sensing reaction of ethanol and oxygen species is written as follows:

$\mathrm{C}_{2} \mathrm{H}_{5} \mathrm{OH}+\mathrm{O}^{-} \rightarrow \mathrm{CO}_{2}+\mathrm{H}_{2} \mathrm{O}+\mathrm{e}^{-}$

Prior to the oxidation of ethanol to $\mathrm{CO}_{2}$ and $\mathrm{H}_{2} \mathrm{O}$ as products, it undergoes two intermediate decomposition reactions, shown in the equations below. The complete oxidation of ethanol on the ZnO NWs' surface may occur at an elevated temperature because of this the pure and $\mathrm{Co}_{3} \mathrm{O}_{4}-\mathrm{ZnO} \mathrm{NW}$ sensors show low responses at $200^{\circ} \mathrm{C}$. However, by increasing the temperature up to $400{ }^{\circ} \mathrm{C}$, the $\mathrm{CO}_{3} \mathrm{O}_{4}$ loaded $\mathrm{ZnO}$ NW sensor shows the highest response. This can be explained by the acidic-basic properties of the used metal oxide catalyst. For example, ethanol gas can be either dehydrogenated at the basic oxide surfaces or dehydrated on an acidic oxide surface at a high temperature. The reactions are as follows [114]:

$\mathrm{C}_{2} \mathrm{H}_{5} \mathrm{OH}(\mathrm{g}) \rightarrow \mathrm{CH}_{3} \mathrm{CHO}(\mathrm{g})+\mathrm{H}_{2}(\mathrm{~g})$ (basic oxide)

$\mathrm{C}_{2} \mathrm{H}_{5} \mathrm{OH}(\mathrm{g}) \rightarrow \mathrm{C}_{2} \mathrm{H}_{4}(\mathrm{~g})+\mathrm{H}_{2} \mathrm{O}(\mathrm{g})$ (acidic oxide)

The enhancement of $\mathrm{C}_{2} \mathrm{H}_{5} \mathrm{OH}$ at $400{ }^{\circ} \mathrm{C}$ in the present study is taken into account by the catalytic effect of $\mathrm{CO}_{3} \mathrm{O}_{4}$ for the total conversion of ethanol to $\mathrm{CO}_{2}$ and $\mathrm{H}_{2} \mathrm{O}$ at the favorable temperature of $\mathrm{Co}_{3} \mathrm{O}_{4}(\sim 380$ $\left.{ }^{\circ} \mathrm{C}\right)$ [115]. The extension of the electron depletion layer due to the $\mathrm{p}-\mathrm{n}$ junction of the $\mathrm{Co}_{3} \mathrm{O}_{4}$ - $\mathrm{ZnO} \mathrm{NW}$ sensor is another possible reason for the enhanced response. However, the gas responses are completely dependent on different sensor configurations.

Other p-type oxides, such as $\mathrm{NiO}$ [116], manganese oxide $\left(\mathrm{Mn}_{3} \mathrm{O}_{4}\right)$ [117], and chromium oxide $\left(\mathrm{Cr}_{2} \mathrm{O}_{3}\right)$ [118], have also been used to modify vertically oriented $\mathrm{ZnO} \mathrm{NW}$ surfaces. $\mathrm{NiO}$ functionalized $\mathrm{ZnO}$ NWs display enhanced sensing sensitivity and selectivity to ethanol. Na et al. reported that $\mathrm{NiO}$ modified $\mathrm{ZnO} \mathrm{NW}$ based gas sensors had high selectivity and high sensitivity of 29.04 to $5 \mathrm{ppm}$ of ethanol at $450{ }^{\circ} \mathrm{C}$, as compared to pure ZnO NWs (3.65) [116]. As discussed in the literature [114], the enhanced response to and selective detection of ethanol by the deposition of basic oxides ( $\mathrm{NiO}$ ) onto $\mathrm{ZnO}$ NWs can be explained by the dissociation of $\mathrm{C}_{2} \mathrm{H}_{5} \mathrm{OH}$ into more reactive products $\left(\mathrm{CH}_{3} \mathrm{CHO}\right.$ and $\mathrm{H}_{2}$ ). In another study, Kwak et al. examined the effect of $\mathrm{Mg}$ doping on urchin-like ZnO NW networks for ethanol gas sensing, and they obtained a high response of 343 to $5 \mathrm{ppm}$ ethanol at $350{ }^{\circ} \mathrm{C}$ [119]. They demonstrated that the urchin-like morphology of Mg doped ZnO NW networks played a crucial role in increasing the gas response due to the large number of NW-NW contacts. In addition, the high selectivity to ethanol of $\mathrm{Mg}$ doped $\mathrm{ZnO}$ NW sensors is attributed to the acidicbasic properties of $\mathrm{Mg}$. Since $\mathrm{Mg}$ is a basic element, the dehydrogenation reaction $\mathrm{CH}_{3} \mathrm{CHO}(\mathrm{g})+\mathrm{H}_{2}(\mathrm{~g})$, which shows higher reactivity with negative oxygen species, is mostly favored. The high response is explained by the effective near-surface electron depletion layer and the numerous NW-NW contacts [116]. The studies reviewed above imply that the high ethanol sensing properties of $\mathrm{ZnO} \mathrm{NW}$ based sensors are due to changes in the acidic-basic properties of the sensing materials, especially the addition of basic oxide additives to the sensing materials.

\subsection{3. $\mathrm{H}_{2}$ sensors}

ZnO NW networks show high sensitivity and faster response to many target gases when compared to other NW configurations as a result of their high surface area and many NW-NW junctions [120]. However, bare $\mathrm{ZnO} \mathrm{NW}$ networks often suffer from limited $\mathrm{H}_{2}$ selectivity in the presence of other interfering gases. Different strategies have been employed to address this issue. One method is to use a porous metal
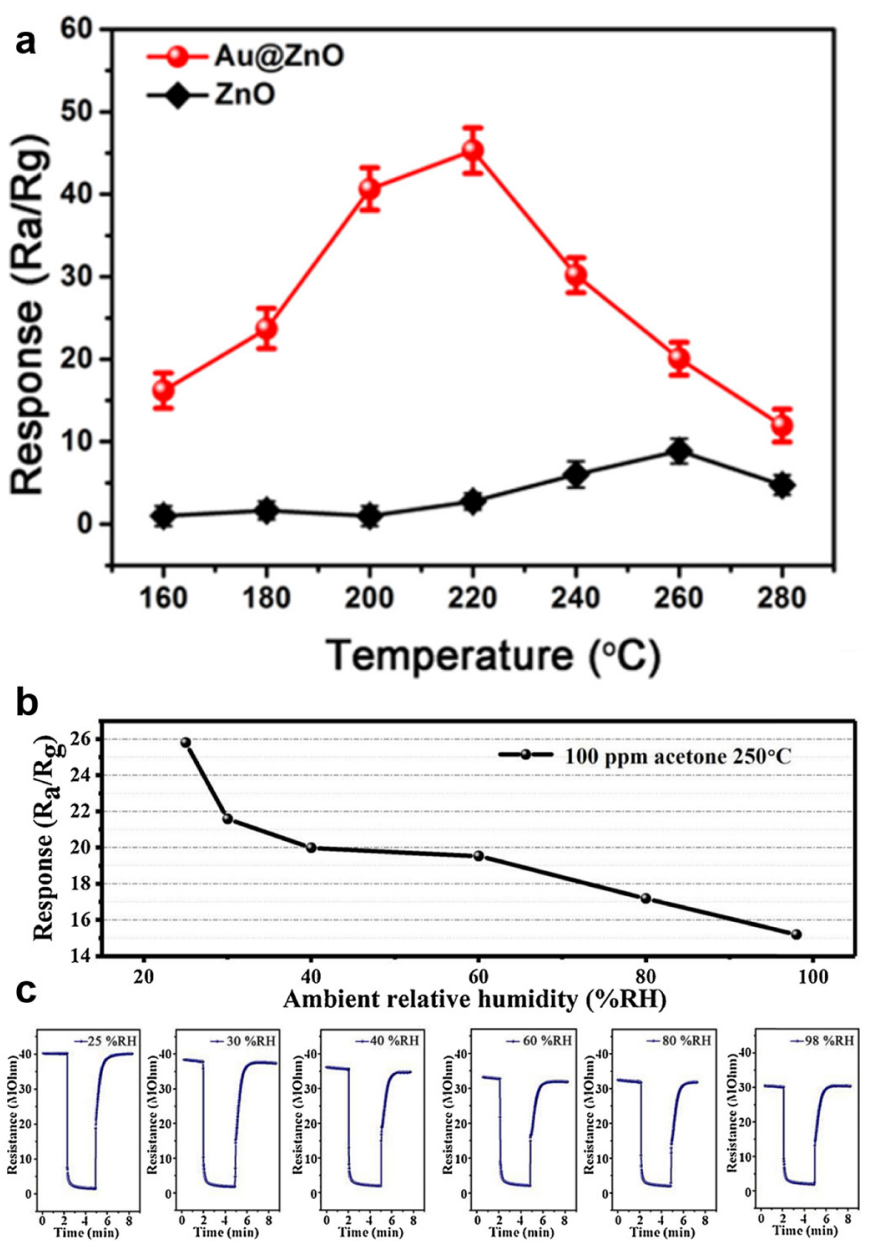

Fig. 10. (a) The relation between response and operation temperature of $\mathrm{Au} @ \mathrm{ZnO}$ and $\mathrm{ZnO}$ NPs sensors. Reproduced from the Ref. [58] with permission, Copyright 2019, American Chemical Society; (b) effect of responses, and (b) baseline resistance with different relative humidity for $\mathrm{NiFe}_{2} \mathrm{O}_{4}$ sensor to $100 \mathrm{ppm}$ acetone at $250{ }^{\circ} \mathrm{C}$ (Reproduced with permission from Ref. [60], Copyright 2019, Elsevier).

organic framework (MOF) as a membrane filter over ZnO NWRs to improve selectivity to $\mathrm{H}_{2}$ gas [121]. In this case, the MOF acts as a molecular sieve and selectively absorbs target gas molecules as a function of their kinetic diameters.

Drobek et al. proposed MOF encapsulated ZnO NWs for highselectivity $\mathrm{H}_{2}$ gas sensors with negligible response to other interfering gases such as benzene and toluene [122]. They further showed a highselectivity $\mathrm{H}_{2}$ gas sensor fabricated using a SIM-1 nanomembrane coated ZnO NWs [123]. SIM-1 stands for substituted imidazole material-1, which is isostructural with zeolite imidazole frameworks (ZIF-8) and has pore apertures $<0.34 \mathrm{~nm}$ and cage sizes of $\sim 0.8 \mathrm{~nm}$. The authors grew vertically oriented $\mathrm{ZnO}$ NWs on $\mathrm{Au} / \mathrm{Pt} / \mathrm{Ti}$ patterned interdigitated electrodes (PIEs) and coated the ZIF based materials using a solvothermal treatment method (Fig. 12a-e). When compared to pristine $\mathrm{ZnO}$ NW based sensors, the ZnO/SIM-1 NW based sensors were remarkably selective to $\mathrm{H}_{2}$ at $300{ }^{\circ} \mathrm{C}$ and showed negligible responses to other interfering gases, such as acetone, methane, toluene, ethanol, and benzene (Fig. 12f). The excellent selectivity to $\mathrm{H}_{2}$ of $\mathrm{ZnO} / \mathrm{SIM}-1$ NW sensors is attributed to the small pore apertures that can accommodate $\mathrm{H}_{2}$ transfer but block larger molecules. The current molecular sieving membrane (SIM-1) coated ZnO NW gas sensors are a promising tool for $\mathrm{H}_{2}$ detection, and they can be used in many fields, both domestic and in industries. The current approach is highly flexible because the synthesis method can be applied to prepare different gases with different MOs and MOFs to tune the selectivity to a specific gas [123]. 
Table 1

List of VOC, toxic, and combustible gases with their physical properties, uses, threshold limit values (TLVs), and immediately dangerous to life or health (IDLH) health effects.

\begin{tabular}{|c|c|c|c|c|c|}
\hline Gas & Properties/use & $\mathrm{TLV}^{*}$ & IDLH & Health effect & Ref. \\
\hline $\mathrm{H}_{2} \mathrm{~S}$ & $\begin{array}{l}\text { Colorless, poisonous gas, flammable, rotten egg smell/ paper, } \\
\text { oil, gas and waste treatment industries, chemical industries }\end{array}$ & $\begin{array}{l}10 \mathrm{ppm} \\
\text { OSHA and } \\
\text { ACGIH }\end{array}$ & $\begin{array}{l}100 \mathrm{ppm} \\
(\mathrm{NIOSH})\end{array}$ & $\begin{array}{l}\text { Known as chemical asphyxiation, death due to } \\
\text { react with hemoglobin reducing the oxygen flow } \\
\text { in blood, quickly paralyzes the olfactory system }\end{array}$ & [64-66] \\
\hline $\mathrm{CO}$ & Colorless, odorless, tasteless, non-irritating/- & $\begin{array}{l}50 \mathrm{ppm} \\
\text { (OSHA) and } \\
35 \mathrm{ppm} \\
(\mathrm{NIOSH})\end{array}$ & $\begin{array}{l}1200 \mathrm{ppm} \\
(\mathrm{NIOSH})\end{array}$ & $\begin{array}{l}\text { Fatal death due to the bind of hemoglobin and } \\
\text { reduction oxygen transportation, headache, } \\
\text { Nausea, dizziness, collapse, loss of consciousness }\end{array}$ & {$[67,68]$} \\
\hline $\mathrm{NO}_{2}$ & Pungent odor, not flammable, & $\begin{array}{l}3 \mathrm{ppm} \\
(\mathrm{ACGIH})\end{array}$ & $\begin{array}{l}20 \mathrm{ppm} \\
(\mathrm{NIOSH})\end{array}$ & $\begin{array}{l}\text { Photochemical smog, produce ozone, irritating to } \\
\text { eyes, lung damage }\end{array}$ & {$[69,70]$} \\
\hline $\mathrm{NH}_{3}$ & $\begin{array}{l}\text { Colorless, strong and sharp smell, corrosive and hazardous/ } \\
\text { precursor to food and fertilizer, drug synthesis, laboratory use } \\
\text { as alkaline }\end{array}$ & $\begin{array}{l}25 \mathrm{ppm} \\
(\mathrm{ACGIH})\end{array}$ & $\begin{array}{l}300 \mathrm{ppm} \\
(\mathrm{NIOSH})\end{array}$ & $\begin{array}{l}\text { Irritant, corrosive and hazardous to skin, eyes, } \\
\text { respiratory tract of humans }\end{array}$ & [71] \\
\hline $\begin{array}{l}\text { Trimethylamine } \\
\text { (TMA) }\end{array}$ & Highly flammable, colorless, fishy odor, & $\begin{array}{l}10 \mathrm{ppm} \\
(\mathrm{ACGIH})\end{array}$ & - & Irritate to eyes, skin, nose, throat & {$[72,73]$} \\
\hline Ethanol & $\begin{array}{l}\text { Colorless, volatile (BP: } 78.3^{\circ} \mathrm{C} \text { ), inflammable, alcoholic smell, } \\
\text { low toxicity }\end{array}$ & 1000 ppm & $\begin{array}{l}3300 \mathrm{ppm} \\
(\mathrm{NiOSH})\end{array}$ & $\begin{array}{l}\text { Irritation of eyes, Headache, drowsiness, difficulty } \\
\text { in breathing }\end{array}$ & [74] \\
\hline Acetone & $\begin{array}{l}\text { Colorless liquid, pungent odor/ used to dissolve plastics, } \\
\text { pharmaceuticals, laboratories as reagent, solvent }\end{array}$ & $\begin{array}{l}750 \mathrm{ppm} \\
(\mathrm{ACGIH})\end{array}$ & $\begin{array}{l}25,00 \mathrm{ppm} \\
(\mathrm{NIOSH})\end{array}$ & $\begin{array}{l}\text { Fatigue, nausea, dizziness, narcosis, muscle } \\
\text { weakness, dryness in mouth, harmful to nerve } \\
\text { system }\end{array}$ & [75] \\
\hline Formaldehyde & $\begin{array}{l}\text { Colorless, flammable/ as industrial fungicide, germicide and } \\
\text { disinfectant, production of urea, phenolic resins }\end{array}$ & $\begin{array}{l}20 \mathrm{ppm} \\
(\mathrm{NIOSH})\end{array}$ & $\begin{array}{l}20 \mathrm{ppm} \\
\text { (OSHA) and } \\
100 \mathrm{ppm} \\
(\mathrm{NIOSH})\end{array}$ & $\begin{array}{l}\text { Human carcinogen (nasopharyngeal cancer) } \\
\text { pulmonary damage and leukemia at } 6 \text { ppm) }\end{array}$ & {$[76,77]$} \\
\hline n-butanol & $\begin{array}{l}\text { Colorless liquid, flammable, slightly toxic, vinous odor/ used } \\
\text { as solvent in industry, ingredient for perfumes and flavor, } \\
\text { extraction of oils, cosmetic nail products, drugs }\end{array}$ & $\begin{array}{l}100 \mathrm{ppm} \\
(\mathrm{NIOSH})\end{array}$ & $\begin{array}{l}8000 \mathrm{ppm} \\
(\mathrm{NIOSH})\end{array}$ & $\begin{array}{l}\text { Dizziness, headache somnolence, dermatitis, } \\
\text { lacrimation, photophobia, blurred vision }\end{array}$ & [78] \\
\hline Toluene & $\begin{array}{l}\text { Colorless liquid, aromatic odor/used in production of paints, } \\
\text { nail polish, lacquers, adhesives, rubber, leather tanning }\end{array}$ & $\begin{array}{l}100 \mathrm{ppm} \\
(\mathrm{NIOSH})\end{array}$ & $\begin{array}{l}500 \mathrm{ppm} \\
(\mathrm{NIOSH})\end{array}$ & $\begin{array}{l}\text { Allergenic, central nervous system depression, } \\
\text { dizziness, headache, fatigue, irritation of eyes, and } \\
\text { skin, unconsciousness }\end{array}$ & [79] \\
\hline Methanol & $\begin{array}{l}\text { Colorless, flammable, high toxicity, mild odor/ automotive } \\
\text { fuel, preparation of dyes, color, drugs, perfumes, }\end{array}$ & $\begin{array}{l}200 \mathrm{ppm} \\
(\mathrm{ACGIH})\end{array}$ & $\begin{array}{l}6000 \mathrm{ppm} \\
(\mathrm{NIOSH})\end{array}$ & $\begin{array}{l}\text { Nausea, abdominal pain, dizziness, headache, } \\
\text { blurred vision, eye irritation, drowsiness }\end{array}$ & {$[80]$} \\
\hline Benzene & Colorless, highly flammable, strong aroma, chronic toxicity & $\begin{array}{l}1 \mathrm{ppm} \\
\text { (OSHA) }\end{array}$ & $\begin{array}{l}500 \mathrm{ppm} \\
(\mathrm{NIOSH})\end{array}$ & $\begin{array}{l}\text { Carcinogenic effect (leukemia), narcotic effect due } \\
\text { to inhalation, fatal death ( } 2 \%, 5-10 \text { min exposure) }\end{array}$ & {$[81,82]$} \\
\hline Xylene & $\begin{array}{l}\text { Colorless, flammable liquid, sweet odor/ petroleum and wood } \\
\text { processing industry }\end{array}$ & $\begin{array}{l}100 \mathrm{ppm} \\
(\mathrm{ACGIH})\end{array}$ & $\begin{array}{l}900 \mathrm{ppm} \\
(\mathrm{NIOSH})\end{array}$ & $\begin{array}{l}\text { Irritate to eyes, nose, skin and throat, headache, } \\
\text { dizziness, confusion, loss of muscle coordination, } \\
\text { fatal death in high dose }\end{array}$ & [83] \\
\hline $\mathrm{H}_{2}$ & $\begin{array}{l}\text { Colorless, tasteless, highly flammable, low minimum ignition } \\
\text { energy }(0.017 \mathrm{~mJ}) \text {, nontoxic, explosive/ used as fuel in } \\
\text { vehicles, metal smelting, glassmaking, petroleum extraction }\end{array}$ & NA & NA & $\begin{array}{l}\text { Pure form is a chemical asphyxiant, dizziness, } \\
\text { nausea, vomiting, stinging of the nose and throat, } \\
\text { headaches and drowsiness }\end{array}$ & [84] \\
\hline
\end{tabular}

* TLV is defined as the maximum concentration of a chemical permitted during a working day of $8 \mathrm{~h}$ for repeated exposure without producing adverse health effects.

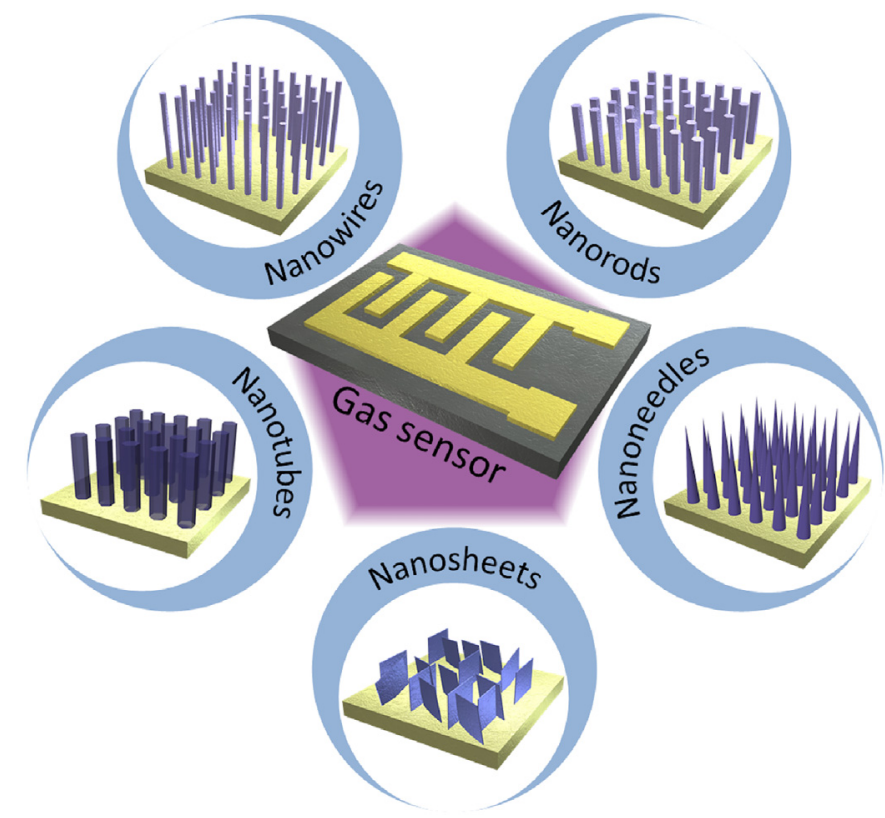

Scheme 1. Different vertically oriented ZnO nanowires (NWs), nanorods (NRs), nanotubes (NTs), nanoneedles (NNs) and nanosheets (NSs) for gas sensing applications.
To reduce the operating temperatures of gas sensing devices, Lupan et al. investigated a Pd functionalized ZnO NW based gas sensor to detect $\mathrm{H}_{2}$ gas [104]. This device displayed a high response of $13,100\left(\mathrm{I}_{\mathrm{g}} /\right.$ $\mathrm{I}_{\mathrm{a}}$ ) to $100 \mathrm{ppm} \mathrm{H}_{2}$ at $\mathrm{RT}$ in $30 \%$ relative humidity ( $\mathrm{RH}$ ). The sensitivity and selectivity were attributed to the known reactivity of the Pd NPs with hydrogen. Lupan et al. also investigated the doping of ZnO NWs with $\mathrm{Ag}$ [124] and $\mathrm{Cd}$ [125] as alternative approaches to $\mathrm{H}_{2}$ sensing at ambient temperatures. It can be concluded that noble metal deposition, especially Pd nanoparticle deposition, would be an effective approach for the highly sensitive and selective detection of $\mathrm{H}_{2}$ at RT.

\subsection{4. $\mathrm{NO}_{2}$ sensors}

$\mathrm{ZnO}$ NWs have also been utilized for $\mathrm{NO}_{2}$ sensing applications [126-128]. Ahn et al. proposed the synthesis of bridged vertically oriented $\mathrm{ZnO} \mathrm{NWs}$ on a $\mathrm{SiO}_{2} / \mathrm{Si} / \mathrm{Ti} / \mathrm{Pt}$ substrate for $\mathrm{NO}_{2}$ sensing [129]. They obtained fast response/recovery properties of a $\mathrm{NO}_{2}$ sensor at $225{ }^{\circ} \mathrm{C}$ via oxygen vacancies and the formation of barriers at the NW network junction points [120]. To grow ZnO NWs, a seed layer is needed. However, this layer can potentially cause a parallel circuit (leakage current) that can compromise the sensor response. Nguyen et al. grew $\mathrm{ZnO}$ NWs on a dendritic Au catalyst without using a seed layer [130]. The NW-NW junctions were formed on the device and the reduced current leakage provided for enhanced sensing responses.

To further improve the sensing properties of sensors for $\mathrm{NO}_{2}$, Chen et al. designed novel core-shell $\mathrm{ZnGa}_{2} \mathrm{O}_{4} / \mathrm{ZnO} \mathrm{NWs}$ vertically grown on 
Table 2

Comparisons of gas sensing properties of vertically oriented $\mathrm{ZnO}$ NW based gas sensor.

\begin{tabular}{|c|c|c|c|c|c|c|c|c|}
\hline Electrodes/Substrates & Materials & Synthesis method & $\begin{array}{l}\text { Target } \\
\text { gas }\end{array}$ & $\begin{array}{l}\text { Concentration } \\
\text { (ppm) }\end{array}$ & $\begin{array}{l}\text { Temp. } \\
\left({ }^{\circ} \mathrm{C}\right)\end{array}$ & $\begin{array}{l}\text { Sensitivity }(S) \\
{\left[R_{a} / R_{g} \text { or }\right.} \\
*\left(R_{a}-R_{g} / R_{a}\right) \times \\
100]\end{array}$ & $\begin{array}{l}\text { Response } \\
\text { (s)/Recovery } \\
\text { time (s) }\end{array}$ & Ref. \\
\hline $\mathrm{Au} / \mathrm{SiO}_{2} / \mathrm{Pt} / \mathrm{Si}_{3} \mathrm{~N}_{4} / \mathrm{Si}$ & ZnO NWs & Hydrothermal & $\mathrm{H}_{2} \mathrm{~S}$ & 0.005 & 300 & 0.81 & - & [106] \\
\hline $\mathrm{Al}_{2} \mathrm{O}_{3} / \mathrm{Au}$ & Mo-ZnO NRs & $\begin{array}{l}\text { Carbothermal reduction \& successive ionic } \\
\text { layer adsorption (SILAR) }\end{array}$ & $\mathrm{H}_{2} \mathrm{~S}$ & 5 & 300 & 14.11 & - & [107] \\
\hline $\begin{array}{l}\text { Biaxial oriented polyethylene } \\
\text { terphathalet (BOPET) }\end{array}$ & n-ZnO NWs-p-CoPc & Hydrothermal & $\mathrm{H}_{2} \mathrm{~S}$ & 10 & RT & $268 \%^{*}$ & $26 /-$ & [108] \\
\hline $\mathrm{SiO}_{2} / \mathrm{Si}$ & $\mathrm{Au}-\mathrm{ZnO} \mathrm{NWs}$ & Hydrothermal & $\mathrm{H}_{2} \mathrm{~S}$ & 5 & RT & 79 & $40 / 15$ & [109] \\
\hline $\mathrm{Al}_{2} \mathrm{O}_{3}$ & Au-ZnO NWs & Thermal oxidation & Ethanol & 1000 & 300 & 478 & - & [110] \\
\hline $\mathrm{ZnO}: \mathrm{Ga} / \mathrm{SiO}_{2} / \mathrm{Si}$ & Pd-ZnO NWs & Carbothermal reduction & Ethanol & 500 & 230 & $61.5 \%^{*}$ & - & [111] \\
\hline Patterned $\mathrm{Cu} / \mathrm{Pt} / \mathrm{Cr}$ & ZnO NWs & Hydrothermal & Ethanol & 100 & 275 & 99.1 & $19 / 28$ & [112] \\
\hline $\mathrm{Al}_{2} \mathrm{O}_{3} / \mathrm{Au}$ & $\mathrm{Co}_{3} \mathrm{O}_{4}-\mathrm{ZnO} \mathrm{NWs}$ & Thermal evaporation & Ethanol & 100 & 400 & 22 & - & [113] \\
\hline $\mathrm{Si}$ & ZnO NWRs & Thermal evaporation & Ethanol & 100 & 400 & 58.17 & - & [115] \\
\hline $\mathrm{Al}_{2} \mathrm{O}_{3}$ & $\mathrm{NiO}-\mathrm{ZnO} \mathrm{NWs}$ & Thermal evaporation & Ethanol & 5 & 450 & 26.15 & - & [116] \\
\hline $\mathrm{Al}_{2} \mathrm{O}_{3}$ & $\mathrm{Mg}-\mathrm{ZnO} \mathrm{NWs}$ & Thermal evaporation & Ethanol & 5 & 350 & 343 & - & [119] \\
\hline $\mathrm{Si} / \mathrm{SiO}_{2} / \mathrm{Ti} / \mathrm{Pt} / \mathrm{Au}$ & $\mathrm{ZnO}-\mathrm{ZIF}-8 \mathrm{NWs}$ & Thermal evaporation \& Solvothermal & $\mathrm{H}_{2}$ & 50 & 300 & 1.44 & - & [122] \\
\hline $\mathrm{Si} / \mathrm{SiO}_{2} / \mathrm{Ti} / \mathrm{Pt} / \mathrm{Au}$ & ZnO-SIM-1 NWs & Thermal evaporation \& Solvothermal & $\mathrm{H}_{2}$ & 50 & 300 & 2.5 & - & [123] \\
\hline $\mathrm{Au} / \mathrm{SiO}_{2} / \mathrm{Pt} / \mathrm{Si}_{3} \mathrm{~N}_{4} / \mathrm{Si}$ & Pd-ZnO NWs & Electrodeposition & $\mathrm{H}_{2}$ & 100 & RT & 13,100 & - & [104] \\
\hline FTO & $\mathrm{Ag}-\mathrm{ZnO} \mathrm{NWs}$ & Electrochemical deposition & $\mathrm{H}_{2}$ & 100 & RT & 50 & $22 / 11$ & [124] \\
\hline FTO & Cd-ZnO NWs & Electrochemical deposition & $\mathrm{H}_{2}$ & 100 & RT & $274 \%^{*}$ & $14 / 11$ & [125] \\
\hline $\mathrm{Al}_{2} \mathrm{O}_{3} / \mathrm{Au}$ & ZnO NWs & Thermal evaporation & $\mathrm{NO}_{2}$ & 100 & 250 & 6 & - & [126] \\
\hline $\mathrm{Si} / \mathrm{SiO}_{2} / \mathrm{C} \mathrm{NWs}$ & $\mathrm{ZnO}$ NWs & Hydrothermal & $\mathrm{NO}_{2}$ & 0.5 & 200 & 140 & - & [127] \\
\hline $\mathrm{SiO}_{2} / \mathrm{Si} / \mathrm{Ti} / \mathrm{Pt}$ & ZnO NWs & Carbothermal reduction & $\mathrm{NO}_{2}$ & 0.5 & 225 & 14 & $24 / 12$ & [129] \\
\hline $\mathrm{Si} / \mathrm{SiO}_{2} / \mathrm{Cr}-\mathrm{Pt} / \mathrm{Au}$ & $\mathrm{ZnO}$ NWs & Carbothermal reduction & $\mathrm{NO}_{2}$ & 1 & 300 & $51 \% *$ & $15 / 20$ & [130] \\
\hline $\mathrm{ZnO}: \mathrm{Ga} / \mathrm{SiO}_{2} / \mathrm{Si}$ & $\begin{array}{l}\mathrm{ZnGa}_{2} \mathrm{O}_{4} / \mathrm{ZnO} \\
\text { core-shell NWs }\end{array}$ & Reactive evaporation & $\mathrm{NO}_{2}$ & 10 & 250 & 10,24 & $90 / 120$ & [131] \\
\hline $\mathrm{Pt} / \mathrm{Au} / \mathrm{Al}_{2} \mathrm{O}_{3}$ & ZnO NWs & Hydrothermal & $\mathrm{NO}_{2}$ & 5 & 250 & 3.3 & $25 / 21$ & [132] \\
\hline $\mathrm{p}-\mathrm{Si} / \mathrm{SiO}_{2} / \mathrm{Au}$ & $\mathrm{ZnO}$ NWs & Thermal evaporation & $\mathrm{NO}_{2}$ & 10 & 300 & $2,37,263 \%^{*}$ & $570 / 180$ & [133] \\
\hline Si/graphene & $\begin{array}{l}\mathrm{ZnO} \\
\text { NWs/graphene }\end{array}$ & Thermal evaporation & $\mathrm{NO}_{2}$ & 10 & 200 & 27 & $200 / 330$ & [135] \\
\hline $\mathrm{Si} / \mathrm{SiO}_{2} / \mathrm{Ti} / \mathrm{Pt} / \mathrm{Au}$ & Pd-ZnO NWs & Thermal evaporation & $\mathrm{CO}$ & 0.1 & 20 & 1.02 & $210 /-$ & [136] \\
\hline Glass & ZnO NWs & Hydrothermal & $\mathrm{CO}$ & 200 & 250 & $93 \% *$ & $1 / 0.002$ & [137] \\
\hline $\mathrm{Al}_{2} \mathrm{O}_{3}$ & ZnO-ZIF-CoZn NWs & Solvothermal & Acetone & 100 & 260 & 27 & $43 / 60$ & [138] \\
\hline $\mathrm{ZnO}: \mathrm{Ga} / \mathrm{SiO}_{2} / \mathrm{Si}$ & Pt-ZnO NWs & Thermal evaporation + UV irradiation & $\mathrm{NH}_{3}$ & 1000 & 300 & $36 \% *$ & - & [139] \\
\hline $\mathrm{Al}_{2} \mathrm{O}_{3}$ & Co-ZnO NWs & Thermal evaporation & Xylene & 5 & 400 & 19 & - & [140] \\
\hline
\end{tabular}

* $\left(\mathrm{R}_{\mathrm{a}}-\mathrm{R}_{\mathrm{g}} / \mathrm{R}_{\mathrm{a}}\right) \times 100$.

electrode chips. These NWs displayed a fast response (90 s) and recovery (120 s) with good repeatability and linearity at ambient temperatures [131]. Chen et al. utilized hydrothermally grown vertically oriented $\mathrm{ZnO} \mathrm{NWs}$ for sensitive and selective detection of $\mathrm{NO}_{2}$ in the presence of different interfering gases [132]. The structure of nanomaterials influences the sensing properties. Therefore, Park et al. designed and compared typical (normal) ZnO NWs with nanograined networked ZnO NWs [133]. The normal ZnO NWs were synthesized on Au coated substrates, whereas the nanograined $\mathrm{ZnO}$ NWs were synthesized from ZnSe NWs. The fabricated nanograined ZnO NW based sensor showed a greatly enhanced response $(237,263 \%)$ to $10 \mathrm{ppm} \mathrm{NO}_{2}$ at $300{ }^{\circ} \mathrm{C}$ compared to the normal $\mathrm{ZnO}$ NWs (6.5\%). The improved sensitivity of the sensor was the result of the high surface area and high number of junctions from the crossed NWs.

Vertically oriented $\mathrm{ZnO} \mathrm{NWs}$ have been utilized to prepare heterojunction structures ( $n-n$ and $p-n)$ with other $p$ - and n-type metal oxides to enhance sensing performance. Park et al. designed $n-n$ $\mathrm{ZnO}-\mathrm{ZnO}$ and $\mathrm{p}-\mathrm{n} \mathrm{CuO}-\mathrm{ZnO} \mathrm{NW}$ junctions for $\mathrm{NO}_{2}$ sensing [134]. The air-bridge structures with heterojunctions showed higher sensitivity with the $n-n$ junction based nanostructured device than with the $p-n$ junctions. Recently, Khai et al. generated catalyst-free, vertically oriented, high-density ZnO NW arrays on graphene/Si substrates for sensor formation (Fig. 13a-d) [135]. These $\mathrm{ZnO}$ NW/graphene nanostructures exhibited a high sensitivity to $\mathrm{NO}_{2}$ at $200{ }^{\circ} \mathrm{C}$ with a long response/recovery time. The sensing performance of the $\mathrm{ZnO}$ NW/graphene based sensor was attributed to different factors, including oxygen vacancies in the lattice of ZnO NW arrays, large specific surface areas, and the formation of $\mathrm{p}-\mathrm{n}$ heterojunctions between the $\mathrm{ZnO}$ NW (n-type) and graphene (p-type) (Fig. 13e-f). Moreover, the graphene buffer layer played a crucial role in the vertical growth of ZnO NWs.

\subsubsection{Other gas sensors}

Recently, Choi et al. demonstrated the utility of a Pd nanodot functionalized ZnO NW based CO sensor [136]. The prepared sensor was highly sensitive to $\mathrm{CO}(0.1 \mathrm{ppm})$ at RT $\left(20^{\circ} \mathrm{C}\right)$ with a high response of 1.02 relative to other gases (i.e., benzene and $\mathrm{NO}_{2}$ ). Ghosh et al. reported an ultra-fast and reversible gas sensor based on ZnO NW arrays [137]. The sensor response was fast (1 s) with ultra-fast recovery time (2 ms) to $200 \mathrm{ppm} \mathrm{CO}$ when tested at an operating temperature of $250{ }^{\circ} \mathrm{C}$. Such sensors possess benefits for practical applications wherein real-time $\mathrm{CO}$ monitoring is needed. Yao et al. designed an acetone gas sensor using a core@shell structured ZnO NW-ZIF array [138]. Selectivity and sensitivity to acetone were improved as a result of the selectivity from the ZIF (sieve membrane). In this scheme, different sizes of ZnO NWs (50-100 nm) were grown on a ZnO seeded sapphire substrate, followed by coating with a hydrophobic and catalytic ZIF-CoZn (ZIFCoZn). The ZIF-CoZN was isostructural with ZIF-8 or ZIF-67, and thin films with different thicknesses (5-15 nm) were investigated (Fig. 14a-b). The results revealed that thin ( $5 \mathrm{~nm}$ ) ZnO- ZIF-CoZn NW arrays showed the highest response to $100 \mathrm{ppm}$ acetone at $260{ }^{\circ} \mathrm{C}$ (Fig. 14c-f).

Chang et al. demonstrated $\mathrm{NH}_{3}$ sensing based on Pt NPs deposited on ZnO NWs [139]. They obtained a response of $36 \%$ to $1000 \mathrm{ppm} \mathrm{NH}_{3}$ using a Pt-ZnO NW based gas sensor at $300{ }^{\circ} \mathrm{C}$. The performance of the sensor was attributed to the catalytic activity of the Pt NPs. Woo et al. prepared branched $\mathrm{ZnO}$ NWs doped with Co for highly sensitive and selective xylene detection [140]. As shown in Fig. 15a, the ZnO NWs were first grown on an $\mathrm{Al}_{2} \mathrm{O}_{3}$ substrate using a thermal 

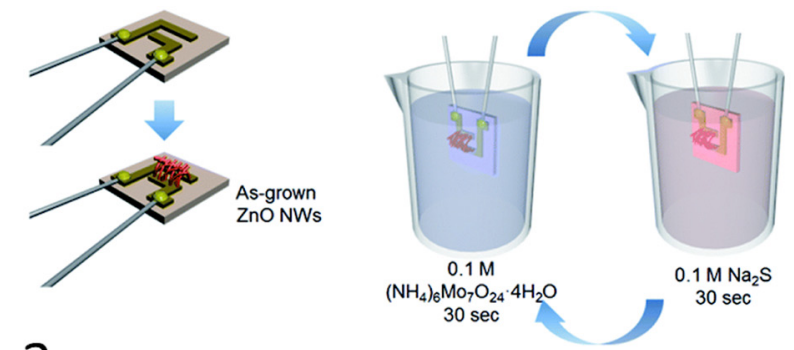

a
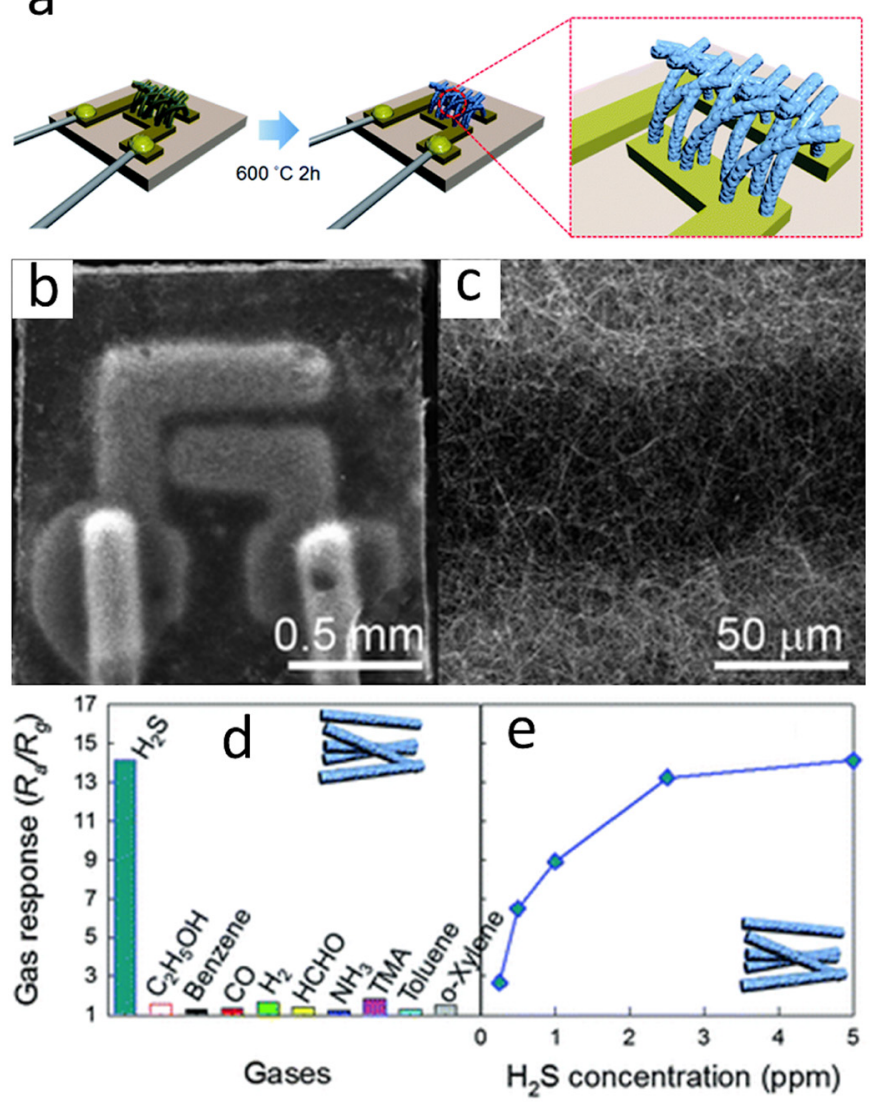

Fig. 11. (a) Schematic diagram of preparation method of Mo modified ZnO NWs grown on alumina substrate, (b-c) SEM images ZnO NW and Mo doped ZnO NWs network sensors, (d) selectivity test plot of Mo modified $\mathrm{ZnO}$ NWs at $300{ }^{\circ} \mathrm{C}$ in presence of different gases including $\mathrm{H}_{2} \mathrm{~S}$, and (e) response vs different concentrations of $\mathrm{H}_{2} \mathrm{~S}$ at $300{ }^{\circ} \mathrm{C}$. Reproduced from Ref. [107] with permission, Copyright 2014, Royal Society of Chemistry.

evaporation technique. The as-grown ZnO NWs were then transformed to $\mathrm{CoO}$ NWs by a cation exchange reaction after thermal evaporation of $\mathrm{CoCl}_{2}$ at $700{ }^{\circ} \mathrm{C}$. The final branched Co doped $\mathrm{ZnO}$ NWs were grown from the $\mathrm{CoO}$ NWs, with the Co centers acting as catalysts for this process. The prepared Co doped $\mathrm{ZnO}$ NW gas sensor showed a high response (19) and selectivity to $5 \mathrm{ppm}$ xylene at $400{ }^{\circ} \mathrm{C}$ with negligible cross responses (Fig. 15b-d).

\subsection{ZnO NR based gas sensors}

The gas sensing properties of a nanomaterial depend on its surface area and porosity relating to gas adsorption/diffusion, the sensing reaction, and the charge transfer phenomenon occurring at its surface [5,6]. Therefore, while designing a nanomaterial, the common goal is to obtain an optimum surface area. In contrast to ZnO NWs, ZnO NRs have the advantage of a low synthesis temperature while still maintaining excellent properties (i.e., high surface area, good charge carrier mobilities, and highly active surface sites for easy gas adsorption) [141]. However, the aspect ratios (width/length) of ZnO NWs are higher than those of ZnO NRs. Nevertheless, vertically oriented ZnO NRs have several advantages in gas sensing applications. In the following subsections, we discuss their gas sensing performance, which is also summarized in Table 3.

\subsection{1. $\mathrm{H}_{2} \mathrm{~S}$ sensors}

Significant effort has been focused on $\mathrm{ZnO}$ nanostructure based sensors for $\mathrm{H}_{2} \mathrm{~S}$. However, issues such as poor gas response/recovery, high working temperatures, and gas sensing stability still remain [142,143]. Hosseini et al. reported a RT operated $\mathrm{H}_{2} \mathrm{~S}$ sensor based on vertically oriented ZnO NRs with flower structures and a length of $1.9 \mu \mathrm{m}$ and a diameter of 300-500 nm [144]. The vapor phase transport (VPT) method was used to synthesize these NRs, which were grown along the c-axis in (0002) crystal planes perpendicular to the substrate. Interestingly, the vertically aligned ZnO NR based sensor displayed a higher response $\left(R_{S}=581\right)$ to $5 \mathrm{ppm} \mathrm{H}_{2} \mathrm{~S}$ at $26{ }^{\circ} \mathrm{C}$ than at $250{ }^{\circ} \mathrm{C}\left(\mathrm{R}_{\mathrm{s}}=3.7\right)$. The sensor showed a high selectivity to $\mathrm{H}_{2} \mathrm{~S}$ gas among many interfering gases, such as $\mathrm{CO}, \mathrm{CH}_{4}$, methanol, ethanol, acetone, and $\mathrm{H}_{2}$. However, the response and recovery times of this sensor were $320 \mathrm{~s}$ and $3592 \mathrm{~s}$, respectively for $1 \mathrm{ppm}$ of $\mathrm{H}_{2} \mathrm{~S}$, which are very long. On the other hand, the sensor showed good stability even after 5 months of storage in air. The high selectivity of this $\mathrm{ZnO}$ NR based $\mathrm{H}_{2} \mathrm{~S}$ sensor was attributed to the strong affinity of $\mathrm{ZnO}$ to $\mathrm{H}_{2} \mathrm{~S}$ even at RT compared to other gases, and the smaller bond dissociation energy of $\mathrm{H}-\mathrm{SH}(381 \mathrm{~kJ} / \mathrm{mol}) \mathrm{com}-$ pared to other interfering gases [85]. On the $\mathrm{ZnO}$ sensing surface, the $\mathrm{H}_{2} \mathrm{~S}$ gas molecules reacted not only with oxygen species $\left(\mathrm{O}_{2}^{-}\right)$but also with the $\mathrm{ZnO}$ sensor directly, and decomposed to form zinc sulfide ( $\mathrm{ZnS})$. The sensing reaction of $\mathrm{ZnO}$ to $\mathrm{H}_{2} \mathrm{~S}$ is explained by the following reactions $[4,144]$ :

$$
\begin{aligned}
& 2 \mathrm{H}_{2} \mathrm{~S}+\mathrm{O}_{2}^{-}(\text {ads }) \leftrightarrow 2 \mathrm{H}_{2} \mathrm{O}(\mathrm{g})+2 \mathrm{SO}_{2}+3 \mathrm{e}^{-} \\
& \mathrm{ZnO}(\mathrm{s})+\mathrm{H}_{2} \mathrm{~S}(\mathrm{~g}) \rightarrow \mathrm{ZnS}+\mathrm{H}_{2} \mathrm{O} \text { (sulfuration) } \\
& 2 \mathrm{ZnS}(\mathrm{s})+3 \mathrm{O}_{2}(\mathrm{~g}) \rightarrow 2 \mathrm{ZnO}+2 \mathrm{SO}_{2} \text { (desulfuration) }
\end{aligned}
$$

In addition, the enhanced response of the sensor was further explained by the porous network structures of flower-like nanostructures, oxygen vacancies, and potential barrier modulation on $\mathrm{ZnO}$ surfaces.

To further enhance the response, selectivity, and working temperature, Hosseini et al. reported ZnO NRs with flower-like bundles grown directly on $\mathrm{SiO}_{2} / \mathrm{Si}$ substrate without any catalyst layer using the VPT method. Later, a Au nanoparticle layer with a nominal thickness of $6 \mathrm{~nm}$ was deposited on the ZnO NR surface by a sputtering process, which showed a significantly enhanced response to $\mathrm{H}_{2} \mathrm{~S}$ when tested at RT (Fig. 16a) [145]. Au nanoparticles are often decorated on the sensor surface due to their chemical and electrical sensitization mechanism. The Au-ZnO NR sensor showed high selectivity to $6 \mathrm{ppm} \mathrm{H}_{2} \mathrm{~S}$ and an excellent response (1270) compared to the bare $\mathrm{ZnO}$ sensor (Fig. 16b-c). The stability and reproducibility of the AuZnO NR sensor were tested after 30 days, and showed $2.5 \%$ variation in response. Fig. 16d shows a schematic representation of the gas sensing mechanism of Au-ZnO NR based gas sensors. The high selectivity to $\mathrm{H}_{2} \mathrm{~S}$ as compared to other interfering gases can be attributed to the lower bond energy of $\mathrm{H}_{2} \mathrm{~S}$ than other tested gases, which can possibly be broken at RT [144]. Since Au nanoparticles have a strong chemical affinity to sulfur compounds, there must be a strong chemical interaction between $\mathrm{Au}$ and $\mathrm{H}_{2} \mathrm{~S}$. Furthermore, $\mathrm{ZnO}$ is decomposed with the spontaneous reaction of $\mathrm{H}_{2} \mathrm{~S}$ to form $\mathrm{ZnS}$, increasing the sensing response [146]. Here, Au nanoparticle sensitization not only introduces extra active sites but also provides a high surface area (Fig. 16d), which leads to more adsorbed oxygen species [144]. Due to the chemical sensitization effect of Au nanoparticles, oxygen molecules and $\mathrm{H}_{2} \mathrm{~S}$ molecules are easily dissociated followed by spill over on the $\mathrm{ZnO}$ surface for further sensing reaction. In addition, Schottky barriers at the interface of $\mathrm{Au}$ and $\mathrm{ZnO}$ NRs increase the width of 


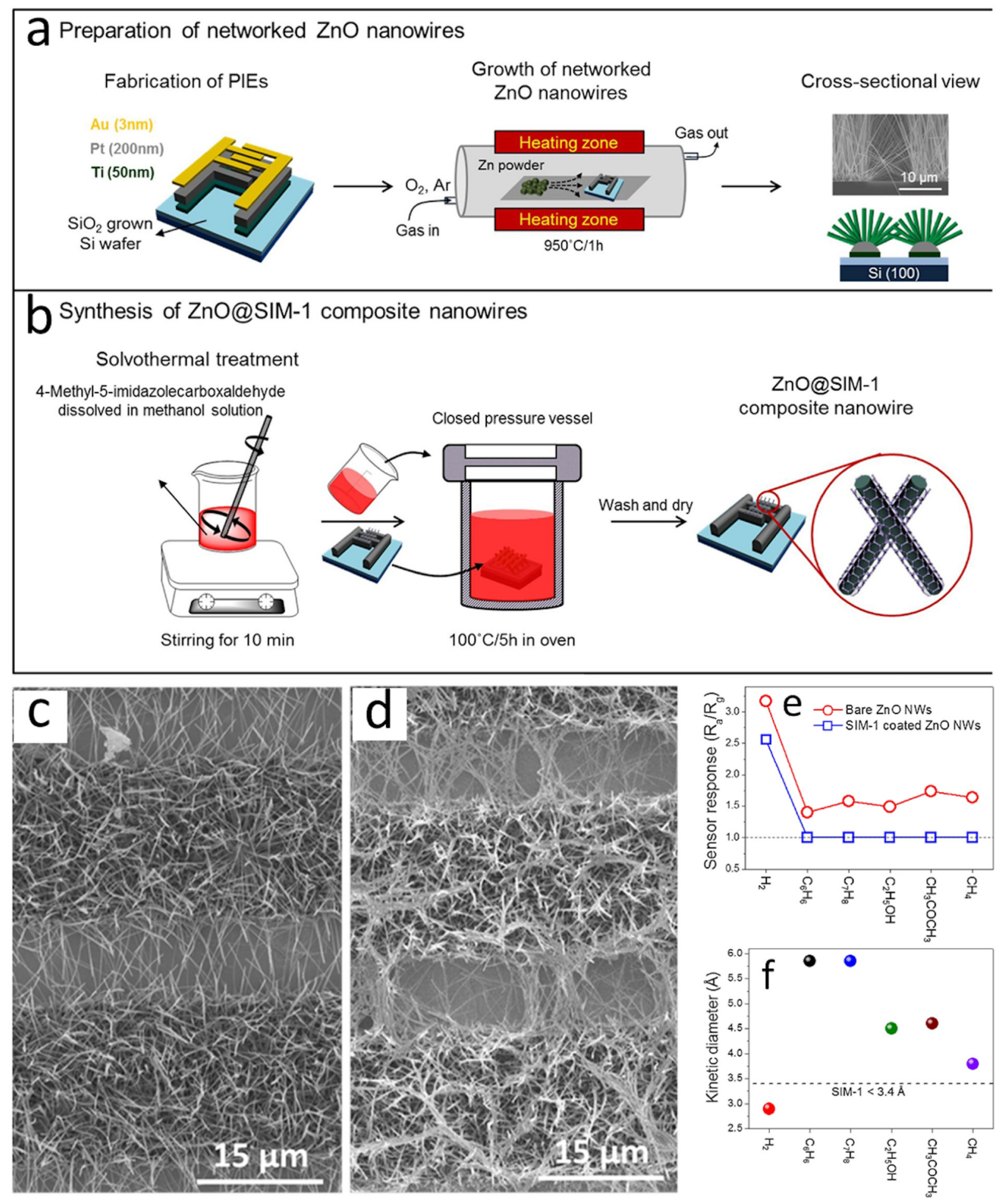

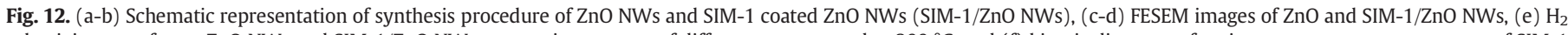

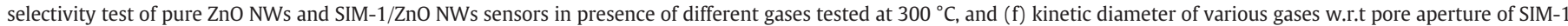
MOFs. Reproduced from Ref. [123] with permission, Copyright 2018, Elsevier.

the depletion layer and hence resistance. Thus, the enhanced responses of this sensor are attributed to nano-Schottky junctions at the $\mathrm{Au}$ and $\mathrm{ZnO}$ interfaces (electronic sensitization), spillover effects (chemical sensitization) from the catalytic activity of Au, more surface-active sites from oxygen vacancies, and the Au catalyst facilitating $\mathrm{H}_{2} \mathrm{~S}$ adsorption and surface reactions.

Qi et al. reported the growth of vertically oriented ZnO NRs on flat ceramic substrates for improved $\mathrm{H}_{2} \mathrm{~S}$ sensor fabrication [147]. They passivated $\mathrm{ZnO}$ NRs with an additional layer of $\mathrm{ZnS}$ to enhance sensor response and stability. The passivated $\mathrm{ZnO}-\mathrm{ZnS}$ core-shell structure

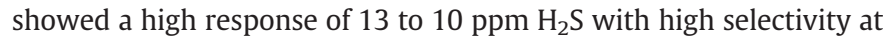
$\mathrm{RT}$. In another study, Qi et al. further improved the sensing performance in $\mathrm{ZnO}-\mathrm{SiO}_{2}$ NR structures [148]. The $\mathrm{ZnO}-\mathrm{SiO}_{2}$ NR based sensors displayed a high response of 116 and high selectivity to $10 \mathrm{ppm} \mathrm{H}_{2} \mathrm{~S}$ at $\mathrm{RT}$. The $\mathrm{SiO}_{2}$ layer on the $\mathrm{ZnO}$ NRs also improved the recovery time of the sensor, with the ability to detect at ppb levels of $\mathrm{H}_{2} \mathrm{~S}$. In summary, 
due to the combined effects of electronic and chemical sensitization, noble metal nanoparticles are a good choice to modify MOS surfaces to improve the sensing performance at RT in terms of sensitivity, selectivity, and response/recovery speed. In addition to the excellent role of noble metal additives, their homogeneous distributions with optimized sizes are important in the enhancement of sensor response.

\subsubsection{Ethanol sensors}

Efforts have been made to integrate gas sensors on flexible substrates to reduce fabrication cost and bring a new dimension to the metal oxide sensor market. Ahn et al. grew vertically oriented $\mathrm{ZnO}$
NRs on a flexible plastic substrate for ethanol vapor sensing [149]. They focused on polyimide (Kapton ${ }^{\mathrm{TM}}$ ) substrate and achieved a response of 3.11 to $100 \mathrm{ppm}$ ethanol with a long response/recovery ( $4 \mathrm{~min} / 5.3 \mathrm{~min}$ ) at an operating temperature of $300^{\circ} \mathrm{C}$. It is important to note that although this polymer is known for its high thermal stability, persistent heating to such a temperature will cause degradation. Furthermore, the vertically oriented $\mathrm{ZnO}$ NRs grown on polyimide substrates failed to achieve high sensing performance. Yi et al. took advantage of the fact that ZnO NWs and NRs can be readily grown on stainless-steel foils for gas sensing applications [150]. Specifically, they coated $\mathrm{ZnO} \mathrm{NRs}$ with graphene ( $\mathrm{ZnO} \mathrm{NR}$ graphene) to form
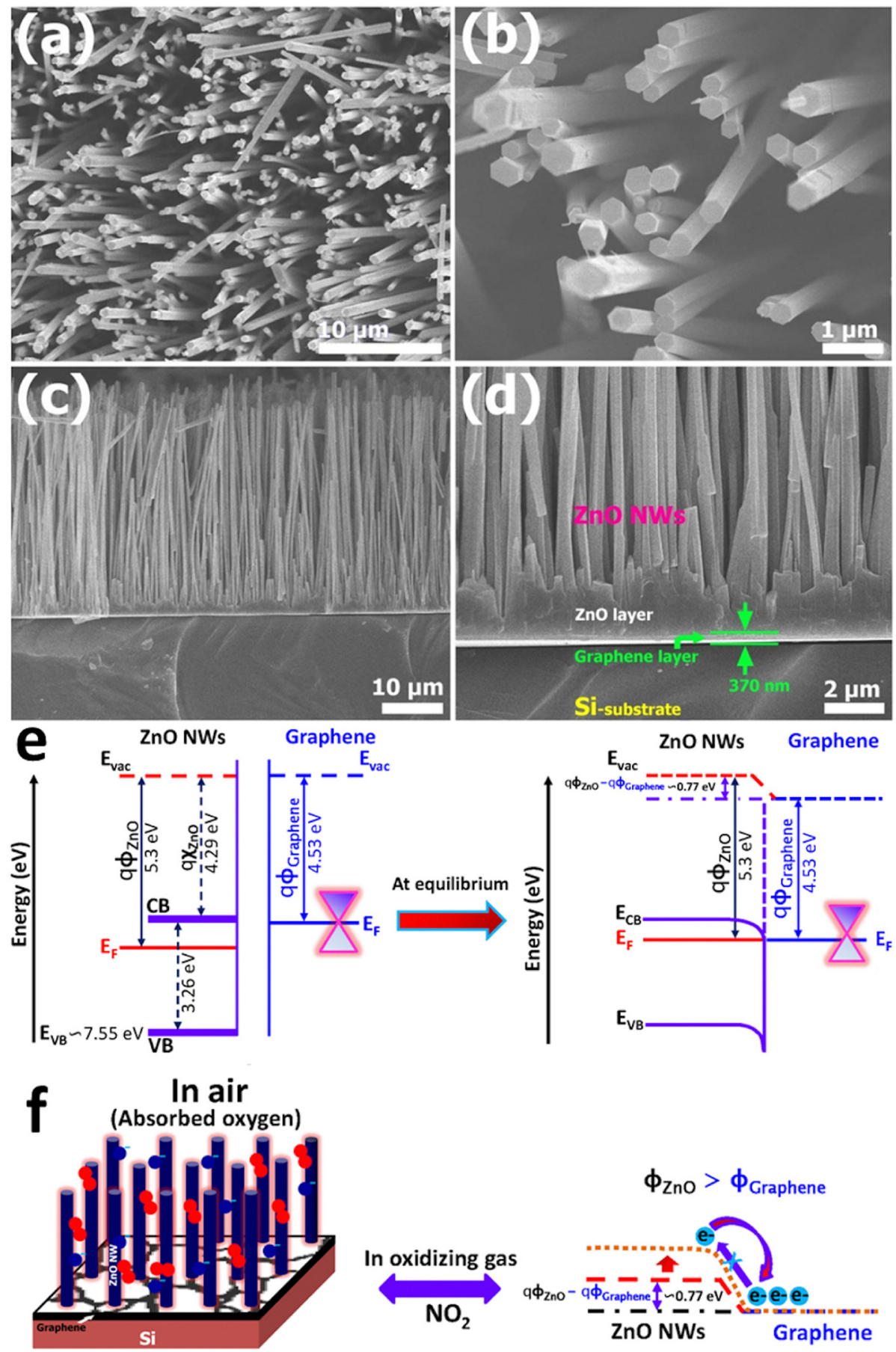

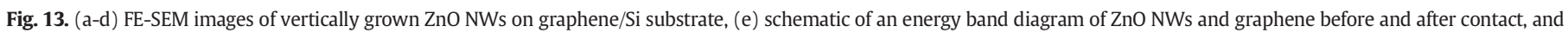
(f) gas sensing mechanism of ZnO NWs/graphene hetero-nanostructure sensor in air and $\mathrm{NO}_{2}$ gas. Reproduced from Ref. [135] with permission, Copyright 2018, Elsevier. 
hybrid structures, which improved ethanol sensitivity (90 for $50 \mathrm{ppm}$ ) at $300{ }^{\circ} \mathrm{C}$.

As mentioned earlier, MOFs have attracted attention in gas sensing as a result of their high surface area, tunable pore size, and molecular sieving properties. Zhou et al. reported a core-shell structure of ZnO@MOF NR arrays [151] using two ZIFs with different pore sizes (i.e., $~ 3.4 \AA$ for ZIF-8 and $\sim 4.8 \AA$ for ZIF-71). They analyzed the sensor performance as a function of the pore size of ZIFs and the size of gas molecules (Fig. 17). The ZnO-ZIF-71 based sensor showed a high response and selectivity to ethanol compared to interfering gases. The selectivity was attributed to the molecular size of ethanol $(4.53 \AA)$ and its match to the pore size of ZIF-71 (4.8 $\AA$ ). In the case of ZIF-8 ( 3.4 $\AA$ ), the sensor responses for ethanol, acetone, and benzene gases impeded. It can be concluded from the above discussion that by varying the pore size of ZIFs, the selectivity of gas sensors can be controlled.

\subsection{3. $\mathrm{H}_{2}$ sensors}

Simple, fast, and cost-effective fabrication processes to synthesize vertically oriented ZnO NR arrays on substrates are preferred. Lee et al. efficiently grew ZnO NR arrays on a Pt-electrode alumina substrate for $\mathrm{H}_{2}$ sensing [152]. The highest response of the ZnO NR gas sensor was found to be $24.8 \%$ for $500 \mathrm{ppm} \mathrm{H}_{2}$ at $250{ }^{\circ} \mathrm{C}$. Among different noble metals, Pd is commonly used to surface modify ZnO NRs for $\mathrm{H}_{2}$ sensing [153-155]. However, the Pd NPs' size and density of coverage greatly affects the gas sensing properties. Chang et al. proposed a $\mathrm{H}_{2}$ sensor based on Pd-ZnO NR arrays [153] with higher responses of 1106 to $500 \mathrm{ppm}$ $\mathrm{H}_{2}$ at $260{ }^{\circ} \mathrm{C}$. The sensing performance of this Pd-ZnO NR sensor was due to the oxygen spillover (chemical effects) and $\mathrm{Pd}^{2+} / \mathrm{PdO}$ redox properties (electronic effects). Similarly, Jiao et al. investigated $\mathrm{ZnO}$ NRs functionalized with Pd NPs prepared by a sputtering method [154]. The Pd was oxidized to form PdO-ZnO NRs at high calcination temperatures. Devices produced from thin Pd layers $(4 \mathrm{~nm})$ displayed
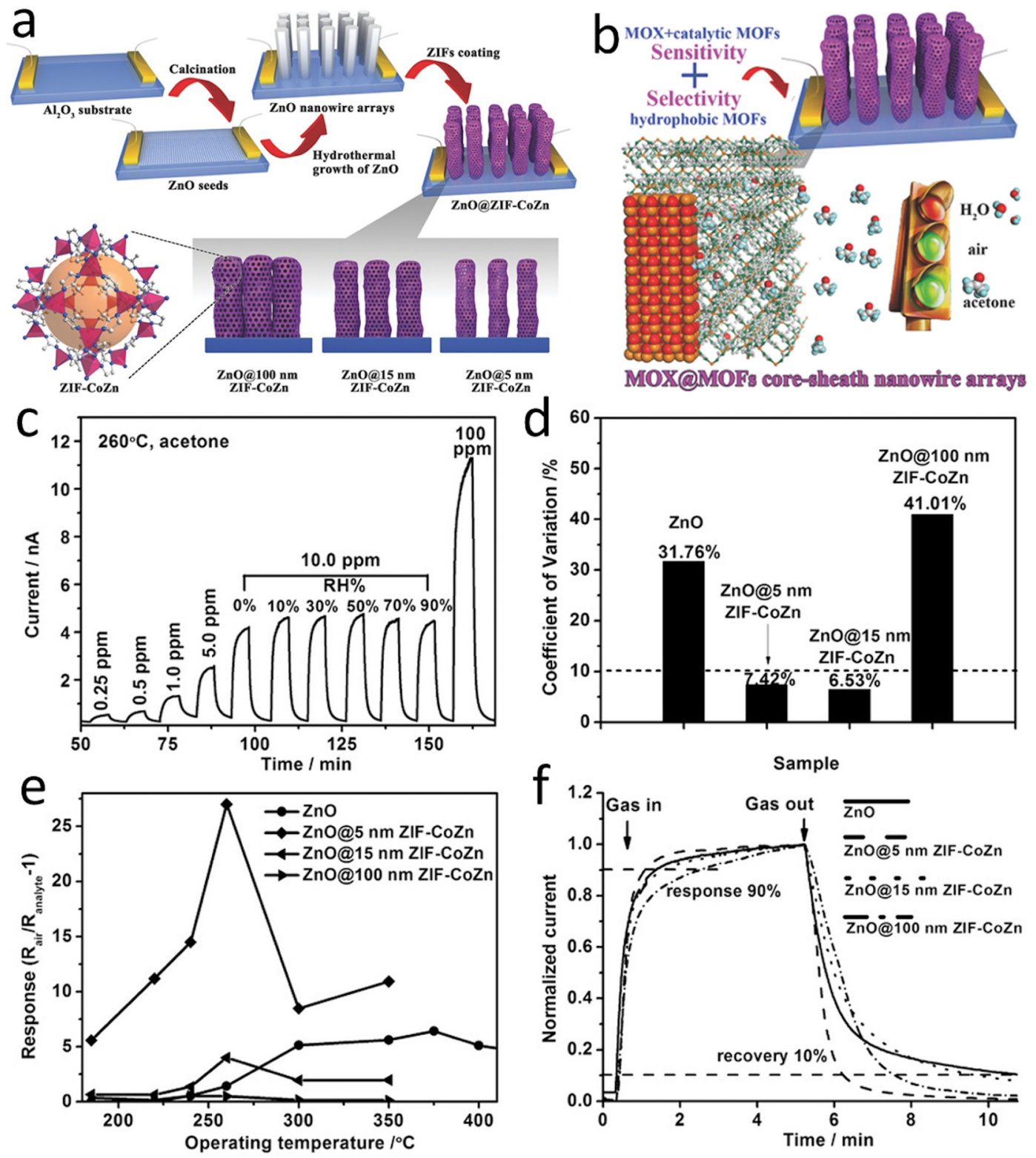

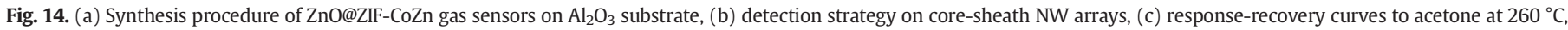

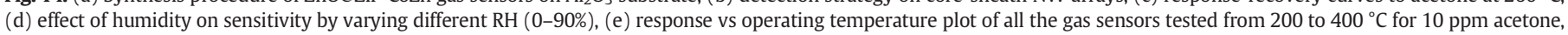
and (f) response-recovery curve of all the sensors for $100 \mathrm{ppm}$ acetone at $260{ }^{\circ} \mathrm{C}$. Reproduced from Ref. [138] with permission, Copyright 2016, MDPI AG, Basel, Switzerland. 

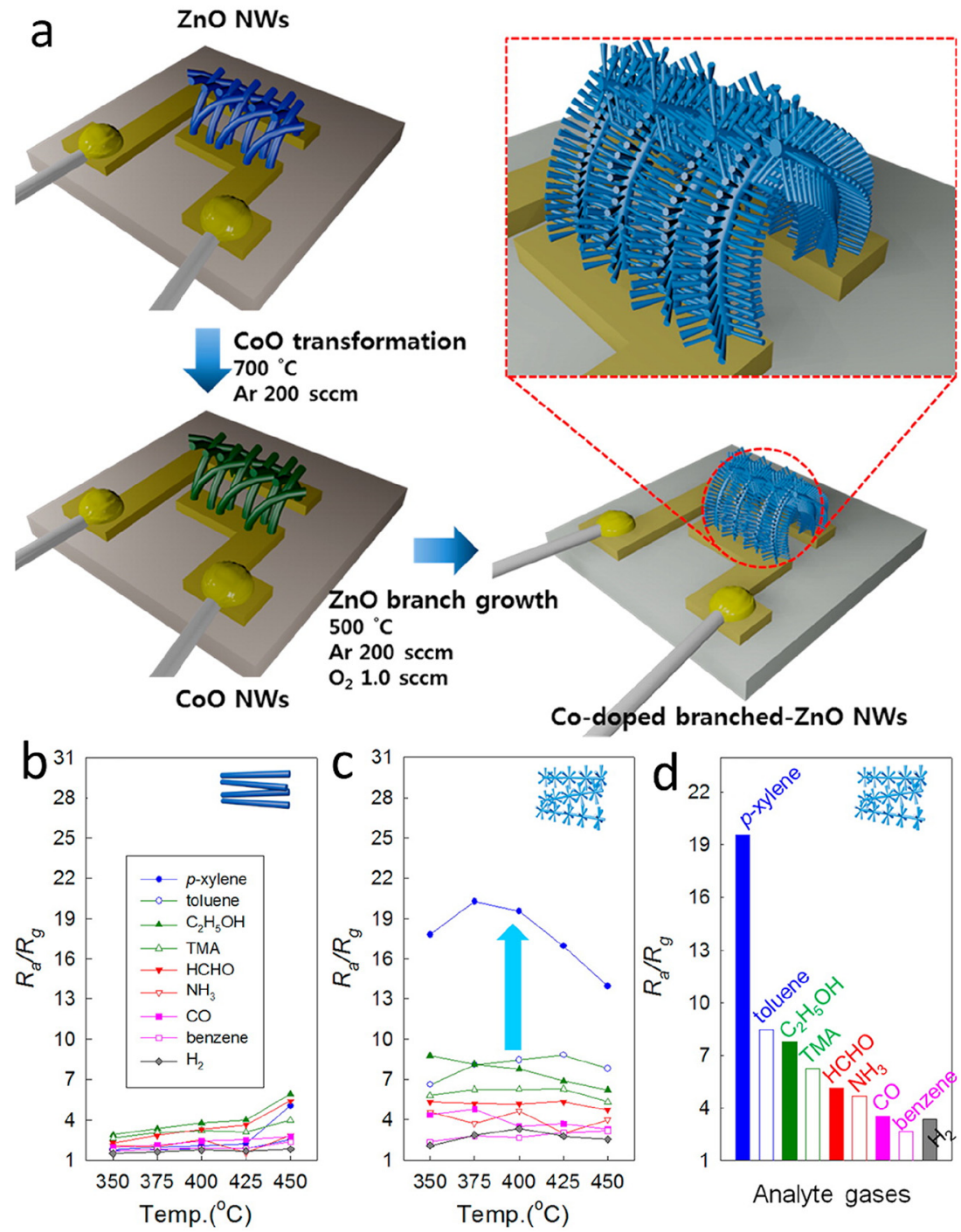

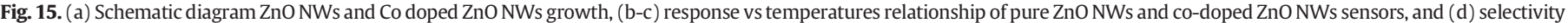
test of co-doped ZnO NWs for 5 ppm of different gases tested at $400{ }^{\circ} \mathrm{C}$. Reproduced from Ref. [140] with permission, Copyright 2014, American Chemical Society.

a high sensing response to $1000 \mathrm{ppm} \mathrm{H}_{2}$ at $350^{\circ} \mathrm{C}$. However, at higher temperatures and thicknesses of Pd layers, drastically changed sensor responses were observed.

Kim et al. proposed Pd functionalized $\mathrm{ZnO}$ NR based devices for $\mathrm{H}_{2}$ sensing [155]. They compared ZnO NRs' surface coated with amorphous Pd layers to those with crystalline Pd NPs. The sensing response of amorphous Pd/ZnO NR devices was remarkably high (12,400\% at $2 \%$ $\mathrm{H}_{2}$ ) when compared to those functionalized with crystalline Pd NPs. This performance was attributed to the complete covering of ZnO NRs with an amorphous Pd layer and the large interfaces between Pd and ZnO. In addition, the amorphous Pd layer coating prevented surface contamination over $\mathrm{ZnO}$ NRs, and these sensors maintained their initial sensing performance for $>5$ months.

$\mathrm{ZnO}$ crystals with nonpolar $\{100\}$ facets show the highest adsorption of $\mathrm{H}_{2}$. Vallejos et al. reported a highly sensitive $\mathrm{H}_{2}$ sensor based on aerosol-assisted vertically oriented ZnO NRs [156]. In this study, the grown ZnO NRs were highly crystalline with structures dominated by $\{100\}$ surface facets. The sensors were tested for several gases at various temperatures between $\mathrm{RT}$ and $350^{\circ} \mathrm{C}$. A high response was obtained to $100 \mathrm{ppm}_{2}$ at $350^{\circ} \mathrm{C}$ with a fast response time of $35 \mathrm{~s}$ and low cross sensitivity to other interfering gases, such as ethanol, $\mathrm{CO}$, acetone, $\mathrm{NO}_{2}$, and toluene. Rashid et al. demonstrated an RT-operable flexible $\mathrm{H}_{2}$ sensor based on the Pd-decorated ZnO NRs grown on a polyimide (PI) tape [157]. The results showed that the Pd NPs with $8 \mathrm{~nm}$ size displayed good responses (91\%) to $1000 \mathrm{ppm}_{2}$ at RT. Notably, the $\mathrm{H}_{2}$ sensing performance was unaffected even when the sensor was bent to a $90^{\circ}$ angle.

\subsection{4. $\mathrm{NO}_{2}$ sensors}

Nguyen et al. examined a $\mathrm{NO}_{2}$ sensor using vertically oriented $\mathrm{ZnO}$ NR based chips [158]. The sensor was highly selective with a sensitivity of 6 for $10 \mathrm{ppm} \mathrm{NO}_{2}$ at $450{ }^{\circ} \mathrm{C}$. However, this high operating temperature is not suitable for practical applications. Efforts have therefore been made to reduce the temperature and improve the sensing performance [159-163]. One approach includes designing $n-n$ and $p-n$ heterojunction nanostructures with two metal oxides. For instance, Sun et al. designed an n-n heterojunction nanostructure between $\mathrm{CaO}$ and $\mathrm{ZnO}$ NRs for $\mathrm{NO}_{2}$ sensing [159]. The enhanced performance indicated a synergetic benefit from combining these materials. In another study, Oh et al. reported high-performance $\mathrm{NO}_{2}$ gas sensors based on ZnO NRs grown using an ultrasonic irradiation method [160]. The sensor was highly sensitive to $10 \mathrm{ppb} \mathrm{NO} \mathrm{N}_{2}$ at $250{ }^{\circ} \mathrm{C}$ with fast response/recovery time.

Zou et al. demonstrated $\mathrm{ZnO} \mathrm{NR} / \mathrm{TiO}_{2} \mathrm{NP}$ heterostructures for enhanced $\mathrm{NO}_{2}$ sensing [161]. The optimal working temperature of the 
Table 3

Comparisons of gas sensing properties of vertically oriented $\mathrm{ZnO}$ NR based gas sensor.

\begin{tabular}{|c|c|c|c|c|c|c|c|c|}
\hline Electrodes/Substrates & Materials & $\begin{array}{l}\text { Synthesis } \\
\text { method }\end{array}$ & Target gas & $\begin{array}{l}\text { Concentration } \\
(\mathrm{ppm})\end{array}$ & $\begin{array}{l}\text { Temp. } \\
\left({ }^{\circ} \mathrm{C}\right)\end{array}$ & $\begin{array}{l}\text { Sensitivity }(S)\left[R_{a} / R_{g} \text { or }\right. \\
\left.*\left(R_{a}-R_{g} / R_{a}\right) \times 100\right]\end{array}$ & $\begin{array}{l}\text { Response (s)/Recovery } \\
\text { time (s) }\end{array}$ & Ref. \\
\hline $\mathrm{SiO}_{2} / \mathrm{Si}$ & ZnO NRs & Vapor phase & $\mathrm{H}_{2} \mathrm{~S}$ & 5 & 25 & 581 & - & [143] \\
\hline $\mathrm{SiO}_{2} / \mathrm{Si}$ & Au-ZnO NRs & Vapor phase & $\mathrm{H}_{2} \mathrm{~S}$ & 3 & 25 & 375 & - & [145] \\
\hline Flat ceramic & ZnO NRs-ZnS & Hydrothermal & $\mathrm{H}_{2} \mathrm{~S}$ & 10 & RT & 13 & - & [147] \\
\hline Flat ceramic & $\mathrm{ZnO}$ NRs-SiO ${ }_{2}$ & Hydrothermal & $\mathrm{H}_{2} \mathrm{~S}$ & 10 & RT & 116 & - & [148] \\
\hline $\begin{array}{l}\text { Interdigital flexible } \\
\text { plastic }\end{array}$ & ZnO NRs & Hydrothermal & Ethanol & 100 & 300 & 3.11 & $240 / 318$ & [149] \\
\hline Stainless steel foils & $\begin{array}{l}\text { ZnO } \\
\text { NRs-graphene/metal }\end{array}$ & Hydrothermal & Ethanol & 50 & 300 & 90 & - & [150] \\
\hline $\begin{array}{l}\text { Interdigital alumina } \\
\text { plate }\end{array}$ & ZnO-ZIF-71 NRs & Hydrothermal & Ethanol & 50 & 250 & $325 \% *$ & - & [151] \\
\hline $\mathrm{Al}_{2} \mathrm{O}_{3} / \mathrm{Pt}$ ceramic & ZnO NRs & Sonochemical & $\mathrm{H}_{2}$ & 500 & 250 & $24.8 \%^{*}$ & $147 / 379$ & [152] \\
\hline $\mathrm{Si} / \mathrm{SiO}_{2} / \mathrm{Pt} / \mathrm{Cr}$ & Pd-ZnO NRs & Hydrothermal & $\mathrm{H}_{2}$ & 500 & 120 & 60.7 & $14 /-$ & [153] \\
\hline Glass & Pd-ZnO NRs & Hydrothermal & $\mathrm{H}_{2}$ & 500 & 350 & 3.6 & - & [154] \\
\hline $\mathrm{SiO}_{2} / \mathrm{Si}$ & $\begin{array}{l}\text { Amorphous } \mathrm{Pd}-\mathrm{ZnO} \\
\text { NRs }\end{array}$ & Hydrothermal & $\mathrm{H}_{2}$ & 20,000 & RT & $12,400 \% *$ & $227 / 95$ & [155] \\
\hline $\begin{array}{l}\mathrm{Si} / \mathrm{PI} / \text { flexible } \\
\text { polyester }\end{array}$ & $\mathrm{Pd} / \mathrm{ZnO}$ NRs & Hydrothermal & $\mathrm{H}_{2}$ & 1000 & RT & $91 \%^{*}$ & - & [157] \\
\hline Glass/Pt/Cr & $\mathrm{ZnO}$ NRs & Hydrothermal & $\mathrm{NO}_{2}$ & 10 & 450 & 6 & - & [158] \\
\hline $\mathrm{Si} / \mathrm{Au}$ & n-CaO-ZnO NRs & $\begin{array}{l}\text { Thermal } \\
\text { evaporation }\end{array}$ & $\mathrm{NO}_{2}$ & 200 & 300 & 141.66 & - & [159] \\
\hline $\mathrm{Al}_{2} \mathrm{O}_{3} / \mathrm{Pt}$ & ZnO NRs & $\begin{array}{l}\text { Ultra-sonic } \\
\text { irradiation }\end{array}$ & $\mathrm{NO}_{2}$ & 0.01 & 250 & $37 \% *$ & $270 / 240$ & [160] \\
\hline Glass & $\mathrm{ZnO} \mathrm{NRs} / \mathrm{TiO}_{2} \mathrm{NPs}$ & Hydrothermal & $\mathrm{NO}_{2}$ & 50 & 180 & 350 & - & [161] \\
\hline Glass/Pt & ZnO NRs & Hydrothermal & $\mathrm{NO}_{2}$ & 5 & 100 & 333 & - & [162] \\
\hline Glass & ZnO NRs & Hydrothermal & $\mathrm{NO}_{2}$ & 100 & 150 & 113.32 & - & [163] \\
\hline $\mathrm{Si} / \mathrm{Si}$ & $\begin{array}{l}\text { ZnO NRs/porous Si } \\
\text { NWs }\end{array}$ & Hydrothermal & $\mathrm{NO}_{2}$ & 50 & RT & 35 & - & [164] \\
\hline Glass & ZnO NRs & Hydrothermal & LPG & 500 & 350 & $60 \% *$ & $100 / 70$ & [165] \\
\hline Glass & Pd-ZnO NRs & Hydrothermal & LPG & 2600 & 225 & $60 \% *$ & $80 / 60$ & [166] \\
\hline $\mathrm{Al}_{2} \mathrm{O}_{3} / \mathrm{Au}$ & $\mathrm{Au}-\mathrm{ZnO} \mathrm{NRs}$ & Hydrothermal & $\begin{array}{l}\text { Triethylamine } \\
\text { (TEA) }\end{array}$ & 50 & 40 & 4 & $1.3 / 85$ & [167] \\
\hline $\mathrm{Al}_{2} \mathrm{O}_{3} / \mathrm{Au}$ & $\begin{array}{l}\mathrm{Au}-\mathrm{ZnO} / \mathrm{SnO}_{2} \\
\text { core-shell NRs }\end{array}$ & Hydrothermal & TEA & 50 & 40 & 12.4 & $1.2 / 75$ & [168] \\
\hline
\end{tabular}

* $\left(\mathrm{R}_{\mathrm{a}}-\mathrm{R}_{\mathrm{g}} / \mathrm{R}_{\mathrm{a}}\right) \times 100$
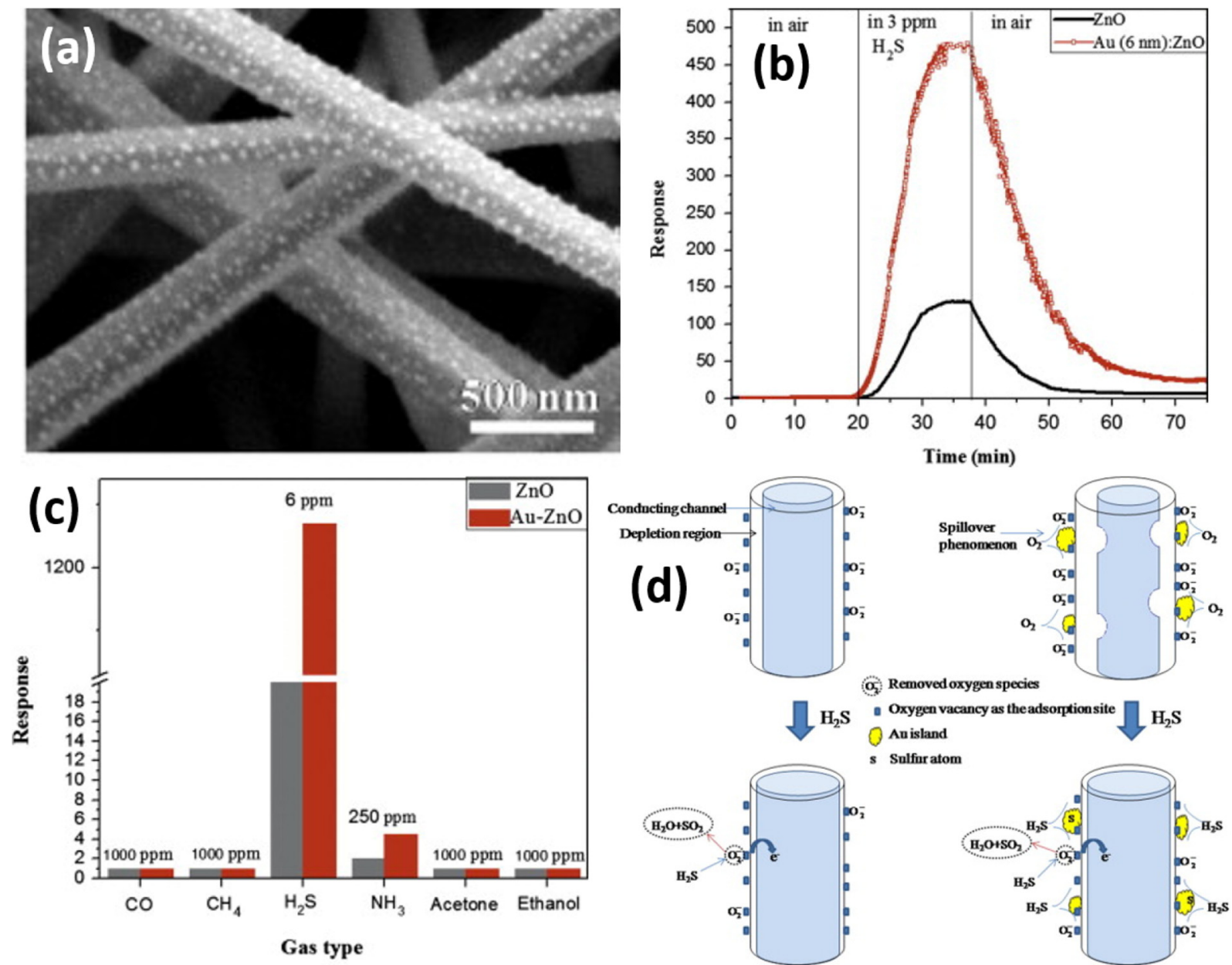

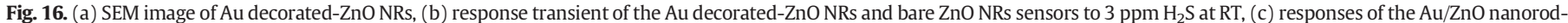
based sensor and pure ZnO nanorod-based sensor to different gases. Reproduced from the Ref. [145] with permission, Copyright 2015, Elsevier. 


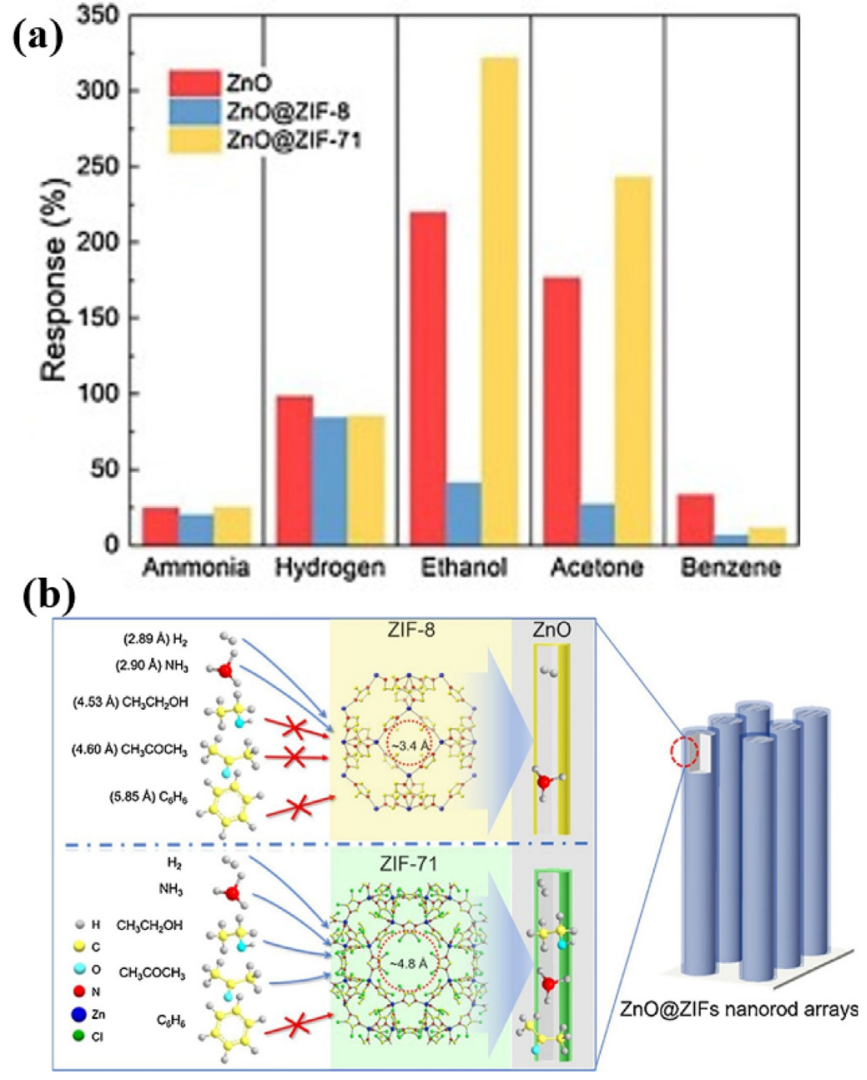

Fig. 17. (a) The mechanism of using the difference between the pore sizes of ZIF-8 and ZIF71 and the gas molecular sizes to select gases passing the ZIFs membrane of ZnO@ZIF NRAs, (b) Gas sensing response of ZnO NRAs, ZnO@ZIF-8 NRAs and ZnO@ZIF-71 NRAs sensors to $50 \mathrm{ppm}$ of different gases at $250{ }^{\circ} \mathrm{C}$. Reproduced from the Ref. [151] with permission, copyright @2018, Elsevier publisher.

$\mathrm{ZnO} \mathrm{NR/TiO}$, sensor was $180{ }^{\circ} \mathrm{C}$, whereas the highest response value of 350 was obtained at $10 \%$ concentrations of $\mathrm{TiO}_{2}$. The active sites were assumed to be created by the attachment of $\mathrm{TiO}_{2}$ NPs onto ZnO NRs. Chang et al. grew $\mathrm{ZnO}$ NRs on an inkjet-printed seed layer for $\mathrm{NO}_{2}$ sensing [162]. Longer ZnO NRs showed a higher response of $355 \%$ to $5 \mathrm{ppm}$ $\mathrm{NO}_{2}$ at $100{ }^{\circ} \mathrm{C}$. Using a similar approach, a low temperature based $\mathrm{NO}_{2}$ sensor was proposed by Jagadale et al. [163]. To further reduce the working temperature, Liao et al. recently reported $\mathrm{ZnO} \mathrm{NR} /$ porous silicon NW (ZnO/p-Si NWs) hybrid nanostructures for highly sensitive $\mathrm{NO}_{2}$ sensing at RT [164].

\subsubsection{Other gas sensors}

Guray et al. examined the liquid petroleum gas (LPG) sensing performance of different aspect ratio ZnO NRs that were vertically oriented [165]. Raising the aspect ratio to $40\left(\mathrm{ZnO}_{40}\right)$ increased the surface area, the number of electron donors related to oxygen vacancies, and the sensory responses. Furthermore, a high response to 2000 ppm LPG with $\mathrm{ZnO}_{40} \mathrm{NRs}$ was measured at $350{ }^{\circ} \mathrm{C}$. To reduce the operating temperature and enhance the sensing performance, Lokhande et al. prepared LPG sensors based on Pd-sensitized ZnO NRs grown on glass substrates [166]. These Pd-ZnO NRs showed a 60\% improved sensing performance for $2600 \mathrm{ppm}$ LPG compared to bare ZnO NRs at $\sim 225^{\circ} \mathrm{C}$. In another study, Ju et al. proposed a trimethylamine (TEA) sensor based on Au-ZnO NRs coated with $\mathrm{SnO}_{2}$ to form a Au-ZnO-SnO 2 coreshell NR structure [167]. The ZnO NRs were grown vertically on an $\mathrm{Al}_{2} \mathrm{O}_{3}$ substrate using a seed mediated hydrothermal method followed by $\mathrm{SnO}_{2}$ shell deposition by pulsed laser deposition (PLD); then, Au NPs were deposited by a DC sputtering process (Fig. 18a-c). The Au$\mathrm{ZnO}-\mathrm{SnO}_{2}$ NR based gas sensor displayed a high (12.4) and fast (1.2 s) response to $50 \mathrm{ppm}$ TEA at a low temperature $\left(40{ }^{\circ} \mathrm{C}\right.$ ) (Fig. $\left.18 \mathrm{~d}-\mathrm{e}\right)$.
The enhanced sensing performance to TEA was attributed to the depletion layer formation (Schottky contacts) at the $\mathrm{Au} / \mathrm{SnO}_{2}$ interface and n$\mathrm{n} \mathrm{SnO} / 2 / \mathrm{ZnO}$ heterojunction. Chung et al. reported a flexible acetylene sensor based on Ag-ZnO NRs grown on a flexible substrate [168]. The sensor showed a high response of 27.2 with fast response and recovery (62 s and $39 \mathrm{~s}$ ) to $1000 \mathrm{ppm}$ acetylene measured at $200{ }^{\circ} \mathrm{C}$ with a negligible drop in performance at a $90^{\circ}$ bending angle. All in all, the large effective surface area, the ordered arrays of ZnO NRs, and small grain size are suggested to enhance sensing performance. Furthermore, the high catalytic activity of Ag to selectively absorb and activate acetylene contributes heavily to the improved selectivity.

\subsubsection{Other vertically oriented $\mathrm{ZnO}$ nanomaterial based gas sensors}

Many other novel vertically oriented $\mathrm{ZnO}$ nanomaterials have been explored as potential candidates in gas sensing applications, such as nanotubes (NTs), nanoneedles (NNs), and nanosheets (NSs) (Table 4). Among these nanostructures, NTs offer several advantages, including charge carrier transport and their length, low grain size, and high surface area from a combination of inner and outer surfaces of their tubular morphology $[169,170]$. Acharyya et al. synthesized hexagonal vertically oriented ZnO NTs for ethanol gas sensing at RT [169]. The ZnO hexagonal NT arrays were grown on a fluorine doped tin oxide (FTO) glass substrate with a combination of electro deposition and selective electrochemical etching methods (Fig. 19a-b). These ZnO NT based gas sensors showed the highest response to ethanol among other gases investigated. A 65\% response to $700 \mathrm{ppm}$ ethanol at RT was obtained for ZnO NTs. The enhanced gas sensing performance for ethanol was explained by the formation of the depletion layer and the modulation of barriers (Fig. 19c-d). In another study, Maithy et al. examined the effect of $\mathrm{ZnO}$ NT surface modification with Pd and reduced graphene oxide (rGO) on gas sensing performance [170]. The results revealed that Pd modified ZnO NT based gas sensors had a high response $(55.7 \%$ for $100 \mathrm{ppm}$ ) to methanol, whereas the r-GO-ZnO NTs offered high sensitivity to ethanol (67\% for $100 \mathrm{ppm}$ ) at RT. Recently, Gonzalez-Chavarri et al. reported a $\mathrm{ZnO}$ NN based $\mathrm{NO}_{2}$ sensor [171]. This gas sensor showed a high response of 6 and the highest selectivity to $5 \mathrm{ppm} \mathrm{NO}_{2}$ with little interference from benzene and formaldehyde at $195^{\circ} \mathrm{C}$. The same authors also investigated the influence of humidity and found that even at $80 \%$ relative humidity (RH), the response of the sensor to $0.5 \mathrm{ppm}$ $\mathrm{NO}_{2}$ was around $350 \%$, which was much higher than for the other two gases.

When compared to the other vertically oriented $\mathrm{ZnO}$ nanomaterials, vertically oriented ZnO NSs offer the interesting features of superior charge carrier transport, high aspect ratios, and controllable thickness, which combine to facilitate high sensing performance $[171,172]$. Ju et al. demonstrated the direct growth of ZnO NSs for ethanol sensing [172]. They grew three types of ZnO NSs with varying hydrothermal reaction times for ethanol sensing experiments (Fig. 20a-c). The sensor responses to $100 \mathrm{ppm}$ ethanol were evaluated at different operating temperatures $\left(200-450{ }^{\circ} \mathrm{C}\right)$, and the highest response of 38.4 was obtained for $\mathrm{ZnO} \mathrm{NSs}-8 \mathrm{~h}$ at an optimum operating temperature of $400{ }^{\circ} \mathrm{C}$ (Fig. 20d-e). The gas sensor based on ZnO NSs-8 h showed a higher response than those based on the others analytes (Fig. 20f). The enhanced ethanol response compared favorably to the other interfering gases evaluated and was attributed to the faster absorption of smaller ethanol molecules on ZnO NSs' surface and the high electron donating effect of this gas (Fig. 20g). Recently, Cao et al. proposed an ethanol sensor based on Al doped ZnO NSs and investigated the effect of metal diffusion on gas sensing [173]. The ZnO NS based sensors displayed a higher response to $100 \mathrm{ppm}$ ethanol vapor than the $\mathrm{ZnO} \mathrm{NR}$ based sensors at an optimum operating temperature of $370{ }^{\circ} \mathrm{C}$ with fast response/recovery times of 1.6/1.8 s. Furthermore, the ZnO NS based sensors showed high selectivity to ethanol gas at $370{ }^{\circ} \mathrm{C}$. The stability of these sensors was investigated over one month and it was found 
(a)

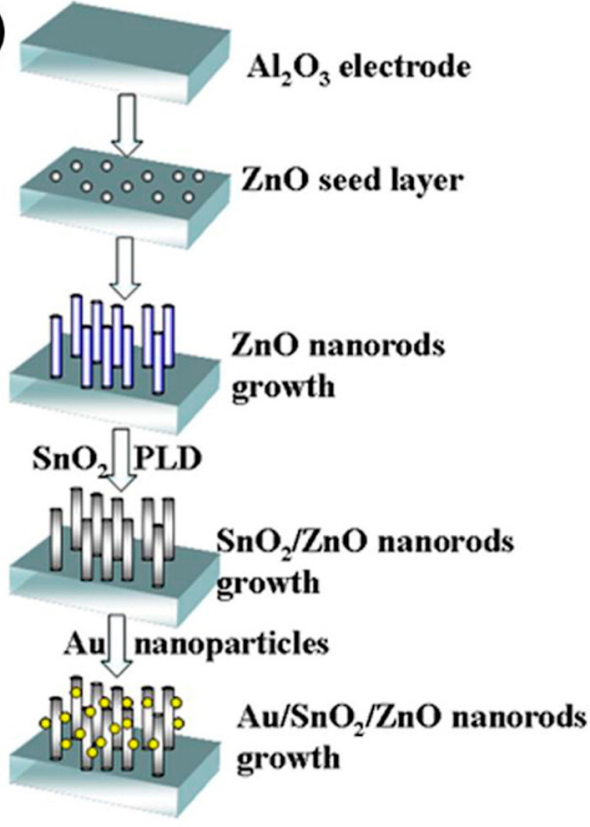

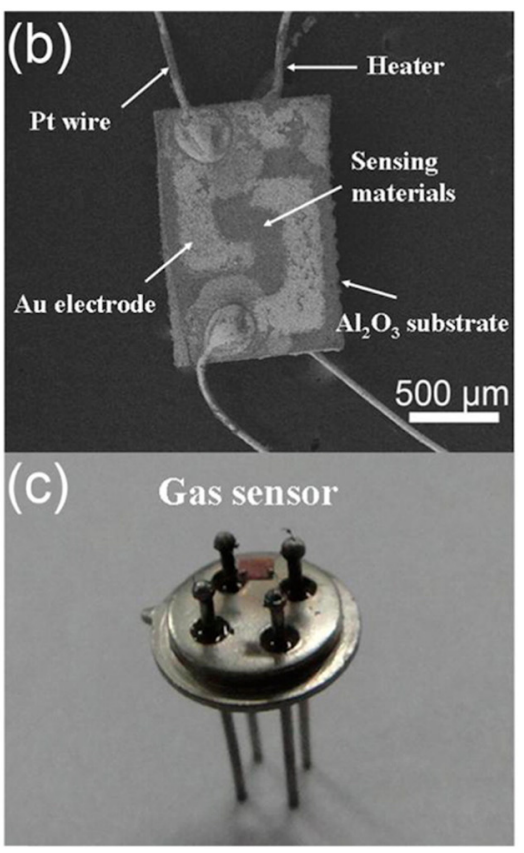
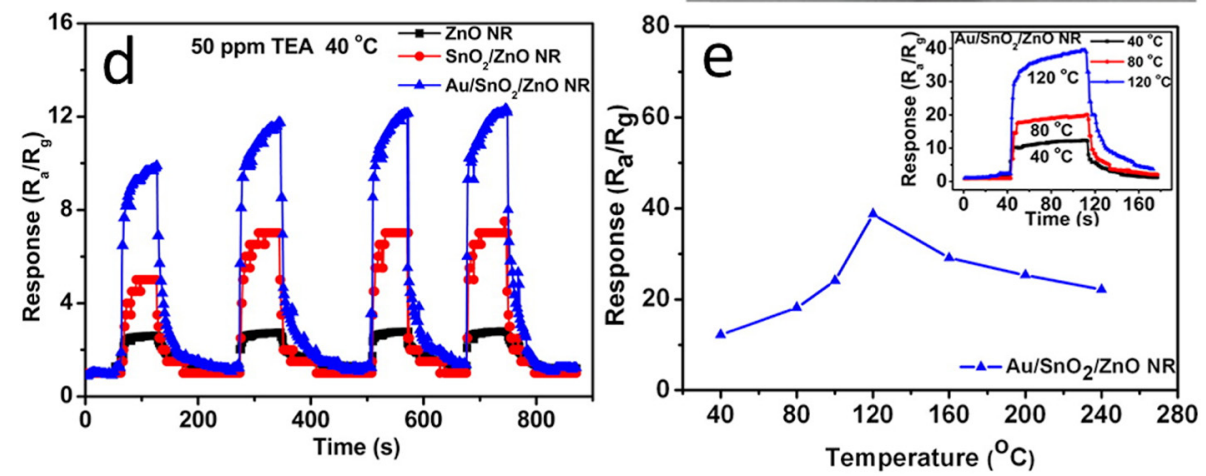

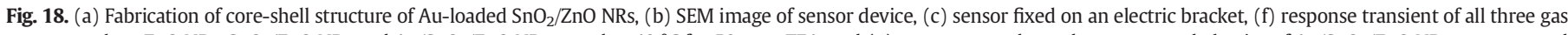

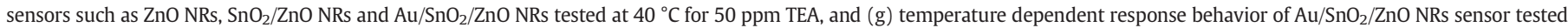
from 40 to $280^{\circ} \mathrm{C}$. Reproduced from Ref. [167] with permission, Copyright 2015, American Chemical Society.

that their response was nearly constant. The excellent ethanol sensing performance of $\mathrm{ZnO}$ NSs was explained by their smaller thickness resulting in a wider depletion layer, high charge transfer from the inner to the outer surface and vice versa, a greater number of electron-generating sites caused by $\mathrm{Al}$ doping, an increased number of oxygen defects, and a greater barrier modulation. Compared to the conventional two-step process of sensor fabrication, direct growth of vertically oriented ZnO NSs on substrates has great potential in gas sensing. The gas sensing properties of these nanostructures have not been explored in detail, and this should be considered an emerging approach. Zhao et al. [174] prepared ZnO nanodisk (ND) based gas sensors directly on Au combshaped $\mathrm{SiO}_{2} / \mathrm{Si}$ substrate using a thermal evaporation method from a mixture of $\mathrm{ZnCl}_{2}$ and $\mathrm{InCl}_{3}$ at $450{ }^{\circ} \mathrm{C}$. For comparison, another sensing material, $\mathrm{ZnO}$ nanorod arrays, was deposited on the substrate by annealing $\mathrm{ZnCl}_{2}$ at $450{ }^{\circ} \mathrm{C}$. The electron microscopy results showed that $\mathrm{ZnO} \mathrm{NDs}$ and $\mathrm{ZnO}$ NRs were exposed mainly in polar (0001) and nonpolar $\{010\}$ planes, respectively.

Table 4

Comparisons of gas sensing properties of other vertically oriented $\mathrm{ZnO}$ nanomaterial-based gas sensor.

\begin{tabular}{|c|c|c|c|c|c|c|c|c|}
\hline Electrodes/Substrates & Materials & $\begin{array}{l}\text { Synthesis } \\
\text { method }\end{array}$ & Target gas & $\begin{array}{l}\text { Concentration } \\
(\mathrm{ppm})\end{array}$ & $\begin{array}{l}\text { Temp. } \\
\left({ }^{\circ} \mathrm{C}\right)\end{array}$ & $\begin{array}{l}\text { Sensitivity }(S)\left[R_{a} / R_{g} \text { or }\right. \\
\left.*\left(R_{a}-R_{g} / R_{a}\right) \times 100\right]\end{array}$ & $\begin{array}{l}\text { Response } \\
\text { (s)/Recovery } \\
\text { time (s) }\end{array}$ & Ref. \\
\hline FTO & ZnO NTs & Electrodeposition & Ethanol & 700 & 27 & $65 \%$ & $271.8 / 91.8$ & [169] \\
\hline FTO & ZnO NTs/Pd & Electrodeposition & Ethanol & 100 & 27 & $48.17 \% *$ & $43.4 / 111.5$ & [170] \\
\hline FTO & $\begin{array}{l}\mathrm{ZnO} \\
\mathrm{NTs} / \mathrm{rGO}\end{array}$ & Electrodeposition & Ethanol & 100 & 27 & $67.01 \% *$ & $41.1 / 98.3$ & [170] \\
\hline $\mathrm{Al}_{2} \mathrm{O}_{3} / \mathrm{Pt}$ interdigital & ZnO NNs & Hydrothermal & $\mathrm{NO}_{2}$ & 5 & 195 & 6 & - & [171] \\
\hline $\mathrm{Al}_{2} \mathrm{O}_{3} / \mathrm{Au} / \mathrm{Pt}$ & ZnO NSs & Hydrothermal & Ethanol & 100 & 400 & 40 & $8 / 17$ & [172] \\
\hline $\mathrm{Al} / \mathrm{Al}_{2} \mathrm{O}_{3} / \mathrm{Pt}$ & $\mathrm{Al}-\mathrm{ZnO} \mathrm{NSs}$ & Hydrothermal & Ethanol & 100 & 370 & 90.2 & $1.6 / 1.8$ & [173] \\
\hline $\mathrm{SiO}_{2} / \mathrm{Si}$ & ZnO NDs & Thermal evaporation & Trimethylamine & 200 & 300 & 60 & NA & [174] \\
\hline
\end{tabular}

\footnotetext{
* $\left(R_{a}-R_{g} / R_{a}\right) \times 100$
} 

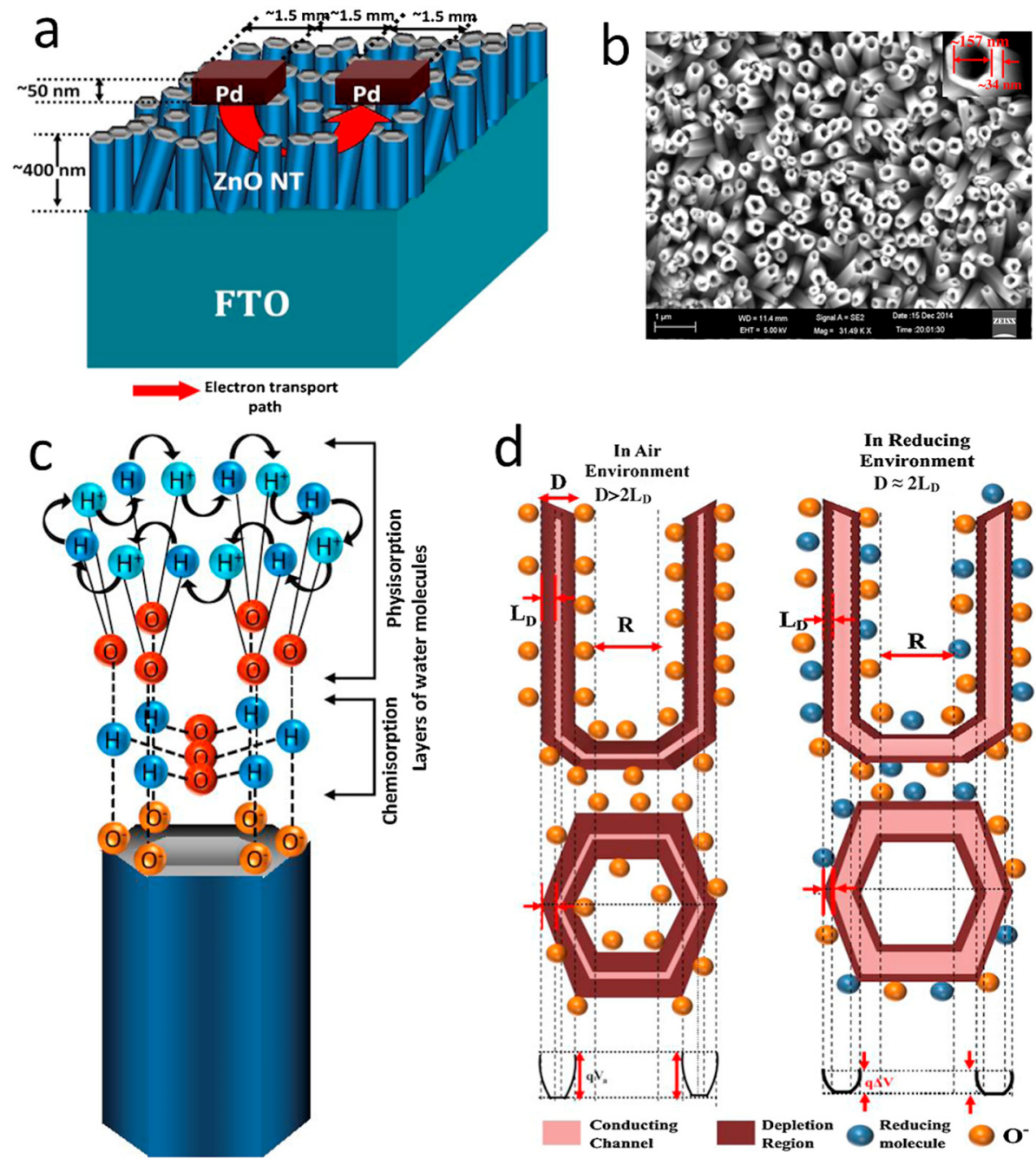

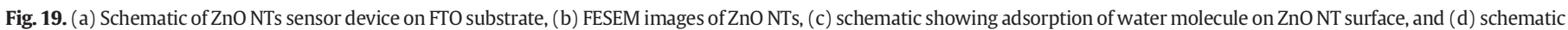
showing potential barrier modulation of ZnO NTs in air and target gas conditions. Reproduced from Ref. [169] with permission, Copyright 2016, Elsevier.

The Brunauer-Emmett-Teller (BET) surface area results showed that ZnO NDs had a smaller surface area $\left(13.70 \mathrm{~m}^{2} / \mathrm{g}\right)$ than the $\mathrm{ZnO}$ NRs $\left(16.11 \mathrm{~m}^{2} / \mathrm{g}\right)$. Furthermore, the sensor based on $\mathrm{ZnO}$ NDs exhibited better gas sensing performance for Triethylamine (TMA) as compared to ZnO NRs at $300{ }^{\circ} \mathrm{C}$ in spite of its lower surface area. The enhanced gas sensing properties of ZnO NDs was mainly attributed to the ZnO polar (0001) plane's high activity in absorbing oxygen ionic species. Hence, it was concluded that $\mathrm{ZnO}$ as a gas sensing material with exposed polar (0001) facet showed improved sensing performance for many target gases. This better gas sensing performance was explained by the smaller thickness, high surface area, wide depletion layers, and fast gas molecule adsorption over the entire surface of vertically oriented $\mathrm{ZnO}$ nanodisk structures. The synthesis of vertically oriented $\mathrm{ZnO}$ nanostructures is simple, but the gas sensing performance of bare $\mathrm{ZnO}$ nanostructures is limited. Hence, hybridization/decoration of $\mathrm{ZnO}$ nanostructures with other metal or metal oxide becomes essential for enhancing gas sensing performance.

\section{Conclusions and future perspectives}

In this paper, we have reviewed recent research on vertically oriented $\mathrm{ZnO}$ nanomaterials for gas sensing applications. There are currently many challenges in the development of nanomaterial based sensing devices to detect toxic and VOC gases, such as $\mathrm{H}_{2} \mathrm{~S}$, ethanol,
$\mathrm{H}_{2}, \mathrm{NO}_{2}, \mathrm{CO}, \mathrm{NH}_{3}$, xylene, TEA, and acetone. Different approaches are available to synthesize sensing materials, and their direct integration onto the sensor electrodes have offered important performance enhancements in gas sensing applications. However, the higher operating temperatures complicate practical applications. Growing nanomaterials directly onto the sensor chips streamlines sensor fabrication (Scheme 2 ). Furthermore, it avoids the use of binders/polymers to fix nanomaterials onto electrodes, integrates stable nanomaterials onto the electrode surfaces, and produces high surface areas. Despite the general progress in nanomaterials, however, few can be directly grown on substrates/electrodes. Importantly, ZnO stands out as enabling the engineering of nanoscale vertically oriented structures on electrode surfaces.

As a result of the aforementioned advantages, we have concentrated our discussion on directly grown vertically oriented $\mathrm{ZnO}$ nanomaterials on electrode surfaces that are currently used to fabricate a variety of gas sensors. These nanomaterials provide high carrier mobilities with high surface area, which are essential for ppb level sensing performance. The surface functionalization of vertically oriented $\mathrm{ZnO}$ nanomaterials with specific metal catalysts, dopants, and other metal oxides is a convincing approach for improving sensing response, selectivity, and response/recovery time. Extensive use of $\mathrm{ZnO}$ nanomaterial reveals that the oxygen vacancy defects play a major role in enhanced sensing. Nanowires offer better surface area than nanorods, nanotubes, and nanosheets due to their high aspect ratio, thus resulting in the better 

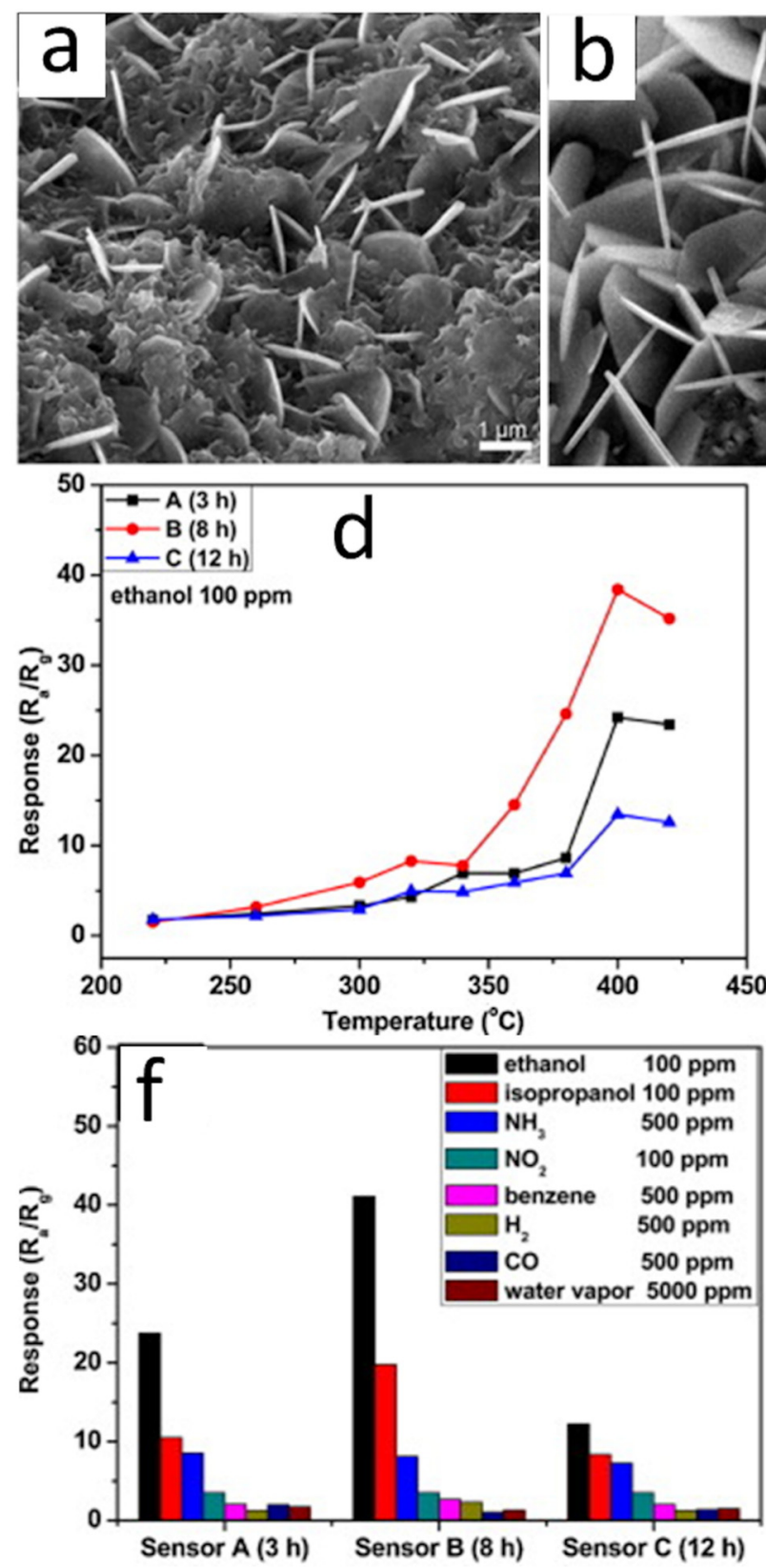
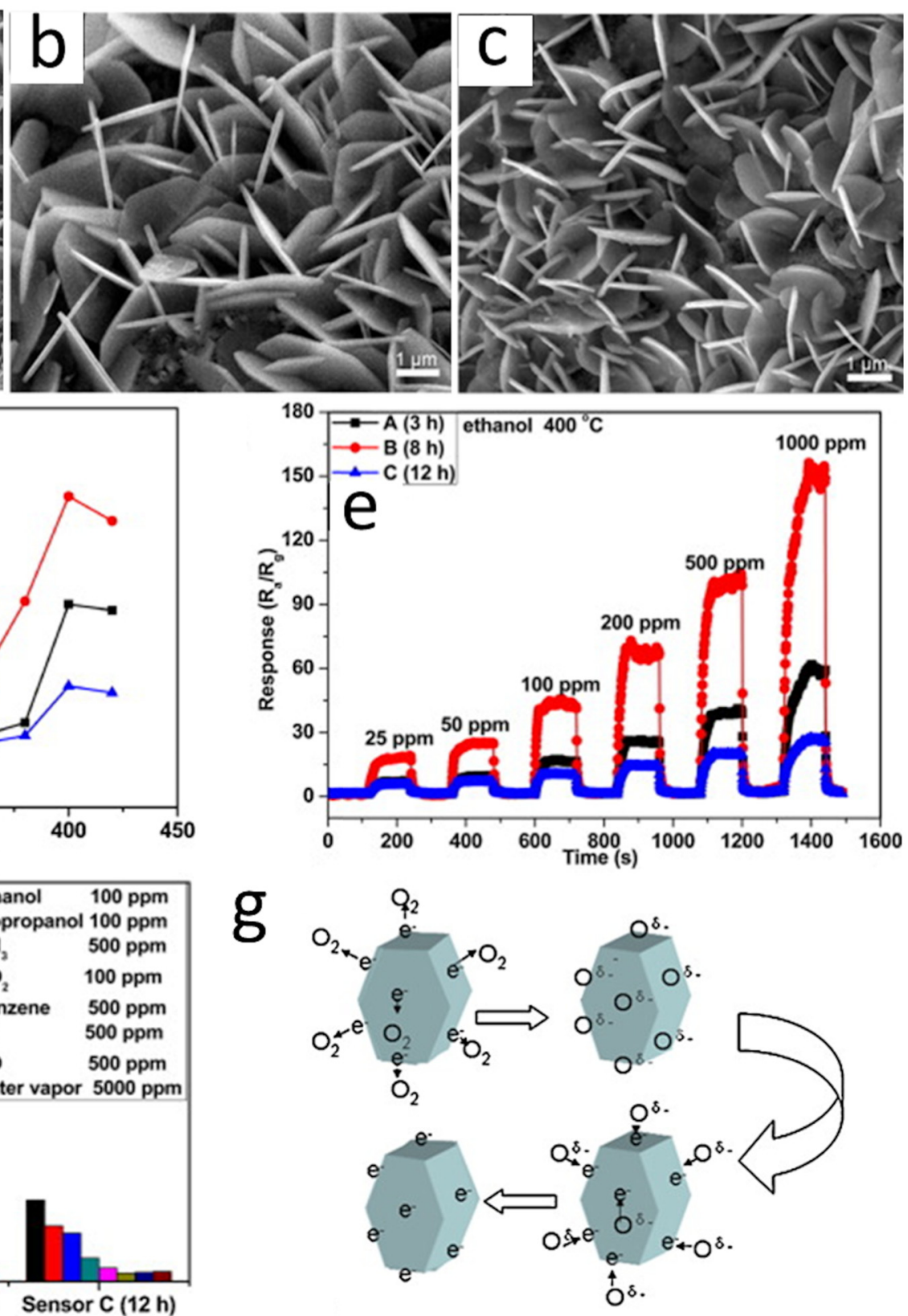

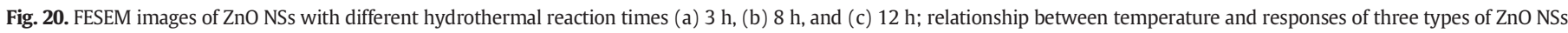

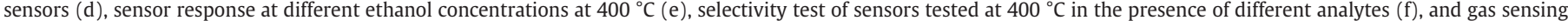
mechanism over ZnO NSs in air and ethanol atmospheres. Reproduced from Ref. [172] with permission, Copyright 2014, Elsevier.

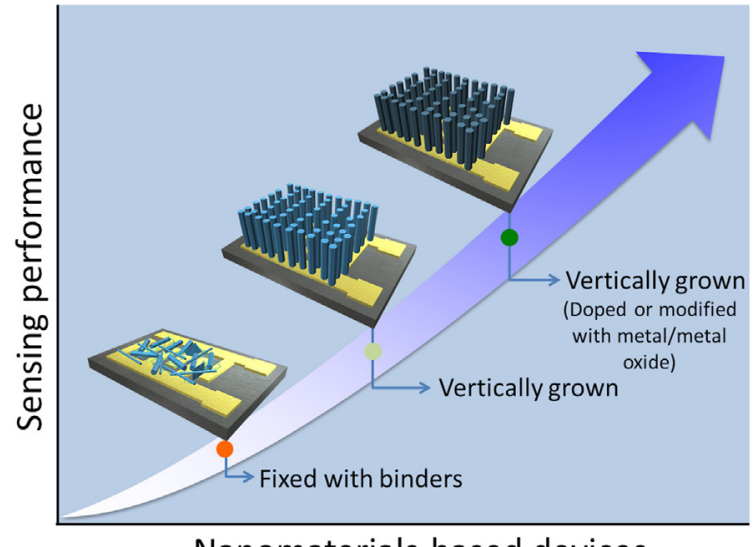

Nanomaterials based devices sensing performance of nanowire based gas sensors (Tables 2-4). In addition, nanowires are an excellent choice for their surface modification with other metals or metal oxides to enhance their gas sensing properties.

Despite the extensive use of $\mathrm{ZnO}$ nanomaterials for gas sensing, their selectivity and high operating temperature remain questionable, and vertically aligned $\mathrm{ZnO}$ nanomaterial based sensors are yet to be commercialized. Recently, MOF and ZIF as molecular sieve membranes have shown promise in improving selectivity due to their controllable pore aperture and excellent porosity. The molecular sized pores in these membranes block larger gas molecules from interacting with the active sensing materials. However, more studies are necessary to clearly understand these processes and select optimal MOFs for the selective diffusion/blocking of gases. The sensitivity of gas sensors depends upon several factors, such as depletion layer formation due to Schottky junctions, oxygen adsorption, 
heterojunction formation, and charge transfer/reactions between analyte gases and sensing materials. The functionalization of $\mathrm{ZnO}$ nanomaterial with noble metal catalysts or metal oxides is one of the better approaches to enhance sensitivity by lowering the operating temperature. The noble metal/metal oxide NPs' dispersion, size, and density greatly affect sensing performance. Therefore, controlled deposition of noble metals/metal oxides on the $\mathrm{ZnO}$ surface with optimized nanosized dimensions is necessary.

An improved low-temperature growth approach for vertically oriented $\mathrm{ZnO}$ nanomaterials on flexible substrates is important for cost effectiveness and applications requiring new form factors. The use of bimetallic NPs (nano-alloys) to modify ZnO nanomaterials' surface can potentially provide superior catalytic properties. Therefore, there are many opportunities for vertically oriented $\mathrm{ZnO}$ nanomaterial surface modification for improved gas sensing properties. The ease of using vertically oriented $\mathrm{ZnO}$ nanomaterials on electrode surfaces in different architectures makes them the ideal choice for further modification/ functionalization investigations targeting a wide range of applications.

\section{Acknowledgments}

The research reported in this publication was supported by funding from King Abdullah University of Science and Technology.

\section{References}

[1] Yoon KR, Shin K, Park J, Cho SH, Kim C, Jung JW, et al. Brush-like cobalt nitride anchored carbon nanofiber membrane: current collector catalyst integrated cathode for long cycle $\mathrm{Li}_{-} \mathrm{O}_{2}$ batteries. ACS Nano 2018;12:128-39.

[2] Lee BR, Jung ED, Park JS, Nam YS, Min SH, Kim BS, et al. Highly efficient inverted polymer light-emitting diodes using surface modifications of $\mathrm{ZnO}$ layer. Nat Commun 2014;5:4840.

[3] Wang HP, He JH. Toward highly efficient nanostructured solar cells using concurrent electrical and optical design. Adv Energy Mater 2017;7:1602385.

[4] Hahn YB, Ahmad R, Tripathy N. Chemical and biological sensors based on metal oxide nanostructures. Chem Commun 2012;48:10369-85.

[5] Jeevanandam J, Barhoum A, Chan YS, Dufresne A, Danquah MK. Review on nanoparticles and nanostructured materials: history, sources, toxicity and regulations. Beilstein J Nanotechnol 2018;9:1050-74.

[6] Wang C, Yin L, Zhang L, Xiang D, Gao R. Metal oxide gas sensors: sensitivity and influencing factors. Sensors 2010;10:2088-106.

[7] Mirzaei A, Janghorban K, Hashemi B, Neri G. Metal-core@metal oxide-shell nanomaterials for gas-sensing applications: a review. J Nanopart Res 2015;17:371.

[8] Sharma B, Sharma A, Kim JS. Recent advances on $\mathrm{H}_{2}$ sensor technologies based on MOX and FET devices: a review. Sens Actuators B 2018;262:758-70.

[9] Meng FL, Guo Z, Huang XJ. Graphene-based hybrids for chemiresistive gas sensors. Trends Anal Chem 2015;68:37-47.

[10] Wang Z, Zhang T, Zhao C, Han T, Fei T, Liu S, et al. Anchoring ultrafine Pd nanoparticles and $\mathrm{SnO}_{2}$ nanoparticles on reduced graphene oxide for high-performance room temperature $\mathrm{NO}_{2}$ sensing. J Colloid Interface Sci 2018;514:599-608.

[11] Zhu G, Guo L, Shen X, Ji Z, Chen K, Zhou H. Monodispersed $\mathrm{In}_{2} \mathrm{O}_{3}$ mesoporous nanospheres: one-step facile synthesis and the improved gas-sensing performance. Sens Actuators B 2015;220:977-85.

[12] Rai P, Kim YS, Song HM, Song MK, Yu YT. The role of gold catalyst on the sensing behavior of $\mathrm{ZnO}$ nanorods for $\mathrm{CO}$ and $\mathrm{NO}_{2}$ gases. Sens Actuators B 2012;165: $133-42$.

[13] Lee CY, Kim SJ, Hwang IS, Lee JH. Glucose-mediated hydrothermal synthesis and gas sensing characteristics of $\mathrm{WO}_{3}$ hollow microspheres. Sens Actuators B 2009; 142:236-42.

[14] Majhi SM, Rai P, Raj S, Chon BS, Park KK, Yu YT. Effect of Au nanorods on potential barrier modulation in morphologically controlled $\mathrm{Au}_{\mathrm{Cu}} \mathrm{O}$ core-shell nanoreactors for gas sensor applications. ACS Appl Mater Interfaces 2014;6: 7491-7.

[15] Han D, Ji Y, Gu F, Wang Z. Cobalt oxide nanorods with special pore structure for enhanced ethanol sensing performance. J Colloid Interface Sci 2018;531:320-30.

[16] Majhi SM, Naik GK, Lee HJ, Song HG, Lee CR, Lee IH, et al. Au@NiO core-shell nanoparticles as a p-type gas sensor: novel synthesis, characterization, and their gas sensing properties with sensing mechanism. Sens Actuators B 2018;268:223-31.

[17] Lyson-Sypien B, Radecka M, Rekas M, Swierczek K, Michalow-Mauke K, Graule T, et al. Grain-size-dependent gas-sensing properties of $\mathrm{TiO}_{2}$ nanomaterials. Sens Actuators B 2015;211:67-76.

[18] Majhi SM, Rai P, Yu YT. Facile approach to synthesize Au@ZnO core-shell nanoparticles, and their application for highly sensitive and selective gas sensors. ACS Appl Mater Interfaces 2015;7:9462-8.

[19] Ahmad R, Tripathy N, Jung DUJ, Hahn YB. Highly sensitive hydrazine chemical sensor based on ZnO nanorods field-effect transistor. Chem Commun 2014;50:1890-3.
[20] Ahmad R, Tripathy N, Ahn MS, Hahn YB. Solution process synthesis of high aspect ratio $\mathrm{ZnO}$ nanorods on electrode surface for sensitive electrochemical detection of uric acid. Sci Rep 2017;7:46475.

21] Yang Y, Han S, Zhou G, Zhang L, Li X, Zou C, et al. Ascorbic-acid-assisted growth of high quality M@ZnO: a growth mechanism and kinetics study. Nanoscale 2013;5: 11808-19.

[22] Zhang J, Qin Z, Zeng D, Xie C. Metal-oxide-semiconductor based gas sensors: screening, preparation, and integration. Phys Chem Chem Phys 2017:19:6313-29.

[23] Li Z, Li H, Wu Z, Wang M, Luo J, Torun H, et al. Advances in designs and mechanisms of semiconducting metal oxide nanostructures for high-precision gas sensors operated at room temperature. Mater Horiz 2019;6:470-506.

[24] Choi KJ, Jang HW. One-dimensional oxide nanostructures as gas-sensing materials: review and issues. Sensors 2010;10(4):4083-99.

[25] Shingange K, Tshabalala ZP, Ntwaeaborwa OM, Motaung DE, Mhlongo GH. Highly selective $\mathrm{NH}_{3}$ gas sensor based on Au loaded $\mathrm{ZnO}$ nanostructures prepared using microwave-assisted method. J Colloid Interface Sci 2016;479: 127-38.

[26] Jiao M, Duy NV, Trung DD, Hoa ND, Hieu NV, Hjort K, et al. Comparison of $\mathrm{NO}_{2}$ gassensing properties of three different $\mathrm{ZnO}$ nanostructures synthesized by on-chip low-temperature hydrothermal growth. J Electr Mater 2018;47:785-93.

[27] Ahn NW, Park KS, Heo JH, Kim DW, Choi KJ, Park JG. On-chip fabrication of ZnOnanowire gas sensor with high gas sensitivity. Sens Actuators B 2009;138:168-73.

[28] Franke ME, Koplin TJ, Simon U. Metal and metal oxide nanoparticles in chemiresistors: does the Nanoscale matter. Small 2006(1):36-50.

[29] Lee J-H. Gas sensors using hierarchical and hollow oxide nanostructures: overview. Sens Actuators B 2009;140:319-36.

[30] Li Z, Huang Y, Zhang S, Chen W, Kuang Z, Ao D, et al. A fast response \& recovery $\mathrm{H}_{2} \mathrm{~S}$ gas sensor based on $\mathrm{Fe}_{2} \mathrm{O}_{3}$ nanoparticles with ppb level detection limit. Hazard Mater 2015;300:167-74.

[31] Li C, Du Z, Yu H, Wang T. Low-temperature sensing and high sensitivity of ZnO nanoneedles due to small size effect. Thin Solid Films 2009;517:5931-4.

[32] Walker JM, Akbar SA, Morris PA. Synergistic effects in gas sensing semiconducting oxide nanoheterostructures: a review. Sens Actuators B 2019;286:624-40.

[33] Yamazoe N. Toward innovations of gas sensor technology. Sens Actuators B 2005; $108: 2-14$.

[34] Korotcenkov G, Cho BK. Metal oxide composites in conductometric gas sensors: achievements and challenges. Sens Actuators B 2017;244:182-210.

[35] Dey A. Semiconductor metal oxide gas sensors. Mater Sci Eng B 2018;229:206-17.

[36] Arunkumar S, Hou T, Kim Y-B, Choi B, Park SH, Jung S, et al. Au decorated ZnO hierarchical architectures: facile synthesis, tunable morphology and enhanced CO detection at room temperature. Sens Actuators B 2017;243:990-1001.

[37] Li F, Guo S, Shen J, Shen L, Sun D, Wang B, et al. Xylene gas sensor based on Au loaded $\mathrm{WO}_{3} \cdot \mathrm{H}_{2} \mathrm{O}$ nano cubes with enhanced sensing performance. Sens Actuators B 2017;238:364-73.

[38] Zhang D, Wu J, Cao Y. Ultrasensitive $\mathrm{H}_{2} \mathrm{~S}$ gas detection at room temperature based on copper oxide/molybdenum disulfide nanocomposite with synergistic effect. Sens Actuators B 2019;287:346-55.

[39] Mirzaei A, Leonardi SG, Neri G. Detection of hazardous volatile organic compounds (VOCs) by metal oxide nanostructures-based gas sensors: a review. Ceramics Int 2016;42:15119-41.

[40] Sun YF, Liu SB, Meng FL, Liu JY, Jin Z, Kong LT, et al. Metal oxide nanostructures and their gas sensing properties: a review. Sensors 2012;12:2610-31.

[41] Sakai G, Matsunaga N, Shimanoe K, Yamazoe N. Theory of gas-diffusion controlled sensitivity for thin film semiconductor gas sensor. Sens Actuators B 2001;80: 125-31.

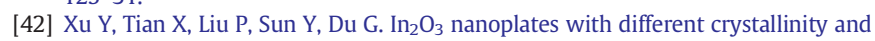
porosity: controllable synthesis and gas-sensing properties investigation. J Alloys Compd 2019;787:1063-73.

[43] Sun L, Fang W, Yang Y, Yu H, Wang T, Dong X, et al. Highly active and porous singlecrystal $\mathrm{In}_{2} \mathrm{O}_{3}$ nanosheet for NOx gas sensor with excellent response at room temperature. RSC Adv 2017;7:33419-25.

[44] Tian H, Fan H, Li M, Ma L. Zeolitic imidazolate framework coated ZnO nanorods as molecular sieving to improve selectivity of formaldehyde gas sensor. ACS Sens 2016;1:243-50.

[45] Shankar P, Rayappan JBB. Monomer: design of $\mathrm{ZnO}$ nanostructures (nanobush and nanowire) and their room-temperature ethanol vapor sensing signatures. ACS Appl Mater Interfaces 2017;9:38135-45.

[46] Rai P, Kwak W-K, Yu Y-T. Solvothermal synthesis of ZnO nanostructures and their morphology-dependent gas-sensing properties. ACS Appl Mater Interfaces 2013;5: 3026-32.

[47] Tamaki J, Nakataya Y, Konishi S. Micro gap effect on dilute $\mathrm{H}_{2} \mathrm{~S}$ sensing properties of $\mathrm{SnO}_{2}$ thin film microsensors. Sens Actuators B 2008;130:400-4.

[48] Tamaki J, Niimi J, Ogura S, Konishi S. Effect of micro-gap electrode on sensing properties to dilute chlorine gas of indium oxide thin film microsensors. Sens Actuators B 2006;117:353-8.

[49] Tamaki J, Miyaji A, Makinodan J, Ogura S, Konishi S. Effect of micro-gap electrode on detection of dilute $\mathrm{NO}_{2}$ using $\mathrm{WO}_{3}$ thin film microsensors. Sens Actuators B 2005; 108:202-6.

[50] Kaneti YV, Zhang Z, Yue J, Zakaria QMD, Chen C, Jiang X, et al. Crystal planedependent gas-sensing properties of zinc oxide nanostructures: experimental and theoretical studies. Phys Chem Chem Phys 2014;16:11471-80.

[51] Alenezi MR, Alshammari AS, Jayawardena KDGI, Beliatis MJ, Henley SJ, Silva SRP. Role of the exposed polar facets in the performance of thermally and UV activated ZnO nanostructured gas sensors. J Phys Chem C 2013;117:17850-8.

[52] Gao X, Zhang T. An overview: facet-dependent metal oxide semiconductor gas sensors. Sens Actuators B 2018;277:604-33. 
[53] Han XG, He H-Z, Zhou QKX, Zhang X-H, Xu T, Xie Z-X, et al. Controlling morphologies and tuning the related properties of nano/microstructured $\mathrm{ZnO}$ crystallites. J Phys Chem C 2009;113:584-9.

[54] Xu J, Xue Z, Qin N, Cheng Z, Xiang Q. The crystal facet-dependent gas sensing properties of $\mathrm{ZnO}$ nanosheets: experimental and computational study. Sens Actuators B 2017;242:148-57.

[55] Li W, Xu H, Yu H, Zhai T, Xu Q, Yang X, et al. Different morphologies of ZnO and their triethylamine sensing properties. J Alloys Compd 2017;706:461-9.

[56] Qin N, Xiang Q, Zhao H, Zhanga J, Xu J. Evolution of ZnO microstructures from hexagonal disk to prismoid, prism and pyramid and their crystal facet-dependent gas sensing properties. CrystEngComm 2014;16:7062-73.

[57] Saito N, Watanabe K, Haneda H, Sakaguchi I, Shimanoe K. Highly sensitive ethanol gas sensor using pyramid-shaped ZnO particles with (0001) basal plane. J Phys Chem C 2018;122:7353-60.

[58] Liua D, Wan J, Wang H, Pang G, Tang Z. Mesoporous Au@ZnO flower-like nanostructure for enhanced formaldehyde sensing performance. Inorg Chem Commun 2019;102:203-9.

[59] Chang JF, Kuo HH, Leu IC, Hon MH. The effects of thickness and operation temperature on ZnO: Al thin film CO gas sensor. Sens Actuators B 2002;84:258-64.

[60] Zhang S, Jiang W, Li Y, Yang X, Sun P, Liu F, et al. Highly-sensitivity acetone sensors based on spinel-type oxide $\left(\mathrm{NiFe}_{2} \mathrm{O}_{4}\right)$ through optimization of porous structure. Sens Actuators B 2019;291:266-74.

[61] Shankar P, Rayappan JBB. Gas sensing mechanism of metal oxides: the role of ambient atmosphere, type of semiconductor and gases - a review. Sci Sci Lett J 2015;4: 126.

[62] Zhu L, Zeng W. Room-temperature gas sensing of ZnO-based gas sensor: a review. Sens Actuators A 2017;242-261(2015):267.

[63] Y. Deng. Semiconducting metal oxides for gas sensing. SpringerISBN 978-981-135853-1.

[64] Annanouch FE, Haddi Z, Vallejos S, Umek P, Guttmann P, Bittencourt C, et al. Aerosol-assisted CVD-grown $\mathrm{WO}_{3}$ nanoneedles decorated with copper oxide nanoparticles for the selective and humidity-resilient detection of $\mathrm{H}_{2} \mathrm{~S}$. ACS Appl Mater Interfaces 2015;7:6842-51.

[65] Tian K, Wang XX, Yu ZY, Li HY, Guo X. Hierarchical and hollow $\mathrm{Fe}_{2} \mathrm{O}_{3}$ nanoboxes derived from metal-organic frameworks with excellent sensitivity to $\mathrm{H}_{2} \mathrm{~S}$. ACS Appl Mater Interfaces 2017;9:29669-76.

[66] Yang M, Zhang X, Cheng X, Xu Y, Gao S, Zhao H, et al. Hierarchical NiO cube/ nitrogen-doped reduced graphene oxide composite with enhanced $\mathrm{H}_{2} \mathrm{~S}$ sensing properties at low temperature. ACS Appl Mater Interfaces 2017;9: 26293-303.

[67] The National Institute for Occupational Safety and Health (NIOSH). Preventing carbon monoxide poisoning from small gasoline-powered engines and tools. Available from http://www.cdc.gov/niosh/docs/96-118/default.html; 2015.

[68] Hjiri M, Mirb LE, Leonardi SG, Pistone A, Mavilia L, Neri G. Al-doped ZnO for highly sensitive CO gas sensors. Sens Actuators B 2014;196:413-20.

[69] Lee SW, Lee W, Hong Y, Lee G, Yoon DS. Recent advances in carbon material-based $\mathrm{NO}_{2}$ gas sensors. Sens Actuators B 2018;255:1788-804.

[70] Schwela D. Air pollution and health in urban areas. Rev Environ Health 2000;15: $13-42$.

[71] Timmer B, Olthuis W, Berg AVD. Ammonia sensors and their application- a review. Sens Actuators B 2005;107:666-77.

[72] Documentation of the threshold limit values and biological exposure indices. 5th ed.. Cincinnati, OH: American Conference of Governmental Industrial Hygienists Inc; 1986; 604-7.

[73] Chen EX, Fu HR, Lin R, Tan YX, Zhang J. Highly selective and sensitive trimethylamine gas sensor based on cobalt imidazolate framework material. ACS Appl Mater Interfaces 2014:6:22871-5.

[74] Kadir RA, Rani RA, Zoolfakar AS, Ou JZ, Shafiei M, Wlodarski W, et al. $\mathrm{Nb}_{2} \mathrm{O}_{5}$ Schottky based ethanol vapor sensors: effect of metallic catalysts. Sens Actuators B 2014;202:74-82.

[75] Patnaik P. A comprehensive guide to the hazardous properties of chemical substances. New Jersey, US: John Wiley \& Sons; 2007.

[76] Zhu Z, Wu RJ. The degradation of formaldehyde using a Pt@TiO ${ }_{2}$ nanoparticles in presence of visible light irradiation at room temperature. J Taiwan Inst Chem Eng 2015;50:276-81.

[77] Castro-Hurtado I, Mandayo GG, Castaño E. Conductometric formaldehyde gas sensors. A review: from conventional films to nanostructured materials. Thin Solid Films 2013:548:665-76.

[78] Liu X, Chen N, Xing X, Li Y, Xiao X, Wang Y, et al. A high-performance n-butanol gas sensor based on $\mathrm{ZnO}$ nanoparticles synthesized by a lowtemperature solvothermal route. RSC Adv 2015;5:54372-8.

[79] Kawamura K, Vestergaard M, Ishiyama M, Nagatani N, Hashiba T, Tamiya E. Development of a novel hand-held toluene gas sensor: Possibleuse in the prevention and control of sick building syndrome. Measurement 2006;39:490-6.

[80] Patel NG, Patel PD, Vaishnav VS. Indium tin oxide (ITO) thin film gas sensor for detection of methanol at room temperature. Sens Actuators B 2003;96:180-9.

[81] Mabrook PHM. Benzene sensing using thin films of titanium dioxide operating at room temperature. Sensors 2002;2:374-82.

[82] Ke MT, Lee MT, Lee CY, Fu LM. A MEMS-based benzene gas sensor with a selfheating $\mathrm{WO}_{3}$ sensing layer. Sensors 2009;9:2895-906.

[83] Cao J, Wang Z, Wang R, Zhang T. Electrostatic sprayed Cr-loaded NiO core-inhollow shell structured micro/nanospheres with ultra-selectivity and sensitivity for xylene. CrystEngComm 2014;16:773-7737.

[84] Wang Z, Li Z, Jiang T, Xu X, Wang C. Ultrasensitive hydrogen sensor based on Pd@ Loaded $\mathrm{SnO}_{2}$ electrospun nanofibers at room temperature. ACS Appl Mater Interfaces 2013;5:2013-21.
[85] Tian ZR, Voigt JA, Liu J, McKenzie B, McDermott MJ, Rodriguez MA, et al. Complex and oriented ZnO nanostructures. Nat Mater 2003;2(12):821-6.

[86] Seo MS, Jeong I, Park JS, Lee J, Han IK, Lee WI, et al. Vertically aligned nanostructured $\mathrm{TiO}_{2}$ photoelectrodes for high efficiency perovskite solar cells via a block copolymer template approach. Nanoscale 2016;8:11472-9.

[87] Ahmad R, Tripathy N, Ahn MS, Hahn YB. Highly stable hydrazine chemical sensor based on vertically-aligned $\mathrm{ZnO}$ nanorods grown on electrode. J Colloid Interface Sci 2017:494:153-8.

[88] Ko WB, Lee SH, Myoung NS, Hong JP. Solution processed vertically stacked ZnO sheet-like nanorod $\mathrm{p}-\mathrm{n}$ homojunctions and their application as UV photodetectors. J Mater Chem C 2016;4:142-9.

[89] Ahmad R, Ahn MS, Hahn YB. A highly sensitive nonenzymatic sensor based on $\mathrm{Fe}_{2} \mathrm{O}_{3}$ nanoparticles coated $\mathrm{ZnO}$ nanorods for electrochemical detection of nitrite. Adv Mater Interfaces 2017;4(22):1700691.

[90] Zhou J, Wei Y, Luo G, Zheng J, Xu C. Electrochromic properties of vertically aligned $\mathrm{Ni}$-doped $\mathrm{WO}_{3}$ nanostructure films and their application in complementary electrochromic devices. J Mater Chem C 2016;4:1613-22.

[91] Ahmad R, Tripathy N, Ahn MS, Bhat KS, Mahmoudi T, Wang Y, et al. Highly efficient non-enzymatic glucose sensor based on CuO modified vertically-grown $\mathrm{ZnO}$ nanorods on electrode. Sci Rep 2017;7:5715.

[92] Yang T, Cui Y, Chen M, Yu R, Luo S, Li W, et al. Uniform and vertically oriented ZnO nanosheets based on thin-layered $\mathrm{MoS}_{2}$ : synthesis and high-sensing ability. ACS Sustain Chem Eng 2017;5(2):1332-8

[93] Ahmad R, Tripathy N, Ahn MS, Yoo JY, Hahn YB. Preparation of a highly conductive seed layer for calcium sensor fabrication with enhanced sensing performance. ACS Sensors 2018;3:772-8.

[94] Stassia S, Caudab V, Ottone C, Chiodoni A, Pirri CF, Canavese G. Flexible piezoelectric energy nanogenerator based on $\mathrm{ZnO}$ nanotubes hosted in a polycarbonate membrane. Nano Energy 2015;13:474-81.

[95] Ahmad R, Wolfbeis OS, Hahn YB, Alshareef HN, Torsi L, Salama KN. Deposition of nanomaterials: a crucial step in biosensor fabrication. Mater Today Commun 2018;17:289-321.

[96] Hassanpour A, Bogdan N, Capobianco JA, Bianucci P. Hydrothermal selective growth of low aspect ratio isolated ZnO nanorods. Mater Design 2017;119 (2017):464-9.

[97] Hung CM, Thanh DT, Hieu LV. On-chip growth of semiconductor metal oxide nanowires for gas sensors: a review. J Sci Adv Mater Devices 2017;2(3):263-85.

[98] Villarreal CC, Pirzada D, Wong A, Vi D, Pham T, Mulchandani A. Characterisation of the heterojunction microstructure for electrodeposited vertical $\mathrm{ZnO}$ nanorods on CVD-graphene. Mater Res Express 2018;5:085031.

[99] Alsultany FH, Hassan Z, Ahmed NM. Large-scale uniform ZnO tetrapods on catalyst free glass substrate by thermal evaporation method. Mater Res Bull 2016;79:63-8.

[100] Tripathy N, Kim DH. Metal oxide modified ZnO nanomaterials for biosensor applications. Nano Convergence 2018;5:27.

[101] Umar AA, Rahman MYA, Taslim R, Salleh MM, Oyama M. A simple route to vertical array of quasi-1D ZnO nanofilms on FTO surfaces: 1D-crystal growth of nanoseeds under ammonia-assisted hydrolysis process. Nanoscale Res Lett 2011; 6(1):564.

[102] Djurišić AB, Chen X, Leung YH, Ng AMC. ZnO nanostructures: growth, properties and applications. J Mater Chem 2012;22:6526-35.

[103] Ramgir N, Datta N, Kaur M, Kailasaganapathi S, Debnath AK, Aswal DK, et al. Meta oxide nanowires for chemiresistive gas sensors: issues, challenges and prospects. Colloids Surfaces A 2013;439:101-16.

[104] Lupan O, Postica V, Adelung R, Labat F, Ciofini I, Schürmann U, et al. Functionalized Pd/ZnO nanowires for nanosensors. Phys Status Solidi RRL 2018;12:1700321.

[105] Kim DY, Son JY. Horizontal ZnO nanowires for gas sensor application: Al-doping effect on sensitivity. Electrochem Solid-Solid-State Lett 2009;12:J109-11.

[106] Chen Y, Pengcheng Xu P, Tao Xu T, Dan Zheng D, Li X. ZnO-nanowire size effect induced ultra-high sensing response to ppb-level $\mathrm{H}_{2} \mathrm{~S}$. Sens Actuators B 2017;240: 264-72.

[107] Woo HS, Kwak CH, Kim ID, Lee JH. Selective, sensitive, and reversible detection of $\mathrm{H}_{2} \mathrm{~S}$ using Mo-doped ZnO nanowire network sensors. J Mater Chem A 2014;2: 6412-8.

[108] Kumar A, Samanta S, Singh A, Roy M, Singh S, Basu S, et al. Fast response and high sensitivity of $\mathrm{ZnO}$ nanowires-cobalt phthalocyanine heterojunction based $\mathrm{H}_{2} \mathrm{~S}$ sensor. ACS Appl Mater Interfaces 2015;7:17713-24.

[109] Ramgir NS, Sharma PK, Datta N, Kaur M, Debnath AK, Aswal DK, et al. Room temperature $\mathrm{H}_{2} \mathrm{~S}$ sensor based on Au modified $\mathrm{ZnO}$ nanowires. Sens Actuators B 2013;186:718-26.

[110] Wongrat E, Hongsith N, Wongratanaphisan D, Gardchareon A, Choopun S. Control of depletion layer width via amount of Au NPs for sensor response enhancement in ZnO nanostructure sensor. Sens Actuators B 2012;171-172:230-7.

[111] Hsueh TJ, Chang SJ, Hsu CL, Lin YR, Chen IC. Highly sensitive ZnO nanowire ethanol sensor with Pd adsorption. Appl Phys Lett 2007;91:053111.

[112] Shi Y, Wang M, Hong C, Yang Z, Deng J, Song X, et al. Multi-junction joints network self-assembled with converging $\mathrm{ZnO}$ nanowires as multi-barrier gas sensor. Sens Actuators B 2013;177:1027-34.

[113] Na CW, Woo HS, Kim ID, Lee JH. Selective detection of $\mathrm{NO}_{2}$ and $\mathrm{C}_{2} \mathrm{H}_{5} \mathrm{OH}$ using a $\mathrm{Co}_{3} \mathrm{O}_{4}$-decorated $\mathrm{ZnO}$ nanowire network sensor. Chem Commun 2011;47: 5148-50.

[114] Jinkawa T, Sakai Tamaki J, Miura N, Yamazoe N. Relationship between ethanol gas sensitivity and surface catalytic property of tin oxide sensors modified with acidic or basic oxides. J Mol Catal A 2000;155:193-200.

[115] Bahlawane N, Rivera EF, Kohse-Höinghaus K, Brechling A, Kleineberg U. Characterization and tests of planar $\mathrm{Co}_{3} \mathrm{O}_{4}$ model catalysts prepared by chemical vapor deposition. Appl Catal Environ 2004;53:245-55. 
[116] Na CW, Woo HS, Lee JH. Design of highly sensitive volatile organic compound sensors by controlling NiO loading on ZnO nanowire networks. RSC Adv 2012;2:414-7.

[117] Na CW, Park SY, Chung JH, Lee JH. Transformation of ZnO nanobelts into singlecrystalline $\mathrm{Mn}_{3} \mathrm{O}_{4}$ nanowires. ACS Appl Mater Interfaces 2012;4:6565-72.

[118] Kwak CH, Woo HS, Lee JH. Selective trimethylamine sensors using $\mathrm{Cr}_{2} \mathrm{O}_{3}$-decorated $\mathrm{SnO}_{2}$ nanowires. Sens Actuators B 2014;204:231-8.

[119] Kwak CH, Woo HS, Abdel-Hady F, Wazzan AA, Lee JH. Vapor-phase growth of urchin-like Mg-doped $\mathrm{ZnO}$ nanowire networks and their application to highly sensitive and selective detection of ethanol. Sens Actuators B 2016;223:527-34.

[120] Das SN, Kar JP, Choi JH, Lee TI, Moon KJ, Myoung JM. Fabrication and characterization of ZnO single nanowire-based hydrogen sensor. J Phys Chem C 2010;114: 1689-93.

[121] Korotcenkov G, Cho BK. Engineering approaches for the improvement of conductometric gas sensor parameters, Part 1. Improvement of sensor sensitivity and selectivity (Short survey). Sens Actuators B 2013;188:709-28.

[122] Drobek M, Kim JH, Bechelany M, Vallicari C, Julbe A, Kim SS. MOF-based membrane encapsulated $\mathrm{ZnO}$ nanowires for enhanced gas sensor selectivity. ACS Appl Mater Interfaces 2016;8:8323-8.

[123] Drobek M, Kim JH, Bechelany M, Vallicari C, Julbe A, Kim SS. Design and fabrication of highly selective $\mathrm{H}_{2}$ sensors based on SIM-1 nanomembrane-coated $\mathrm{ZnO}$ nanowires. Sens Actuators B 2018;264:410-8.

[124] Lupan O, Cretu V, Postica V, Ahmadi M, Cuenya BR, Chow L, et al. Silver-doped zinc oxide single nanowire multifunctional nanosensor with a significant enhancement in response. Sens Actuators B 2016;223:893-903.

[125] Lupan O, Chow L, Pauporte T, Ono LK, Cuenya BR, Chai G. Highly sensitive and selective hydrogen single-nanowire nanosensor. Sens Actuators B 2012:173:772-80.

[126] Roso S, Güell F, Martínez-Alanis PR, Urakawa A, Llobet E. Synthesis of ZnO nanowires and impacts of their orientation and defects on their gas sensing properties. Sens Actuators B 2016;230:109-14.

[127] Lim Y, Kim S, Kwon YM, Baik JM, Shin H. A highly sensitive gas-sensing platform based on a metal-oxide nanowire forest grown on a suspended carbon nanowire fabricated at a wafer level. Sens Actuators B 2018;260:55-62.

[128] Zhang R, Pang W, Feng Z, Chen X, Chen Y, Zhang Q, et al. Enabling selectivity and fast recovery of $\mathrm{ZnO}$ nanowire gas sensors through resistive switching. Sens Actuators B 2017;238:357-63.

[129] Ahn MW, Park KS, Heo JH, Park JG, Kim DW, Choi KJ, et al. Gas sensing properties of defect-controlled ZnO-nanowire gas sensor. Appl Phys Lett 2008;93:263103-5.

[130] Nguyen H, Quy CT, Hoa ND, Lam NT, Duy NV, Quang VV, et al. Controllable growth of $\mathrm{ZnO}$ nanowires grown on discrete islands of Au catalyst for realization of planartype micro gas sensors. Sens Actuators B 2014;193:888-94.

[131] Chen IC, Lin SS, Lin TJ, Hsu CL, Hsueh TJ, Shieh TY. The assessment for sensitivity of a $\mathrm{NO}_{2}$ gas sensor with $\mathrm{ZnGa}_{2} \mathrm{O}_{4} / \mathrm{ZnO}$ core-shell nanowires-a novel approach. Sensors 2010;10:3057-72.

[132] Chen X, Shen Y, Zhang W, Zhang J, Wei D, Lu R, et al. In-situ growth of ZnO nanowire arrays on the sensing electrode via a facile hydrothermal route for highperformance $\mathrm{NO}_{2}$ sensor. Appl Surface Sci 2018;435:1096-104.

[133] Park S, An S, Ko H, Jin C, Lee C. Synthesis of nanograined ZnO nanowires and their enhanced gas sensing properties. ACS Appl Mater Interfaces 2012;4:3650-6.

[134] Park JW, Choi KJ, Kim MH, Koo BH, Lee JL, Baik JM. Self-assembled and highly selective sensors based on air-bridge-structured nanowire junction arrays. ACS Appl Mater Interfaces 2013;5:6802-7.

[135] Khai TV, Thu LV, Ha LTT, Thanh VM, Lam TD. Structural, optical and gas sensing properties of vertically well-aligned $\mathrm{ZnO}$ nanowires grown on graphene/Si substrate by thermal evaporation method. Mater Characteriz 2018:141296-317.

[136] Choi SW, Kim SS. Room temperature CO sensing of selectively grown networked ZnO nanowires by Pd nanodot functionalization. Sens Actuators B 2012:1688-713.

[137] Sinha M, Mahapatra R, Mondal B, Maruyama T, Ghosh R. Ultrafast and reversible gas-sensing properties of $\mathrm{ZnO}$ nanowire arrays grown by hydrothermal technique. J Phys Chem C 2016;120:3019-25.

[138] Yao MS, Tang WX, Wang GE, Nath B, Xu G. MOF thin film-coated metal oxide nanowire array: significantly improved chemiresistor sensor performance. Adv Mater 2016;28:5229-34

[139] Chang SJ, Weng WY, Hsu CL, Hsueh TJ. High sensitivity of a ZnO nanowire-based ammonia gas sensor with Pt nano-particles. Nano Commun Netw 2010:1283-8.

[140] Woo HS, Kwak CH, Chung JH, Lee JH. Co-doped branched $\mathrm{ZnO}$ nanowires for ultraselective and sensitive detection of xylene. ACS Appl Mater Interfaces 2014; 6:22553-60.

[141] Kumar M, Bhati VS, Ranwa S, Singh J, Kumar M. Pd/ZnO nanorods based sensor for highly selective detection of extremely low concentration hydrogen. Sci Rep 2017; 7:236.

[142] Wang $\mathrm{C}$, Chu $\mathrm{X}, \mathrm{Wu} \mathrm{M}$. Detection of $\mathrm{H}_{2} \mathrm{~S}$ down to ppb levels at room temperature using sensors based on ZnO nanorods. Sens Actuators B 2006;113:320-3.

[143] Wang D, Chu X, Gong M. Hydrothermal growth of ZnO nano screwdrivers and their gas sensing properties. Nanotechnology 2007;18:185601-4.

[144] Hosseini ZS, Zad AI, Mortezaali A. Room temperature $\mathrm{H}_{2} \mathrm{~S}$ gas sensor based on rather aligned $\mathrm{ZnO}$ nanorods with flower-like structures. Sens Actuators B 2015; 207:865-71.

[145] Hosseini ZS, Mortezaali A, Zad AI, Fardindoost S. Sensitive and selective room temperature $\mathrm{H}_{2} \mathrm{~S}$ gas sensor based on au sensitized vertical $\mathrm{ZnO}$ nanorods with flowerlike structures. J Alloys Compd 2015;628:222-9.

[146] Liua Z, Fan T, Zhang D, Gong X, Xu J. Hierarchically porous ZnO with high sensitivity and selectivity to $\mathrm{H}_{2} \mathrm{~S}$ derived from biotemplates. Sens Actuators B 2009;136: 499-509.
[147] Qi G, Zhang L, Yuan Z. Improved $\mathrm{H}_{2} \mathrm{~S}$ gas sensing properties of $\mathrm{ZnO}$ nanorods decorated by a several nm ZnS thin layer. Phys Chem Chem Phys 2014;16:13434-9.

[148] Qi G, Lu X, Yuan Z. Improved $\mathrm{H}_{2} \mathrm{~S}$ gas sensing properties of $\mathrm{ZnO}$ nanorods via decoration of nano-porous $\mathrm{SiO}_{2}$ thin layers. RSC Adv 2016;6:45660-3.

[149] Ahn H, Park JH, Kim SB, Jee SH, Yoon YS, Kim DJ. Vertically aligned ZnO nanorod sensor on flexible substrate for ethanol gas monitoring. Electrochem Solid St 2010;13:J125-8.

[150] Yi J, Lee JM, Park WI. Vertically aligned ZnO nanorods and graphene hybrid architectures for high-sensitive flexible gas sensors. Sens Actuators B 2011;155:264-9.

[151] Zhou T, Sang Y, Wang X, Wu C, Zeng D, Xie C. Pore size dependent gas-sensing selectivity based on ZnO@ZIF nanorod arrays. Sens Actuators B 2018:258:1099-106.

[152] Lee MS, Oh E, Jeong SH. Fabrication of $\mathrm{H}_{2}$ gas sensor based on $\mathrm{ZnO}$ nanorod arrays by a sonochemical method. Bull Korean Chem Soc 2011;32:3735-7.

[153] Chang CM, Hon MH, Leu IC. Outstanding $\mathrm{H}_{2}$ sensing performance of Pd nanoparticle-decorated $\mathrm{ZnO}$ nanorod arrays and the temperature-dependent sensing mechanisms. ACS Appl Mater Interfaces 2013;5:135-43.

[154] Jiao M, Duy NV, Chien NV, Hoa ND, Hieu NV, Hjort K, et al. On-chip growth of patterned $\mathrm{ZnO}$ nanorod sensors with PdO decoration for enhancement of hydrogensensing performance. Int J Hydrogen Energy 2017;42:16294-304.

[155] Kim H, Pak Y, Jeong Y, Kim W, Kim J, Jung GY. Amorphous Pd-assisted $\mathrm{H}_{2}$ detection of $\mathrm{ZnO}$ nanorod gas sensor with enhanced sensitivity and stability. Sens Actuators B 2018:262:460-8.

[156] Vallejos S, Gracia I, Lednicky T, Vojkuvka L, Figueras E, Hubalek J, et al. Highly hydrogen sensitive micromachined sensors based on aerosol-assisted chemical vapor deposited ZnO rods. Sens Actuators B 2018;268:15-21.

[157] Rashid TR, Phan DT, Chung GS. A flexible hydrogen sensor based on Pd nanoparticles decorated ZnO nanorods grown on polyimide tape. Sens Actuators B 2013;185: 777-84.

[158] Jiao M, Chien NV, Duy NV, Hoa ND, Hieu NV, Hjort K, et al. On-chip hydrothermal growth of $\mathrm{ZnO}$ nanorods at low temperature for highly selective $\mathrm{NO}_{2}$ gas sensor. Mater Lett 2016;169:231-5

[159] Sun GJ, Lee JK, Choi SB, Lee WI, Kim HW, Lee C. Selective oxidizing gas sensing and dominant sensing mechanism of $\mathrm{n}-\mathrm{CaO}$-decorated $\mathrm{n}-\mathrm{ZnO}$ nanorod sensors. ACS Appl Mater Interfaces 2017;9:9975-85.

[160] Oha E, Choi HY, Jung SH, Choc S, Kim JC, Lee KH, et al. High-performance $\mathrm{NO}_{2}$ gas sensor based on $\mathrm{ZnO}$ nanorod grown by ultrasonic irradiation. Sens Actuators B 2009;141:239-43.

[161] Zou CW, Wang J, Xie X. Synthesis and enhanced $\mathrm{NO}_{2}$ gas sensing properties of $\mathrm{ZnO}$ nanorods $/ \mathrm{TiO}_{2}$ nanoparticles heterojunction composites. J Colloid Interface Sci 2016;478:22-8.

[162] Chang CJ, Hung ST, Lin CK, Chen CY, Kuo EH. Selective growth of ZnO nanorods for gas sensors using ink-jet printing and hydrothermal processes. Thin Solid Films 2010;519:1693-8

[163] Jagadale SB, Patil VL, Vanalakar SA, Patil PS, Deshmukh HP. Preparation, characterization of 1D ZnO nanorods and their gas sensing properties. Cer Int 2018;44: 3333-40.

[164] Liao J, Li Z, Wang G, Chen C, Lv S, Li M. ZnO nanorod/porous silicon nanowire hybrid structures as highly-sensitive $\mathrm{NO}_{2}$ gas sensors at room temperature. Phys Chem Chem Phys 2016;18:4835-41.

[165] Gurav KV, Gang MG, Shin SW, Patil UM, Deshmukh PR, Agawane GL, et al. Gas sensing properties of hydrothermally grown $\mathrm{ZnO}$ nanorods with different aspect ratios. Sens Actuators B 2014;190:439-45.

[166] Gurav KV, Deshmukh PR, Lokhande CD. LPG sensing properties of Pd-sensitized vertically aligned ZnO nanorods. Sens Actuators B 2011;151:365-9.

[167] Ju DX, Xu HY, Qiu ZW, Zhang ZC, Xu Q, Zhang J, et al. Near room temperature, fastresponse, and highly sensitive triethylamine sensor assembled with Au-loaded $\mathrm{ZnO} / \mathrm{SnO}_{2}$ core-shell nanorods on flat alumina substrates. ACS Appl Mater Interfaces 2015;7:19163-71

[168] Iftekhar Uddin ASM, Yaqoob U, Phan DT, Chung GS. A novel flexible acetylene gas sensor based on PI/PTFE-supported Ag-loaded vertical ZnO nanorods array. Sens Actuators B 2016;222:536-43.

[169] Acharyya D, Bhattacharyya P. Alcohol sensing performance of ZnO hexagonal nanotubes at low temperatures: a qualitative understanding. Sens Actuators B 2016; 228:373-86.

[170] Maity I, Acharyya D, Huang K, Chung P, Ho M, Bhattacharyya P. A comparative study on performance improvement of $\mathrm{ZnO}$ nanotubes based alcohol sensor devices by Pd and rGO hybridization. IEEE Trans Electr Dev 2018;65:3528-34.

[171] Gonzalez-Chavarri J, Parellada-Monreal L, Castro-Hurtado I, Castano E, Mandayo G. $\mathrm{ZnO}$ nanoneedles grown on chip for selective $\mathrm{NO}_{2}$ detection indoors. Sens Actuators B 2018;255:1244-53.

[172] Ju D, Xu H, Zhang J, Guo J, Cao B. Direct hydrothermal growth of ZnO nanosheets on electrode for ethanol sensing. Sens Actuators B 2014;201:444-51.

[173] Cao F, Li C, Li M, Li H, Huang X, Yang B. Direct growth of Al-doped ZnO ultrathin nanosheets on electrode for ethanol gas sensor application. Appl Surface Sci 2018;447:173-81.

[174] Zhao Q, Shen Q, Yang F, Zhano H, Liu B, Liang Q et al. Direct growth of ZnO nanodisk networks with an exposed (0001) facet on Au comb-shaped interdigitating electrodes and the enhanced gas-sensing property of polar $\{0001\}$ surfaces. Sens Actuators B 2014;195:71-9. 